\title{
WestVirginiaUniversity
}

THE RESEARCH REPOSITORY @ WVU

Graduate Theses, Dissertations, and Problem Reports

2016

\section{Potential biomarkers to predict fertility in dairy cattle}

Melissa Jill Wise

Follow this and additional works at: https://researchrepository.wvu.edu/etd

\section{Recommended Citation}

Wise, Melissa Jill, "Potential biomarkers to predict fertility in dairy cattle" (2016). Graduate Theses, Dissertations, and Problem Reports. 6963.

https://researchrepository.wvu.edu/etd/6963

This Thesis is protected by copyright and/or related rights. It has been brought to you by the The Research Repository @ WVU with permission from the rights-holder(s). You are free to use this Thesis in any way that is permitted by the copyright and related rights legislation that applies to your use. For other uses you must obtain permission from the rights-holder(s) directly, unless additional rights are indicated by a Creative Commons license in the record and/ or on the work itself. This Thesis has been accepted for inclusion in WVU Graduate Theses, Dissertations, and Problem Reports collection by an authorized administrator of The Research Repository @ WVU. For more information, please contact researchrepository@mail.wvu.edu. 
Potential biomarkers to predict fertility in dairy cattle

\author{
Melissa Jill Wise \\ Thesis submitted to the \\ Davis College of Agricultural, Natural Resources and Design \\ at West Virginia University \\ in partial fulfillment of the requirements \\ of the degree of \\ Master of Science \\ in
}

Reproductive Physiology

Robert A. Dailey, Ph.D., Chair

Ida Holásková, Ph.D.

Scott A. Bowdridge, Ph.D.

Division of Animal \& Nutritional Sciences

Davis College of Agriculture, Natural Resources and Design

Morgantown, West Virginia

2016

Key Words:

Dairy Cattle, Reproductive Success, Haptoglobin, Leukocytes, Somatic Cell Count, Illness, Transition Period

Copyright 2016 Melissa Jill Wise 


\section{Abstract \\ Potential biomarkers to predict fertility in dairy cattle}

\section{Melissa Wise}

The aim of this study was to use leukocyte counts and haptoglobin concentrations in blood, milk, and uterine luminal secretion as biomarkers of health status and to associate those biomarkers and milk yield with reproductive success in dairy cattle. The study used a commercial dairy milking three times daily. One hundred and twenty six (25 primiparous and 101 multiparous) Holstein dairy cows were used. Reproductive success was evaluated with variables measured at three time points: [20-26 (prebreeding), 54-60 (breeding), and 90-96 (pregnancy diagnosis) days in milk (DIM)]. Variables included concentrations of leukocytes from blood, milk [measured by QScout Farm Lab MLD Slides (Advanced Animal Diagnostics, Morrisville, NC)], and uterine endometrium, culture of endometrial cells; Hp concentrations in plasma and milk; health status; and milk yield. Changes occurred in concentrations of biomarkers in blood, the uterus, and the mammary gland; however, concentrations showed no significant correlation between variables from the mammary gland and uterus ( $p>0.05$ ) or blood and the uterus ( $p>0.05$ ). Incidence of health disorders at 0 to 26 DIM was negatively related to conception to the first service $(\mathrm{p}=0.0387)$. Reproductive diseases, including positive uterine culture for bacteria, negatively affected conception to first service $(\mathrm{p}=0.0430)$. Both calving difficulty $(\mathrm{p}=0.0223)$ and positive uterine culture $(\mathrm{p}=0.055)$ negatively affected conception to first service; however, there was no interaction between the two. Plasma Hp concentration was affected by time ( $\mathrm{p}<0.0001$ ), QScout Farm Lab udder diagnosis ( $\mathrm{p}<0.0001)$, and illness ( $\mathrm{p}<$ $0.0001)$, and time by lactation interaction ( $\mathrm{p}=0.0384)$, with differences between primiparous and multiparous animals 20-26 DIM ( $\mathrm{p}=0.043$ ). Illness status was associated with plasma Hp and milk yield (low $<41.95 \mathrm{~kg}$, high $>41.96 \mathrm{~kg}$ ) with higher plasma Hp concentrations having higher illness rates at 54-60 DIM ( $p<0.0001)$ but not at 20-26 DIM $(\mathrm{p}=0.0615)$. Mastitis negatively affected conception to first service with numbers of milk lymphocytes $(p=0.0357)$ and neutrophils $(p=0.0259)$ being elevated in mastitis positive animals. Milk neutrophils were positively correlated with milk Hp concentration ( $\mathrm{p}<0.0001)$. Logistic regression determined that illness status between 0-26 DIM was the most predictive variable $(\mathrm{p}=0.0408)$ on conception to the first service with positive uterine culture $(\mathrm{p}=0.0764)$ as the second most predictive. Plasma Hp concentration was not associated with illness status at 20-26 DIM but was a valuable marker of illness after the transition period, 54-60 DIM. The combination of calving difficulty, clinical signs of illness, uterine culture, and Hp plasma concentration (after 26 DIM) produced in the most predictive model of fertility. Hence, evidence of disease at the postpartum herd check was the most predictive of fertility in this herd of Holstein cows. 


\section{Acknowledgments}

I would like to thank my mentor Dr. Robert Dailey for the opportunities that you have allowed me to pursue. The encouragement that you gave me always pushed me to strive for my best. Your passion for animal science, especially the dairy cow is contagious along with your passion for the scientific process. I will always be grateful for the knowledge you have provided me.

I would like to thank Dr. Brooks for his support in my education both financially and in the learning process. Without your generosity I would not have had this opportunity. Thank you for teaching me to strive for excellence while working to reach my goals.

I would like to thank my committee members Dr. Robert Dailey, Dr. Ida Holásková, and Dr. Scott Bowdridge for their, time, wisdom, constant support, and encouragement. I would also like to thank Dr. Inskeep, Dr. Minch, and Dr. Taylor for their expertise and advice.

I would like to thank Advanced Animal Diagnostics, specifically Dr. Hockett and Martha Payne for the support of this project. The ability to test and analyze the volume and array of samples would not have been possible without your support and expertise.

I would like to thank the VanGuilders and DoVan Dairy for the opportunity to use their animals and facilities for this project. Your hospitality and care shows in every aspect of the dairy, animals, and staff. The amount of assistance and knowledge I received will not be forgotten.

I would especially like to thanks my fellow graduate students, both past and present for the countless hours of help preparing, sampling, and lab work. Meghan Graham and Keli Akers for their guidance and advice beginning graduate school and the opportunity to follow in their footsteps. I would especially like to thank Dr. Elizabeth Bowdridge, Crista Crawford, and Jess Forest for the constant support and organizational help while I was ill. I also want to thank Jessalyn Hadfield, Hoda Nikpour, Jesica Jacobs, and Elizabeth Sheppard with your assistance sampling and help in the lab. I would not have been able to do this with you.

I would like to thank Dr. Dustin Davis and Catherine Davis for the numerous opportunities you have given me to grow and pursue animal science.

Finally, I would like to thank my friends and family for the constant love and support they have given me through the years. I am thankful for the strong work ethic you instilled in me and the drive to continue to reach for my dreams. No matter where in the country you are I know that your support is with me. 


\section{Table of Contents}

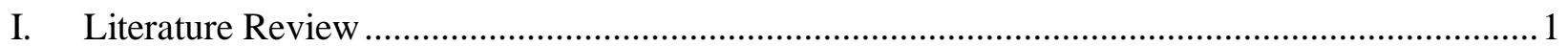

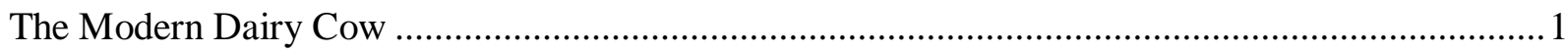

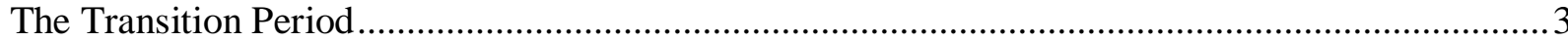

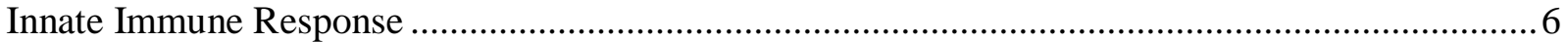

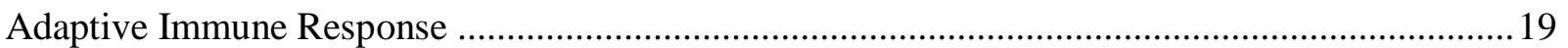

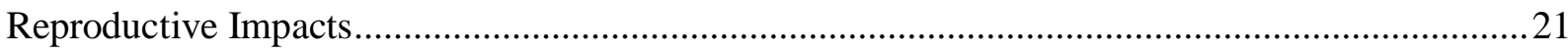

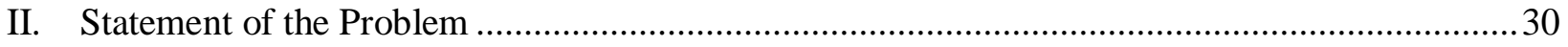

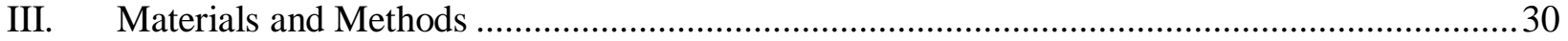

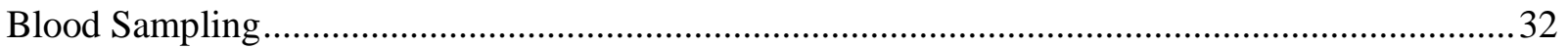

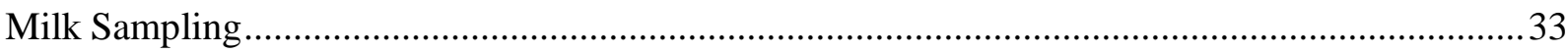

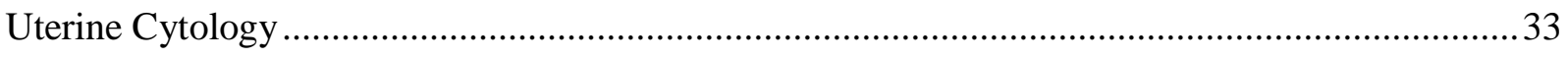

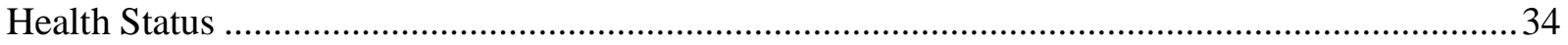

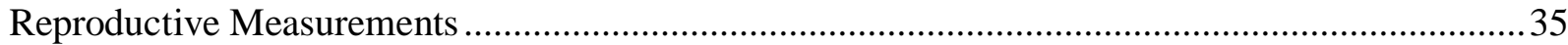

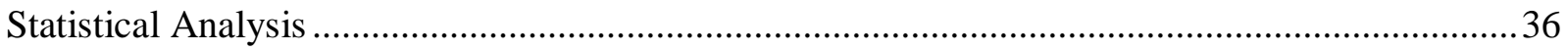

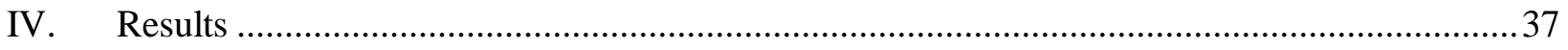

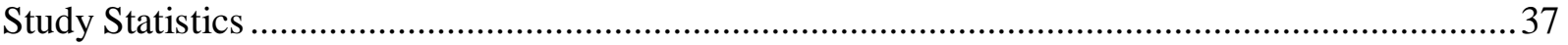

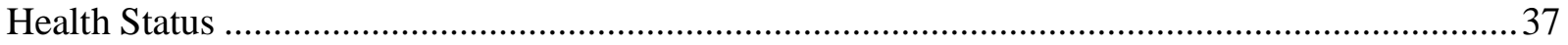

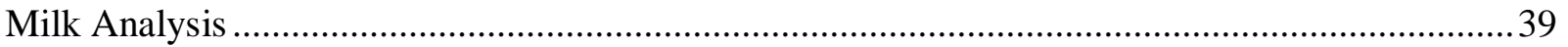

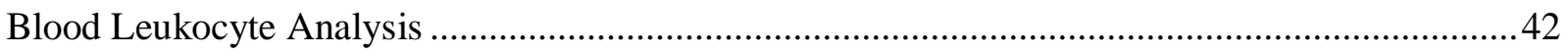

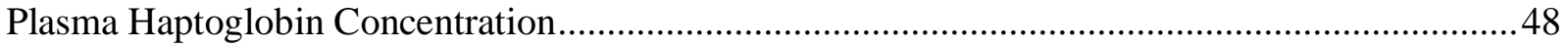

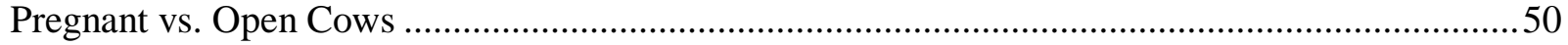

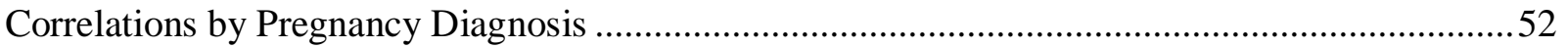

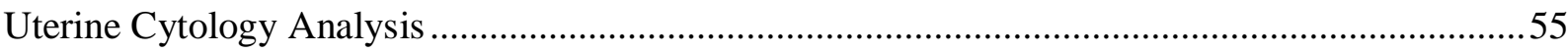

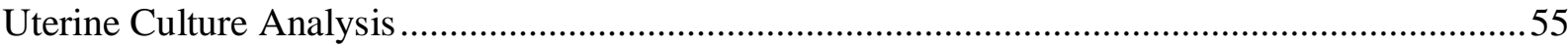

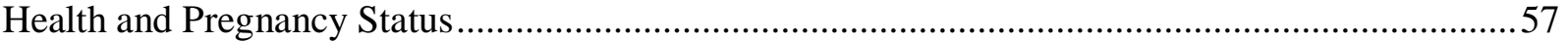

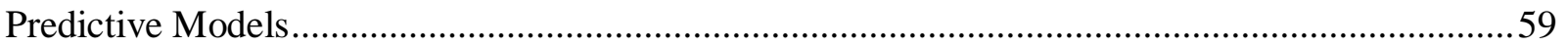

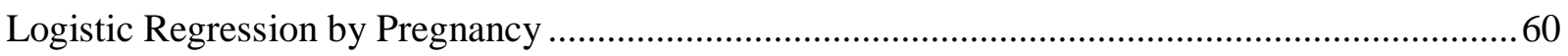

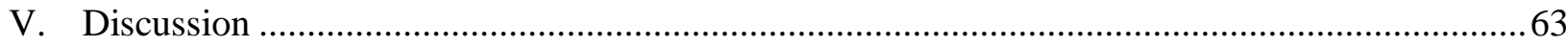

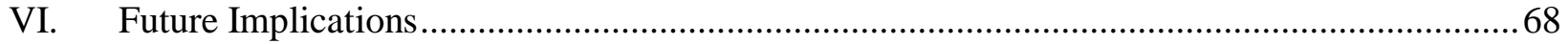

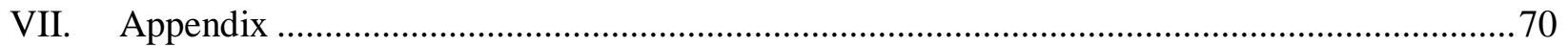

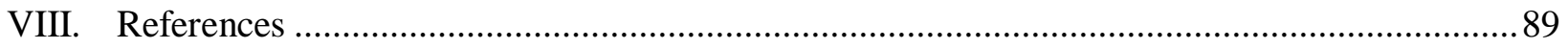




\section{Table of Figures}

Figure 1: Nonparametric coefficients between blood constituents in dairy cattle at 20-26 DIM.

Figure 2: Proposed pathway for the interaction of systemic and local cellular components affecting the outcome of the first service in the lactating dairy cow. .......................................29

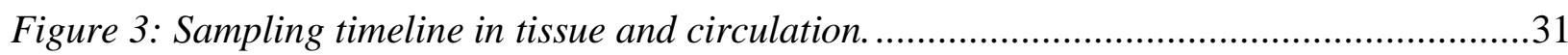

Figure 4: Cell differential counts from QScout Farm Lab by mastitis diagnosis. ........................32

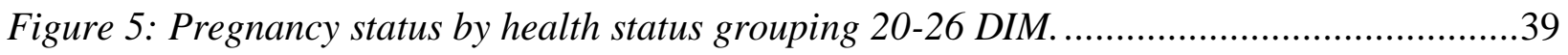

Figure 6: Total somatic cell count and leukocyte differential over time. ...................................41

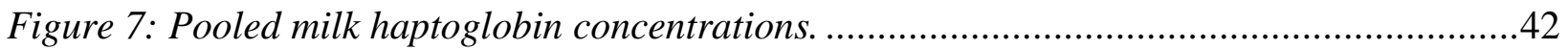

Figure 8: White blood cell differentials over time by illness status. ........................................4

Figure 9: Plasma haptoglobin concentrations over time by illness status. ................................49

Figure 10: Plasma haptoglobin concentration and milk somatic cell count over time by parity. 50

Figure 11: Contingency analysis of haptoglobin/milk production category at 20-26 DIM by

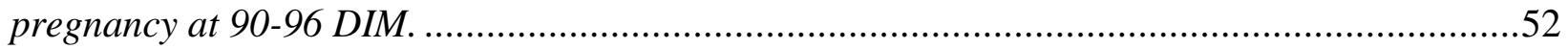

Figure 12: Contingency analysis of haptoglobin/milk production category at 54-60 DIM by

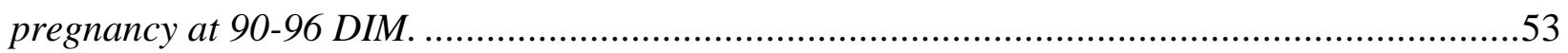

Figure 13: Contingency analysis of haptoglobin/milk production category at 20-26 DIM by

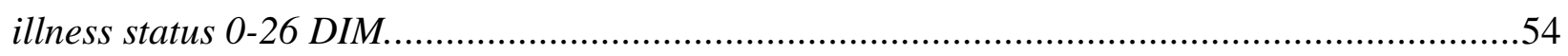

Figure 14: Contingency analysis of haptoglobin/milk production category at 54-60 DIM by

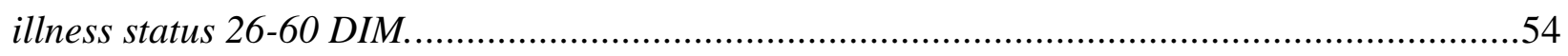

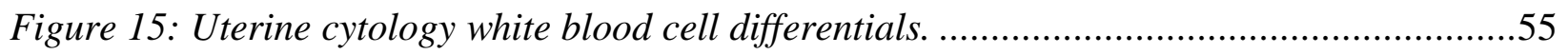

Figure 16: Frequency of bacterial species in uterine culture .................................................56

Figure 17: Contingency table of negative or positive uterine culture at 20-26 DIM by pregnancy status at 54-90 DIM. ...................................................................................................5

Figure 18: Contingency analysis of pregnancy by postpartum treatment 0-26 DIM..................58

Figure 19: Contingency analysis of pregnancy by postpartum illness. ....................................77

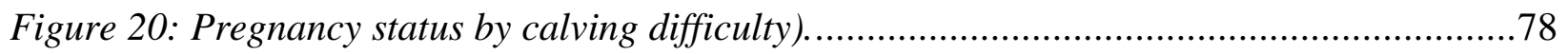

Figure 21: Pooled milk Hp concentrations at 20-26 DIM of healthy and diseased animals by

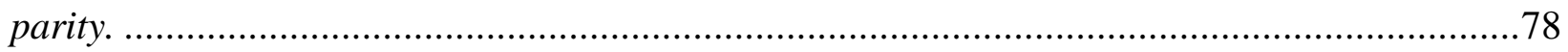

Figure 22: Illness Status 20-26 DIM by pregnancy status to first AI .....................................8

Figure 23: Conception rate by health factors clinical disease, plasma Hp concentration, and

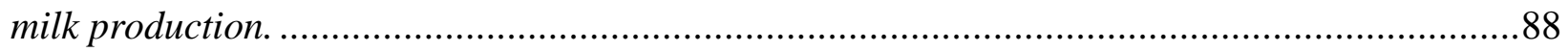




\section{List of Tables}

Table 1: Experimentally determined bovine haptoglobin standards....................................16

Table 2: Disease frequency by health category at each sampling period. ...............................35

Table 3: Disease frequency with illness count ...................................................................38

Table 4: Correlations between blood and milk leukocytes all animals 20-90 DIM...................45

Table 5: Cows treated for mammary infection combined 0-96 DIM.......................................47

Table 6: Correlations at 20-26 DIM by pregnancy diagnosis ................................................51

Table 7: Illness, uterine, and mastitis status 20-26 DIM ......................................................59

Table 8: Linear regression of cell types by tissue and pregnancy.........................................60

Table 9: Predictive equations generated by logistic procedure: Partial models .......................61

Table 10: Plasma Hp by illness status .......................................................................................63

Table 11: Milk somatic cell summary by QScout Farm Lab diagnosis .....................................70

Table 12: Milk total leukocyte summary by QScout Farm Lab diagnosis.................................71

Table 13: Blood leukocyte summary by QScout Farm Lab diagnosis.....................................72

Table 14:Mean uterine leukocyte summary by QScout Farm Lab diagnosis ...........................73

Table 15: Average milk yield summary by QScout Farm Lab diagnosis.................................74

Table 16: Disease status by QScout Farm Lab diagnosis ................................................... 75

Table 17: Conception rates to rirst AI by QScout Farm Lab diagnosis ......................................76

Table 18: Repeated measures ANOVA of WBC type by QScout diagnosis and time ..................79

Table 19: Autoregressive contrasts.................................................................................. 79

Table 20: Milk culture by QScout Farm Lab positive udder diagnosis...................................80

Table 21: McNemars test of agreement: Milk culture and QScout Farm Lab positive udder

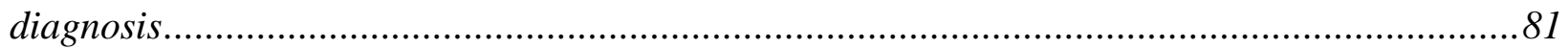

Table 22: DoVan treated mastitic cows by QScout Farm Lab positive udder diagnosis .............82

Table 23: McNemars test of agreement: DoVan treated cows by QScout Farm Lab positive

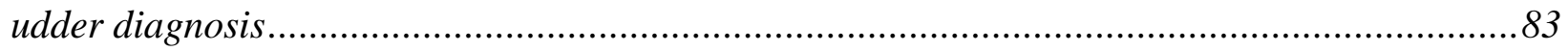

Table 24: Milk and blood correlations 20-26 DIM ...........................................................84

Table 25: Milk and blood correlations 54-60 DIM ...........................................................85

Table 26: Milk and blood correlations 90-96 DIM ...............................................................86 


\section{Literature Review}

\section{The Modern Dairy Cow}

The modern Holstein-Friesian dairy cow evolved from breeding Batavian and Friesian cattle (Prescott et al., 1930) to create black and white cattle. These cattle were selected to produce milk on limited forage for migrant Netherland tribes (Lush et al., 1936). Because of the selection for efficiency, the Holstein-Friesian breed became popular in the 1850s, when the demand for cattle in the newly settled Americas increased (Prescott et al., 1930). Milk production averaged $390 \mathrm{~kg}$ per lactation in 1921 (Holstein-Friesian World, 1922). Genetic selection soon intensified toward milk production, and genetic improvement for milk production increased while generation interval decreased (Yeu et al., 2015). The Holstein is still the highest milk producing breed of cattle in the United States, supplying an average of 10,432 $\mathrm{kg}$ of milk per lactation (NASS, 2015). Modern dairy operators constantly search for ways to increase milk production while decreasing costs and boosting efficiency. Such a production-focused view emphasizes increased milk yield, increased feed efficiency, and decreased calving interval while maintaining health status of the cow through improved disease prevention and treatments.

However, intense genetic selection for milk production has increased inbreeding, negatively impacted metabolic and reproductive traits (Kim and Kirkpatrick, 2009). Therefore, the modern dairy cow is susceptible to metabolic and hormonal challenges during the periparturient period lasting three weeks prior to and three weeks post parturition, termed the transition period (Goff and Horst, 1997; Simenew and Wondu, 2013). Metabolic changes mostly stem from the cow entering a state of negative energy balance defined as, the intake of insufficient calories to meet the needs of the animal (Bauman and Currie, 1980). Dry matter intake (DMI) decreases as parturition approaches (Bertics et al., 1992; Hayirli et al., 1998), 
which when combined with growing needs of the fetus, causes negative energy balance and increased fat mobilization. Negative energy balance is increased at parturition with the onset of lactation (Martinez et al., 2012). Milk production increases after calving until reaching its peak about 90 days in milk (DIM) after which production will gradually decline through the end of lactation. At this time nutrient partitioning draws energy via gluconeogenesis from fat reserves and lower priority tissues, such as the reproductive system, and shuttles it to the mammary gland for milk production and vital organs for maintenance.

A persistent challenge for dairy herd managers is maintaining an efficient calving interval: the days from one calving to the subsequent calving. In an efficient dairy operation, cows will be bred postpartum between 60-100 DIM to maintain an efficient calving interval. By minimizing services per conception, producers could save considerable time and money spent on getting cows pregnant. Fertile cows that breed back efficiently have economical calving intervals and decreased costs associated with heat detection and insemination. Thus, optimizing fertility is important to maintain an economically viable dairy operation.

The periparturient period includes a proinflammatory environment in the reproductive tract (Koets et al., 1998; Van Engelen et al., 2009). This time period also is associated with impairment of polymorphonuclear leukocytes (PMNs) and oxidative burst activity (Kehrli et al., 1989; Hoben et al., 2000b). Early changes coupled with the physical stress of calving result in suppression of immunity, increasing the risk of disease (Hiss et al., 2009). Immune suppression also occurs presumably from physical and hormonal stress (Hiss et al., 2009). This immunosuppression can result in subclinical infections (Detilleux et al., 1995). Cows that were sick at their prebreeding health examination (20-26 DIM) had extended intervals to rebreeding (Akers, 2014). 
Mastitis remains one of the largest challenges to the dairy industry resulting in profit loss (Bradley, 2002). Subclinical mastitis which lacks visible symptoms of inflammation,as with clinical mastitis, cows with subclinical mastitis exhibit decreased milk production (Sandholm et al., 1995). The National Animal Health Monitoring System Dairy Study in 2007 cited that $16.5 \%$ of cow mortalities were due to mastitis. During the early postpartum period, cows have higher susceptibility to mastitis than the remainder of lactation (Smith et al., 1998). Cebra et al. (1996) reported lower total protein levels in milk from cows with mastitis than in healthy animals. Cows with mastitis have increased somatic cell counts, inflammation, and acute phase responses in the udder that are reflected in a systemic innate immune response (Bochsler and Slauson, 2002). These challenges, specifically those associated with mastitis (Barker et al., 1998), impact cow health and increase time to next conception (Coleman et al., 1985).

\section{The Transition Period}

The transition period contains many changes for the dairy cow (Goff and Horst, 1997; Simenew and Wondu, 2013). During the early dry (non-lactating) period of gestation, cows are housed with other dry cows that are not due to calve immediately and are fed a dry cow ration. Three weeks prepartum, cows typically are moved to a pen and fed a diet higher in energy and protein to meet increasing energy demands of the fetus (Overton and Waldron, 2004). This can cause a voluntary decrease in DMI and an increase in standing time (Phillips and Rind, 2001). Decreased DMI and rumen volume during late gestation due to fetal growth results in a state of negative energy balance. Due to the cow's negative energy balance, glycogen and fat from the liver and adipose tissue, respectively, are mobilized (Holtenius et al., 2003). Plasma nonesterified fatty acids (NEFAs) mobilized from fat reserves rapidly increase as parturition approaches and lipolysis increases. As the cow's energy deficit grows, increasing amounts of adipose tissue are mobilized to be used for energy resulting in a loss of body condition prior to 
parturition (Taylor et al., 2003). During the transition period concentrations of endocrine levels also are changing. Plasma insulin levels decrease inversely with growth hormone (Hayirli et al., 2002), both of which surge at parturition (Kunz et al., 1985). Progesterone (P4), which has been high during gestation, rapidly declines two days prior to parturition followed by a drop in estrogen at parturition (Chew et al., 1979). On the day of calving, glucocorticoids and prolactin spike (Edgerton and Hafs, 1973). Blood calcium levels decrease close to parturition as it is shuttled to the mammary gland for colostrum synthesis (Goff and Horst, 1997). The combination of these endocrine changes prepare the cow for parturition and lactation.

As the fetus grows, uterine size limits the space available. This triggers the fetus to release corticotrophin from the fetal anterior pituitary (Senger, 2012), which promotes synthesis of 17 $\alpha$-hydroxylase, 17-20 desmolase, and aromatase (Strange et al., 1995). Progesterone is first converted to $17 \alpha$-hydroxyprogesterone by $17 \alpha$-hydroxylase, and 17-20 desmolase then converts $17 \alpha$-hydroxyprogesterone to androstenedione. The steroid ring then goes through aromatization and the removal of a carbon to produce estradiol. Progesterone loses its action of suppressing myometrial contractions causing an increase in myometrial activity and contractions (Csapo, 1956). Combined with the increase in estrogen, prostaglandin $\mathrm{F} 2$-alpha ( $\left.\mathrm{PGF}_{2 \alpha}\right)$ causes luteolysis and stimulates the release of relaxin to relax the ligaments of the pelvis and the cervix (Goff et al., 1987). The elevation of both estradiol and $\mathrm{PGF}_{2 \alpha}$ stimulate uterine contractions and increase internal pressure on the cervix, which stimulates oxytocin release from the posterior pituitary that subsequently increases the force of contractions to expel the fetus and fetal membranes (Senger, 2012). This entire process degrades normal anatomical barriers of the cow's reproductive tract and exposes it to an environment that is filled with foreign anaerobic and aerobic bacteria (Sheldon et al., 2014). Contamination from the environment, feces, and 
fetal membranes, which can work up the genital tract from the vulva to the vagina through the cervix and to the uterus due to the enlargement and relaxation of the tissues, can cause infection.

The puerperium period begins immediately post calving. During this time the uterus returns to its normal non-pregnant state, a process known as involution. During involution uterine tissue size is reduced, damage is repaired, and ovarian function resumes, all of which are essential for a subsequent pregnancy. Involution has been shown in the dairy cow to last 45-50 days (Gier and Marion, 1968), and even 90 days in other dairy cattle (LeBlanc et al., 2002). Postpartum contractions continue to push lochia; blood and remnants of placental and endometrial tissue, compress uterine vasculature to minimize risk of hemorrhage, and reduce the size of the uterus. Immediately postpartum the bovine uterus is nearly a meter long weighing approximately $9 \mathrm{~kg}$ (Gier and Marion, 1968). The first few days postpartum necrosis of the remaining carunclular tissue and residual leukocytes progresses, sloughing off in layers 1 to 2 mm thick (Senger, 2012; Gier and Marion, 1968). By four days postpartum, uterine contractions and reduced uterine size pushes lochia out of the uterus so that it pools in the vagina (Tizard, 2013). As involution progresses, there is a reduction in uterine edema and new epithelium forms in the uterine lumen (Gier and Marion 1968; Tizard, 2013). It has been extensively shown that time to uterine involution in dairy cows is extended when compared to other breeds of cattle (Lauderdale et al., 1968). Delayed involution is an important factor of fertility in the dairy cow and is due to lack of tactile stimulation from milking once or twice daily compared to beef cattle. During milking, or nursing of young, there is tactile stimulation of the teat end that sends a message to the periventricular nuclei of the hypothalamus (Senger, 2012), to release oxytocin. Oxytocin acts on smooth muscle of the mammary gland and uterus, which results in milk ejection (Senger, 2012) and release of $\mathrm{PGF}_{2 \alpha}$ from the uterine endometrium stimulating uterine 
contractions (Guilbault et al., 1984a; Guilbault et al., 1984b). In the weeks post-calving, the circulating levels of $\mathrm{PGF}_{2 \alpha}$ decrease to basal levels (Edqvist et al., 1978; Eley et al., 1981; Guilbault et al., 1984a; Guilbault et al., 1985). Involution is dependent upon magnitude (Guilbault et al., 1985) and duration of $\mathrm{PGF}_{2 \alpha}$ release (Lindell et al., 1982; Madej et al., 1984). Decreased oxytocin release decreases uterine contractions and lengthens time of involution in dairy cattle that are milked two to three times a day compared to the continuous suckling of a beef calf that is left on its dam (Izaike, 1990; Yavas and Walton, 2000).

Plasma P4 is high throughout gestation and suppresses leukocyte activity (Clemens et al., 1979), which is thought to allow tolerance to the fetus (Weinberg, 1987). The estrogen peak prior to calving has been shown to have an immune stimulating effect (Trawick and Bahr, 1986); however, Wyle and Kent (1977) found that estrogen suppresses leukocyte function. Plasma cortisol, the hormone of stress, increases prior to parturition and continues to increase postpartum (Goff et al., 1987; 1989). van Knegsel et al. (2007) proposed that the combination of estrogen and cortisol cause immune suppression at parturition. The severity of negative energy balance has also been positively associated with the immune status of the cow (van Knegsel et al., 2007).

\section{Innate Immune Response}

Natural immunosuppression, which is marked by an attack of the innate immune system occurs during the period surrounding parturition. This non-specific section of the immune system is composed of the physical barriers to infection: epithelium, phagocytic cells, dendritic and natural killer cells, and plasma proteins (Murphy, 2012).

The four functions of the innate immune system are: recognizing foreign pathogens, eliminating foreign pathogens, regulating the immune response, and building memory of foreign 
pathogens for future responses through antigen presentation (Murphy, 2012). The recognition of foreign pathogens is initiated by leukocytes. Mature leukocytes are present in circulation and tissue after maturing in bone marrow. Macrophages are considered the body's first response to a foreign pathogen. Found in tissue, these mature monocytes are phagocytic and act to engulf foreign pathogens through receptor binding of toll-like receptors (TLRs). Some toll-like receptors are located on the cell membrane of leukocytes that sense and bind pathogenassociated molecular patterns (PAMPs) of microbial/pathogen products to recruit other leukocytes to stimulate an immune response (Beutler, 2009; Takeuchi and Akira, 2010). Cell recruitment resulting from cytokine signaling and a consequence of TLR ligation, causes inflammation in tissue due to the induced secretion of prostaglandins, cytokines, and chemokines. Classical symptoms of inflammation include redness, swelling, heat, and pain of the affected area (Murphy, 2012). Inflammation is mediated by several factors that continue to recruit leukocytes to the area to remove damaged cells and pathogens (Chen and Nuñez, 2010). Other mediators, like cytokines and prostaglandins, work as redundant signals, to further recruit immune cells. Neutrophils (PMNs), eosinophils, and basophils are classified as granulocytes, because their cytoplasm contains granules that are bactericidal or contain potent enzymes and toxic proteins (Murphy, 2012). Neutrophils are present in high numbers and act as bactericidal agents that have phagocytic processes and have antibacterial agents stored in their granules. The sum of multiple cell actions stimulates immune response to fight foreign pathogens through the down-stream signaling due to the ligation of PAMPs to TLRs (Beutler, 2009; Sheldon et al., 2014; Takeuchi and Akira, 2010). Memory of the immune system is built as innate immune cells present antigen to lymphocyte cells (Murphy, 2012), as the humoral or adaptive arm of the immune system discussed later. 
Circulating neutrophils increase as a result of parturition and subsequent inflammation of the reproductive tract (O'Connor et al., 2000). Hematocrit and total leukocyte counts increase from 6,000 to $9,000 \times 10^{3} / \mu \mathrm{L}$ as parturition approached (Jones and Allison, 2007; Jain, 2013). Nazifi et al. (2008) also showed hematocrit levels in the pregnant cow were higher than in the postpartum cow, accounting for the decrease in packed cell volume postpartum. The same study also showed that leukocyte and hemoglobin counts were higher during gestation than 2530 DIM in cows (Nazifi et al., 2008). Leukocyte numbers then fall sharply in the first 24 hours postpartum and return to basal levels in four to six days postpartum (Jain, 2013; Straub et al., 1959).

Polymorphonuclear leukocytes make up approximately $25 \%$ of total leukocytes in healthy cattle (Paape et al., 2003; Table 1). In postpartum cattle that number has been shown to increase to 43\% (Dosogne et al., 1999). Number of circulating neutrophils increase prepartum and sharply decline one week postpartum (Detilleux et al., 1995). During this time the number of immature, or banded neutrophils, increase in circulation, referred to as left shift (Detilleux et al., 1995). A limited number of mature neutrophils are stored in bone marrow, resulting in an increase in the number of circulating immature neutrophils during an immune challenge. A negative correlation exists between the number of mature neutrophils in circulation and the severity of an infection (Waller, 2002). Monocytes are lowest at parturition and return to average $(4,200$ cells $/ \mu \mathrm{L})$ two-three weeks postpartum (Detilleux et al., 1995). In the same study eosinophils were lowest two weeks postpartum and returned to basal values three to four weeks postpartum (Detilleux et al., 1995). Merrill and Smith (1954) found that lymphocyte and eosinophil numbers increased, neutrophils decreased, while monocytes showed no significant change through ten days postpartum. The number of blood lymphocytes decrease before and at 
parturition, returning to a higher level during the second week postpartum (Saad et al., 1989). Inflammation, in combination with parturition and onset of lactation, leads to increasing NEFA and reactive oxidative species, which impair the phagocytic function of neutrophils (Esposito et al., 2014; Hammon et al., 2006; Krause et al., 2014), and when combined with parturition stress further impair oxidative burst activity (Kehrli et al., 1998; Hoben et al., 2000a).

During gestation P4 is high and maintains the latent uterine environment. Prior to parturition effects of P4 diminish as estradiol increases (Senger, 2012) resulting in an increase in circulation to the uterus. This increase in circulation can be characterized by an increase in leukocytes and proinflammatory signals or cytokines. Leukocyte infiltration is accompanied by cell lysis forming pus in the uterus, which are expelled during normal uterine contractions that occur during involution. However, if bacteria are able to colonize the uterus in greater magnitude than the immune response, uterine disease develops. Metritis, clinical endometritis or subclinical endometritis develop as a result of the severity of leukocyte infiltration, accumulation of pus, and number of days postpartum (Sheldon et al., 2006). Metritis involves inflammation of the endometrium, myometrium and perimetrium of the uterus, which is accompanied by myometrial degeneration and infiltration of leukocytes. Seldon et al. (2006) defined metritis as an abnormally large uterus postpartum with discharge of brown lochia, signs of systemic illness, and fever within three weeks postpartum. This classification is different than that of clinical metritis where the uterus is abnormally large postpartum accompanied by discharge of lochia but the animal shows no systemic signs of illness (Sheldon et al., 2006), accompanied by a uterine cytology sample $\geq 10 \%$ PMN (Galvao et al., 2010). Endometritis is inflammation of the endometrium, which does not affect the myometrium (Bondurant, 1999). Presence of an enlarged uterus with greater than $50 \%$ purulent or mixed mucopurulent discharge greater than three week 
postpartum is diagnosed as clinical endometritis (Sheldon et al., 2006). An animal presenting with a lack of discharge but has greater than $18 \%$ neutrophils in a uterine cytology sample three to four weeks postpartum, is diagnosed as having subclinical endometritis (Sheldon et al., 2006). Subclinical endometritis diagnosis extends four to five weeks postpartum if the neutrophil content is greater than $10 \%$ (Sheldon et al., 2006).

It has been accepted that $\mathrm{P} 4$ contributes to immune suppressive effects. P4 regulates the release and function of $\mathrm{PGF}_{2 \alpha}$ (Vincent and Inskeep, 1986), and proinflammatory cytokines that stimulate luteolysis resulting in subsequent uterine contractions that would expel contaminants from the uterus (Murray et al., 1990; Heuwiser et al., 2000). Experimental intrauterine infusion of Escherichia coli (E. coli) and Arcanobacterium pyogenes (A. pyogenes) in beef cattle were unsuccessful in establishing a uterine infection until P4 increased during the luteal phase (Del Vecchio et al., 1992; Rowson et al., 1953; Lewis, 2003b). It has also been observed that three weeks postpartum, when P4 increases prior to the LH surge of the first dominant follicle, spontaneous uterine infections will establish (Sheldon et al., 2002; Savio et al., 1990). Associated inflammation that develops can suppress LH pulses causing a persistent follicle with the inability to ovulate (Sheldon et al., 2002; Peter and Bosu, 1988). For this reason it is common for producers to use exogenous $\mathrm{PGF}_{2 \alpha}$ in cows that are suspected to have a uterine infection. The alternative treatment for uterine infection is the intrauterine infusion of antimicrobial agents (LeBlanc et al., 2002; Sheldon and Nokes, 1998). Common pathogens include environmental aerobes and anaerobes: A. pyogenes, E. Coli, Fusobacterium, Bacteriodes, and Prevotella species (Bonnet et al., 1991; Sheldon et al., 2002; Sheldon et al., 2006). 
As in the uterus, common pathogens infiltrate the mammary gland and stimulate innate immune responses. These environmental and contagious pathogens stimulate inflammation known as mastitis. Environmental pathogens are bacteria that are naturally present in the animal's environment, typically caused by teat contamination during or post milking. These specific bacteria include E. coli, Streptococcus dysgalactiae, Streptococcus uberis, Klebsiella pneumonia, and Bacillus species (Dego et al., 2002). Infectious bacteria spread from quarter to quarter within the mammary gland and from cow to cow through direct or indirect contact. Specific pathogenic bacteria include Staphlococcus aureus (S. aureus), Streptococcus agalactiae, and Arcanobacterium species (Zadoks et al., 2001; Dego et al., 2002). S. aureus was identified as the most prevalent contagious mastitis causing pathogen, being cultured in $43 \%$ of herds tested regardless of herd size (NAHMS, 2008).

The invasion of the mammary gland by pathogenic bacteria begins at the skin level, with the teat canal not only serving as the first point of defense against pathogens but also as a direct path into the mammary gland for infection (Zecconi et al., 2002; Paulrud, 2005). In a healthy mammary gland the teat skin is lined with fatty acids that act as antimicrobials while the teat canal is lined with smooth muscle that maintains tight closure of the sphincter on the teat end (Zecconi et al., 2002; Paulrud, 2005). Keratin, produced by stratified squamous epithelium cells lining the teat canal, acts as an antimicrobial agent (Paulrud, 2005). Damage to the teat canal musculature, stratified squamous epithelium of the canal or subsequent keratin can allow pathogens into the mammary gland to establish an infection. This damage can be caused by improper administration of intramammary therapies, defective milking machines (Nickerson, 1987; Capuco et al., 1994), or during normal milking when the keratin can be stripped out of the teat canal (Rainard and Riollet, 2006). 
These insults permit colonization of the teat canal and bacteria to move up into the teat cistern of the mammary gland allowing further colonization. Additionally, action of a mechanical milker can force bacteria present on the teat end during milking into the teat canal for colonization (Griffin et al.,1988). Once milking is complete, the teat sphincter can remain relaxed, or open, allowing bacteria to enter from the environment. Once bacteria colonizes in the mammary gland, innate immune responses occur quickly. Leukocytes and proinflammatory mediators are drawn to the site of infection,produceing cytokines and acute phase proteins (APPs) that further work to clear the infection. The first leukocytes present in the mammary gland include neutrophils, macrophages, and natural killer cells (Boutinaud and Jammes, 2002). These cells cause inflammation and the characteristic signs of mastitis: redness and heat from the mammary gland accompanied by discomfort of the animal and a spectrum of milk clots when milked.

The most problematic form of mastitis is subclinical (Sandholm et al., 1995). Although asymptomatic, subclinical mastitis results in decreased milk production. The migration of leukocytes into the mammary gland increases milk somatic cell count (Harmon, 1994; Bradley and Green, 2005). In the average bovine mammary gland, free from mastitis, somatic cell count averages 75,000 cells/mL of milk. Cell composition includes epithelial cells that are constantly being shed during lactation, aveolar epithelial cells, and leukocytes lacking cytoplasmic particles with 5-20\% of cells neutrophils, 10-30\% lymphocytes and about 60\% macrophages (Boutinaud and Jammes, 2002; Dulin et al., 1983).

The most numerous leukocyte in the healthy and infected mammary gland is the macrophage (Lee et al., 1980). During the periparturient period, leukocyte concentrations increase to $80,000,000 / \mathrm{mL}$ with neutrophils and lymphocytes having the highest concentration in 
milk in the mammary gland (Concha, 1986). Neutrophils are resident in the mammary gland but also migrate into the tissue out of circulation (Lin et al., 1995). As macrophages and neutrophils respond to an infection or site of inflammation bacteria is lysed within the mammary gland. (Blosher and Slauson, 2002) Macrophages and neutrophils also produce cytokines such as tumor necrosis factor- $\alpha$ (TNF- $\alpha$ ), interlukin-1 (IL-1), interlukin-1 beta (IL-1 $\beta$ ), and interlukin-6 (IL-6) that increase chemotactic activity of cells to the tissue (Alluwamim, 2004) and acute phase proteins (APP; Kurash et al., 2004) that act as pro and anti-inflammatory mediators in tissue (Lai et al., 2009).

The inflammatory response is amplified through activation of cytokine receptors and these tissues produce APPs, such as hepatocytes in the liver (Gruys et al., 2005; Baumann and Gauldie, 1994). During an acute phase response the liver shifts $30-40 \%$ of anabolic function to production of APP (Mackiewicz, 1997). Major APP concentration increases within 24 to 48 hours post triggering event and then decrease rapidly, due to APP short half-life (Niewold et al., 2003). During more chronic inflammatory events, APP have exhibited consistent low to moderate levels in circulation (Horadgoda et al., 1999). For this reason, APP have shown high sensitivity for inflammatory or stressful events however low specificity for diagnosing the cause (Ceron et al., 2005).

Major APPs in cattle are haptoglobin (Hp) and serum amyloid A (Peterson et al., 2004), which show significant positive correlations in serum concentration values (Ekersall et al., 2001). Haptoglogin and serum amyloid A were shown to increase 100-fold as opposed to the three to four fold increase of $\alpha$-glycoprotein in dairy cattle (Ekersall et al., 2001). Haptoglobin is a plasma macromolecule (>1000kD) (Eckersall and Conne, 1990) with beta-alpha-alpha-beta chains connected by disulfide bridges (Morimastsu et al., 1991). The main function of Hp is to 
scavenge free hemoglobin $(\mathrm{Hb})$ during oxidative stress (Kristiansen et al., 2001; Langlois et al., 1996), and is produced by neutrophils, liver hepatocytes, and alveolar cells (Aronowski and Zhao, 2011; Levy et al., 2010; Lim et al., 1998).. Cooray et al. (2007) demonstrated elevated Hp of multiple isoforms in circulating granulocytes of healthy cattle. During an infection, bacteria use the heme structure of $\mathrm{Hb}$ for growth and colonization (Hiss et al., 2004).

Hemoglobin is released by the rupture of erythrocytes (Rother et al., 2005), then bound $\mathrm{Hp}$ in what has been described as an irreversible interaction (Rother et al., 2005). The Hb iron intermediate has oxidative potential (Banerjee et al., 2012) that causes free heme to be released into circulation and prevent clearance from the body (Buehler et al., 2009). Released Hb contains an iron intermediate that reacts with downstream hydrogen peroxide resulting in formation of hydrogen radicals (Banerjee et al., 2012). Haptoglobin complexes with $\mathrm{Hb}$ to reduce the oxidative potential there by limiting iron availability to bacteria. Therefore Hp acts as an antioxidant (Yang et al., 2003; Tseng et al., 2004). Oxygen has shown an increased affinity for the $\mathrm{Hp}-\mathrm{Hb}$ complex when compared to uncomplexed $\mathrm{Hb}$ (Banerjee et al., 2012). Thus the $\mathrm{Hp}-\mathrm{Hb}$ complex is considered bacteriostatic and antinflammatory (Levy et al., 2010).

The $\mathrm{Hp}-\mathrm{Hb}$ complex reduces the toxic potential of $\mathrm{Hb}$, allowing its removal by the glycoprotein CD163 (Freeman et al., 1990), a transmembrane protein found on monocyte and macrophage cells. Expression of CD163 in vitro was influenced by administration of cytokine and TLR ligand. Downregulation of CD163 was acheived by administration of IFN $\gamma$, TNF- $\alpha$, IL-4, and lipopolysaccharide (LPS) with glucocorticoids, IL-6, and IL-10 induced up regulation of CD163 (Etzerodt and Moestrup, 2012; Van Gorp et al., 2010). With nine scavenger receptor cysteine rich domains (Van Gorp et al., 2010), the third domain of CD163 is essential in $\mathrm{Ca}^{2+}$ dependent ligand formation with the Hp-Hb complex (Madsen et al., 2004). CD163 can also, 
uptake free $\mathrm{Hb}$ allowing a backup system if $\mathrm{Hp}$ is depleted or there is excessive hemolysis (Schaer et al., 2006). The uptake of free Hb is shown by high affinity CD163 subunits (Etzerodt et al., 2013). The binding of $\mathrm{Hb}$ to CD163 (uncomplexed or complexed with $\mathrm{Hp}$ ) causes secretion of IL-6 and IL-10 as well as heme oxygenase, a stress response protein (Philippidis et al., 2004). If uncomplexed, $\mathrm{Hb}$ accumulates in the kidney. Therefore, $\mathrm{Hp}$ protects from renal failure due to the buildup of $\mathrm{Hb}$ in the kidneys as well as prevents iron loss (Kim et al., 1998).

Bovine $\mathrm{Hp}$ is not typically expressed in healthy animals (Table 1). The reference value for serum is $<0.35 \mathrm{mg} / \mathrm{mL}$ for healthy animals in a variety of ages and breeds (Horadagoda et al., 1994; Table 2). Concentrations specifically found in healthy cattle being $0.08 \pm 0.017 \mathrm{mg} / \mathrm{mL}$ (Lipperheide et al., 1997; Nakagawa et al., 1997). However, Hp concentration increases during bacterial challenge (Lai et al., 2007; Petersen et al., 2004), with peak activity of 24-48 hours (Slocombe and Colditz, 2005), thus Hp has been used as an acute phase inflammatory marker in cattle (Horoadagoda et al., 1999; Skinner et al., 1991; Takahashi et al., 2006). Alsemgeest et al. (1995) observed an increase in serum Hp in acute, subacute, and chronic inflammations such as pneumonia, peritonitis, and abscess, which led to the use of $\mathrm{Hp}$ as a factor for diagnosing sick cattle (Skinner et al., 1991). 
Table 1: Experimentally determined bovine haptoglobin standards.

\begin{tabular}{|c|c|c|}
\hline Serum & Concentration (mg/ml) & Source \\
\hline Healthy & 0.0003 & $\begin{array}{l}\text { Weinkauf et al., } 2005 \\
\text { Lipperheide et al., 1997; }\end{array}$ \\
\hline Healthy & $0.108 \pm 0.017$ & Nakagawa et al., 1997 \\
\hline Healthy & $<0.259$ & Slocombe and Colditz, 2005 \\
\hline Healthy & 0.35 & Horadagoda et al., 1994 \\
\hline Healthy & $0.108 \pm 0.017$ & Khoshvaghti et al., 2009 \\
\hline Healthy & $0.02-0.1$ & Ekersall et al., 2001 \\
\hline Acute Metritis & $0.890 \pm 0.071$ & Khoshvaghti et al., 2009 \\
\hline Subclinical Mastitis & $0.570 \pm 0.063$ & Khoshvaghti et al., 2009 \\
\hline Mild Mastitis & $0.47 \pm 0.45$ & Ekersall et al., 2001 \\
\hline $\begin{array}{l}\text { Moderate Mastitis } \\
\text { Chronic }\end{array}$ & $0.74 \pm 0.72$ & Ekersall et al., 2001 \\
\hline Inflammation & $0.18-2.0$ & Takahashi et al., 2006 \\
\hline Milk & Concentration $(\mathrm{mg} / \mathrm{ml})$ & Source \\
\hline Healthy & 0.0003 & Weinkauf et al., 2005 \\
\hline Acute Metritis & $0.000112 \pm 0.000020$ & Khoshvaghti et al., 2009 \\
\hline Subclinical Mastitis & $0.000107 \pm 0.000026$ & Khoshvaghti et al., 2009 \\
\hline
\end{tabular}

Serum Hp levels significantly increase post parturition (Gymnich et al., 2003; Uchida et al., 1993). Hiss et al. (2009) showed the concentration of serum Hp was low $(0.19 \pm 0.03$ $\mathrm{mg} / \mathrm{mL}$ ) four weeks prepartum, increased to $1.6 \pm 0.27 \mathrm{mg} / \mathrm{mL}$ one week postpartum and returned to basal levels three weeks postpartum. Highest concentrations in milk were found one week postpartum, declining to basal levels six weeks postpartum (Hiss et al., 2009).

Haptoglobin levels during uterine infection and uterine involution have been correlated with illness status (Sheldon et al., 2001), as well as in cases of metritis (Smith et al., 1998; Chan et al., 2010). This can be demonstrated by the increase in Hp three days after parturition (Chan et al., 2010). Huzzey et al. (2009) showed that cows with Hp serum levels higher than $1 \mathrm{mg} / \mathrm{mL}$ three days postpartum were 6.7 times more likely to develop metritis. Speculation has been made that 
high Hp could be a result of cows in a negative energy balance (Crawford et al., 2005), agreeing with the presence of Hp in cows with fatty liver (Yoshino et al., 1992).

Haptoglobin has been measured in milk as well as serum. Nielsen et al. (2004) reported that Hp concentration in serum and milk of cows with clinical mastitis was higher than those with extra mammary infection. Permeability of the blood-milk barrier has been shown to increase during mastitis allowing serum proteins to gain access to milk (Shuster et al., 1997). Ekersall et al. (2001) showed a significant correlation between Hp in serum and milk. The increase in Hp in all quarters has been shown to reflect the presence of an extra mammary disorder (Grouland et al., 2005). Serum Hp levels increased with California Mastitis Test (CMT) score and clinical changes in the mammary gland (Kovack et al., 2011).

The production of cytokines by macrophages suggests that APPs, specifically Hp can be produced in several tissues like the kidneys, gastrointestinal tract, muscle, alveolar cells of the mammary gland (Van Gorp et al., 2010), lung (D’Armiento et al., 1997), and oviduct (Lavery et al., 2004). These tissues are highly vascularized and contain extensive capillary beds to maximize exchange of blood from mammary arteries to capillaries, draining into interstitial tissues. The increased blood flow also increases circulating leukocytes and macrophages in the tissues. Tissue inflammation results in increased cytokine and lysosomal activity in epithelial cells and production of arachidonic acid from prostaglandins. These factors expedite transfer of leukocytes and APPs into the tissue. In the case of the mammary gland the blood-milk barrier leaks due to the loosening of tight junctions during mastitis. In a healthy mammary gland, leukocytes are transported between blood and tissues through para-cellular transportation and are incorporated into the milk in the intralobular milk collecting duct from the superficial inguinal lymph node, dorsal to the gland. These leukocytes can migrate to the site of inflammation, and 
are induced to generate cytokines and APP further recruit other cells required to resolve infection. These leukocytes will die and be incorporated into the whey while APP are bound to albumin for solubility to be ejected from the gland during milking.

Confirmation of leukocyte increase with milk Hp concentration has been shown with significant relationship between milk Hp and CMT score in cows with mastitis (Nielsen et al., 2004). Milk $\mathrm{Hp}$ and somatic cell count ah a strong positive correlation, proving to be an indicator of infection severity (Khoshvaghti et al., 2009). Hirvonen et al. (1999) demonstrated that milk Hp is elevated prior to the increase in somatic cell count, in cows with clinical mastitis. Elevated Hp concentrations in milk may also contribute to circulating Hp levels (Hiss et al., 2004; Thielen et al., 2007). Hiss et al. (2004) demonstrated there is a rapid increase in Hp concentration of milk from infected quarters; quarters treated with LPS increase followed by a decrease to normal levels while serum levels continue to rise with time of treatment. The early increase of Hp in milk confirms the hypothesis that Hp synthesis occurs in the mammary gland. Ekersall et al. (2001) concluded that the failure to distinguish mild and moderate cases of mastitis was due to the extrahepatic synthesis of $\mathrm{Hp}$ by the mammary gland in combination with serum Hp leaking across the blood-milk barrier.

In addition to bacteria, there is also a link between the acute phase response and noninflammatory stress (Murata, 2007). Kim et al. (2011) classified stress in to three categories: physical, psychological, and a combination of the two. Psychological stress, which is a perceived danger that lacks a physical stressor, such as weaning of calves (Kim et al., 2011). Psychological stresses are thought to activate the hypothalamic-pituitary-adrenal axis via the nervous system cascading into acute phase responses (Johnson et al., 2005; Kelly et al., 1994) to affect the immune system (Sivakumar et al., 2010). A common theory is that stress responses 
suppress immune activity thus increasing the susceptibility of the animal to disease (Kim et al., 2011).

\section{Adaptive Immune Response}

After induction of innate immunity by pathogen recognition, the adaptive or acquired immune response is required to prevent and promote antigen-specific responses in the future. This branch of the immune system is based on the systematic elimination of pathogens through antibody synthesis and cell mediated immunity. Leukocytes that take part in the innate immune response phagocytize pathogens and present pieces of the pathogen on their cell wall (e.g., macrophages). Lymphocytes, presented antigen from dendritic cells, are leukocytes that are activated when presented with a foreign peptide antigen. The antigen presented on the outside of the cell stimulates T-lymphocytes to stimulate B-lymphocyte expansion in the lymph node. These B-lymphocytes secrete antigen specific antibodies to fight the pathogen. The adaptive response takes more time to mount a response however it is more specific.

Lymphocytes act by recognition of antigen by membrane receptors that give them specificity and memory. Once an animal is exposed to a pathogen lymphocytes, specifically Bcells, retain antibody memory for future immune challenges (Stelwagen et al., 2009). During the periparturient period and subsequent lactation, when stress and pathogen exposure are high, lymphocytes in circulation increase (Merril and Smith, 1954). In circulation, T-lymphocytes with a cellular marker cluster of differentiation 4 (CD4+), have been identified as the predominate T-cell subset (Shafer-Weaver et al., 1996). These CD4+ cells are known as Thelper cells, involved in memory response following antigen recognition as well as cytokine production (Sordillo and Streicher, 2002; Riollet et al., 2000; Worku et al., 1994). In contrast to circulation the mammary gland has been shown to have a predominate CD8+ T-cell population 
(Shafer-Weaver et al., 1996). These cells are recognized as cytotoxic T-cells that act as cytotoxic cells. It has been shown that even in the healthy mammary gland lymphocyte numbers fluxuate through lactation (Taylor et al., 1994; Park et al., 1993; Park et al., 1992). This has been attributed to the population of memory T-lymphocytes in the mammary gland (Taylor et al., 1994) as well as the lack of efficiency of antigen presenting cells in the mammary gland (Waller, 2002). It has been further shown that CD8+ T-cells in the mammary gland during a bacterial infection can function as suppressor cells allowing a chronic subclinical infection to establish (Park et al., 1993; Hisatsune et al., 1990). Cytotoxic T-cells combine immune suppressive function with the removal of epithelial cells thus increasing susceptibility to infection (Taylor et al., 1994). However, cytotoxic T-cell function changes through lactation. Postpartum lymphocytes did not express cytotoxic activity but express IL-4, which promotes B-cell differentiation. Mid-lactation lymphocytes expressed cytotoxic activity combined with IFN- $\gamma$ (Park et al., 1993). Unlike T-cells, B-cells have been shown to remain constant though lactation (Paape et al., 2002; Shafer-Weaver et al., 1996) and infection (Riollet et al., 2001).

Individual B-cells produce antigen specific antibodies or immunoglobulins (Igs). Once antigen is encountered a naïve B-cell is activated and differentiates into a plasma cell able to secrete antibodies (Alberts et al., 2002). These effector cells contain membrane bound antibodies that serve as antigen receptors while also secreting antibodies into circulation. Effector cells produce large amounts of antibody during maturation, once they reach growth and differentiation potential they are classified as plasma cells. Majority of these cells die post maturation, however numerous are able to survive for long periods of time in bone marrow continuing secretion of antibodies into circulation (Alberts et al., 2002). 
It has been demonstrated that E.coli is the predominant bacteria causing uterine infection postpartum that subsequently impairs reproductive function (Bicalho et al., 2012; Machado et al., 2010). Early uterine contamination leads to Fusobacterium necrophorum (F. necrophorum) and Trueperella pyogenes (T. pyogenes) infection (Bicalho et al., 2012). These common pathogens are known to induce metritis and endometritis (Bicalho et al., 2012; Machado et al., 2012). Based on these observations Machado et al. (2014) created inactivated recombinant proteins from whole cells of E. coil, F. necrophorum and T. pyogenes to vaccinate heifers between 230260 days of gestation. Vaccinated heifers had increased serum IgG titers against all antigens with the subcutaneous vaccinations reaching higher levels than heifers vaccinated intravaginaly. Subcutaneous vaccination also resulted in a decrease in the incidence of puerperal metritis but not endometritis postpartum. This is supported by the intramuscular vaccination of cattle with Histophilus somni, uterine secretions yielded high amounts of $\operatorname{IgG}$ from circulation (Butt et al., 1993). Corbeil et al. (1974) demonstrated an increase of IgG in the bovine reproductive tract post systemic immunization with Campylobacter fetus, drawing the conclusion that antibodies, specifically IgG, work to facilitate opsonification in the reproductive tract. Opsonins work to alert the body to foreign cells to make them vulnerable to phagocytosis by leukocytes (Jain, 2013). This theory would allow the innate immune system to recognize pathogens more readily to phagocytize and clear the bacteria.

\section{Reproductive Impacts}

Pregnancy rates in dairy cattle have declined in the last 40 years, from $50-60 \%$ to $35-45 \%$

(Royal et al., 2000; Stevenson, 2001). An interaction between the reproductive system and immune response to infection or inflammation in non-reproductive organs or system in the body has been proposed (Stofkova et al., 2009; Pittman, 2011). The first study to propose an impact on fertility due to mastitis found that cows diagnosed with clinical mastitis between the first 
insemination and pregnancy check when compared to cows with clinical mastitis at other times during lactation (Barker et al., 1998), when cows were inseminated according to estrus after 60 DIM. An increase in services per conception was observed in cows with clinical mastitis between insemination and pregnancy check along with an increase in days to the first insemination in cows with clinical mastitis prior to the first insemination. This finding was verified by Santos et al. (2004); as cows with clinical mastitis had longer intervals to pregnancy with the average days to conception increasing by a median of 20 days when compared to control animals. Cows categorized by milk culture as having subclinical mastitis between first insemination and pregnancy check had increased services per conception (Schrick et al., 2001). Cows with subclinical mastitis that progressed to clinical mastitis had greater services per conception averaging greater than four (Schrick et al., 2001). These pregnancy rates were independent of mastitis causing bacterial species or type (gram-positive or gram-negative) (Barker et al., 1998; Schrick et al., 2001).

Inflammatory diseases, as mastitis, increase proinflammatory factors. Increased expression of IL-1 $\alpha$, IL-1 $\beta$, TNF- $\alpha$, and IL-12 have been shown by somatic cells from cows with mastitis (Riollet et al., 2001). Induced and naturally occurring mastitis resulted in elevated levels of circulating IL-1, IL-6, and TNF- $\alpha$ (Blum et al., 2000; Hoben et al., 2000; Nakajima et al., 1997). Proinflammatory molecules increase production of nitric oxide (Blum et al., 2000; Bouchard et al., 1999) and $\mathrm{PGF}_{2} \alpha$ in milk (Giri et al., 1984). Hockett et al. (2000) demonstrated that cows with experimentally induced gram-positive mastitis had increased levels of 13, 14dihydro-15keto-prostaglandin $\mathrm{F}_{2 \alpha}$, the metabolite of $\mathrm{PGF}_{2} \alpha$, in circulation post oxytocin administration. These results led to the conclusion that cows with mastitis due to gram-positive 
bacteria may have increased sensitivity to $\mathrm{PGF}_{2 \alpha}$, which may result in an increase in $\mathrm{PGF}_{2 \alpha}$ receptors.

The production of $\mathrm{PGF}_{2 \alpha}$, nitric oxide, and TNF- $\alpha$ have demonstrated embryo toxic effects. Administration of $\mathrm{PGF}_{2 \alpha}$ to cattle undergoing $\mathrm{P} 4$ supplementation resulted in decreased pregnancy rates (Buford et al., 1996; Seals et al., 1998). Soto et al. (2003b) showed that PGF ${ }_{2 \alpha}$ compromises oocyte maturation, but had no effect on fertilized embryos. Nitric oxide has shown toxic effects through its interaction with $\mathrm{O}_{2}^{-}$to form oxidant peroxynitrate (Hobbs et al., 1999). Increases in vasoconstriction have been shown as a result of nitric oxide signaling, which can be impaired by binding of $\mathrm{Hb}$ (Rother et al., 2005). Bovine embryos cultured with a nitric oxide donor, sodium nitroprusside dehydrate, inhibited development to blastocysts (Soto et al., 2003a). The addition of TNF- $\alpha$ to culture medium resulted in a decreased proportion of oocytes becoming blastocysts, while increasing the proportion of apoptotic blastomeres (Soto et al., 2003a). A feedback of these molecules due to proinflammatory molecules can affect the uterus. Production of TNF- $\alpha$ in circulation during mastitis (Blum et al., 2000) can cause the endometrium to produce $\mathrm{PGF}_{2 \alpha}$ (Skarznski et al., 2000). Nitric oxide production can then be induced by TNF- $\alpha$ and $\mathrm{PGF}_{2 \alpha}$ (Perez et al., 1998). Changes in nitric oxide production have been shown to inhibit gonadotropin releasing hormone $(\mathrm{GnRH})$ during inflammation due to IL-1 release interfering with LH (McCann et al., 2000). Therefore, mastitis can cause the release of cytokines like TNF- $\alpha$ into circulation inducing $\mathrm{PGF}_{2 \alpha}$ release from uterine endometrial cells resulting in luteolysis. Darbon et al. (1989) reported that TNF- $\alpha$ inhibited LH receptor formation by blocking FSH's stimulation in rat the in vitro. Due to this action it was hypothesized that during inflammation and subsequent TNF- $\alpha$ release, granulosa cell differentiation under FSH was reduced. Therefore, TNF- $\alpha$ alters estrogen production for follicle growth, maturation, and 
subsequent ovulation due to decreased LH receptors (Darbon et al., 1989). Systemic endotoxin administration resulted in an increase in circulating 13, 14-dihydro-15keto-prostaglandin $\mathrm{F}_{2 \alpha}$ (Jackson et al., 1990). Gilbert et al. (1990) showed that intrauterine infusion of E. coli in heifers on days 7-9 of the estrous cycle resulted in shortened estrous cycles.

An additional proposed mechanism of increased services per conception for mastitic cows is dysfunction of the hypothalamic-pituitary-ovarian axis. Cytokines, including IFN- $\alpha$ (Barros et al., 1992), have been shown to decrease luteinizing hormone (LH) release from the pituitary (McCann et al., 2000). Cortisol also has been shown to decrease LH secretion during mastitis (Hockett et al., 2000), stressful events (Stephens, 1980), and systemic challenges (Kujjo et al., 1995; Peter et al., 1989). In heifers, endotoxin administration preceding estrus suppressed LH concentration through GnRH pulse suppression (Battaglia et al., 1996), maintained anovulatory follicles resulting in follicular cysts, and subsequently delayed ovulation (Peter et al., 1989; Suzuki et al., 2001), as elevated cortisol concentrations with decreased follicular size (Peter et al., 1989). Hockett et al. (2002) also showed elevated cortisol levels resulted in a delay of estrus behavior in cows with induced mastitis. The proposed mechanism is the result of research involving bacterial induced inflammation of the mammary gland. Leukocytes are drawn to the tissue and produce proinflammatory cytokines that act in tissue and circulation to increase proinflammatory responses, thus recruiting more leukocytes to tissue to resolve the infection. In circulation these cytokines act on various leukocyte and endothelial cells increasing secondary inflammatory products like nitric oxide and $\mathrm{PGF}_{2 \alpha}$ while inhibiting hormone feedback needed for normal reproductive function (Hansen et al., 2004). Hockett et al, (2002) observed decreased estrus expression in cows with clinical mastitis eight days post $\mathrm{PGF}_{2 \alpha}$ administration. A decrease in circulating $E_{2}$ levels was observed in experimentally-induced mastitic cows with 
infected animals lacking estrus behavior (Hockett et al., 2005). Pulsatile frequency of LH was decreased in infected cows lacking estrus behavior (Hockett et al., 2005). Intravenous administration of endotoxins in ewes blocked the preovulatory rise of $\mathrm{E}_{2}$ and the LH surge while decreasing LH pulse frequency and estrus behavior (Battaglia et al., 1999). A small dose of endotoxin was sufficient to decrease GnRH which blocked LH pulses in some ewes (Battaglia et al., 2000). Cytokines and other proinflammatory mediators may suppress GnRH release affecting subsequent gonadotrophin release therefore affecting cyclicity (Hockett et al., 2005).

Coupled with cytokine production the acute phase response also is activated. Production of Hp by macrophages and neutrophils (Levy et al., 2010; Theilgaard-Monch et al., 2006) increases with hemolysis and leukocytosis (Rother et al., 2005). Patterns of Hp release vary between species and degree of inflammation. In humans there are two Hp alleles (Wicher and Fries, 2010), giving rise to three unique Hp phenotypes (Hp1-1, Hp2-1, and Hp2-2) in which $\alpha$ chain duplication causes the Hp2 allele (Levy et al., 2010). These three phenotypes are implicated in the concentration of plasma Hp levels, with the Hp1 allele having higher average concentrations followed by the heterozygous and Hp2 homozygous genotypes (Nielsen and Moestrup, 2009). In dairy cattle, high Hp serum concentration has been implicated with decreased reproductive efficiency. Nightingale et al. (2015) demonstrated that increasing Hp concentration two to eight days postpartum increased days to conception. This study proposed that increase in the acute phase response, triggered by upregulation of innate immune responses, suppressed mitogen induced IFN- $\gamma$ secretion negatively impacting reproduction. Plasma Hp levels one to three weeks postpartum also increased with bacterial contamination in the uterus (Sheldon et al., 2001). Galvao et al. (2010) demonstrated that cows with clinical metritis had 
elevated plasma Hp levels 7 DIM and returned to baseline by 14 DIM. In the same study cows with subclinical metritis did not show elevated plasma Hp.

Further evidence of Hp concentration negatively affecting days to conception has been shown (Huzzey et al., 2015). Evidence of decreased hepatic function was shown in cattle with a negative energy balance, increased bilirubin levels, and increased plasma Hp concentrations (Bertoni et al., 2008). This study also showed that cows in this group exhibited lower fertility with greater number of days open, greater services per conception, and lower than average milk yield at 28 DIM.

Cows with low incidence of disease at 20-26 DIM that also had high systemic haptoglobin (> $3 \mathrm{mg} / \mathrm{mL}$ ), above herd average milk yield (42.67 kg/day), and low blood lymphocyte $(<2.5$ cells $/ \mu \mathrm{L})$ and monocyte $(<0.8$ cells $/ \mu \mathrm{L})$ counts had higher pregnancy rates to first service than their herd mates. Lymphocyte and monocyte concentrations were correlated with total white blood cells in circulation (Akers, 2014; Figure 1). 
(A)

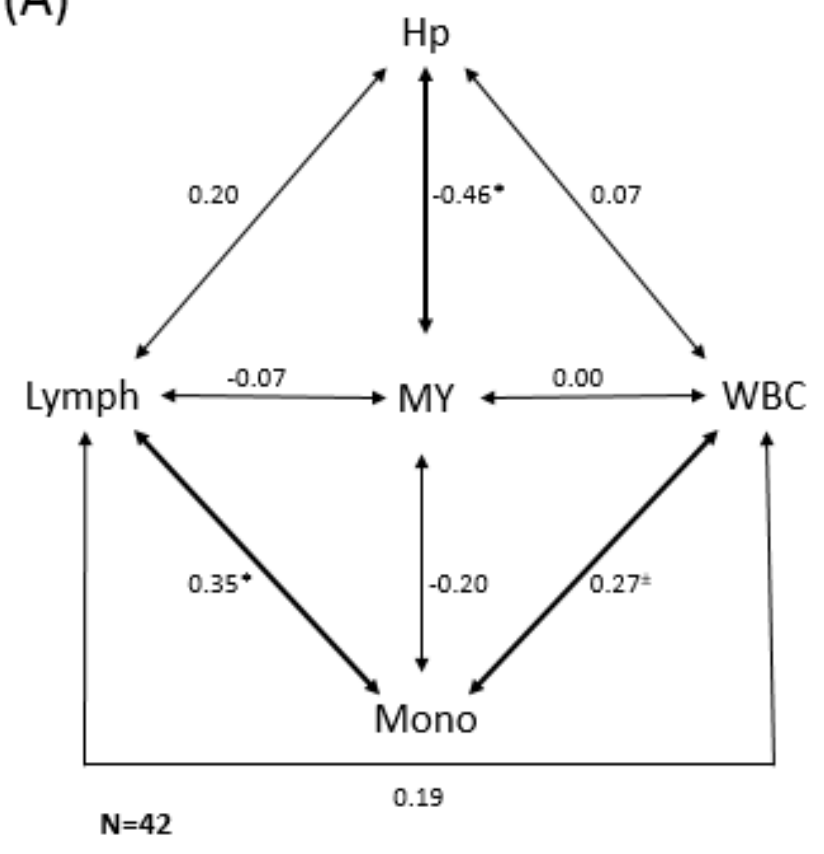

(B)

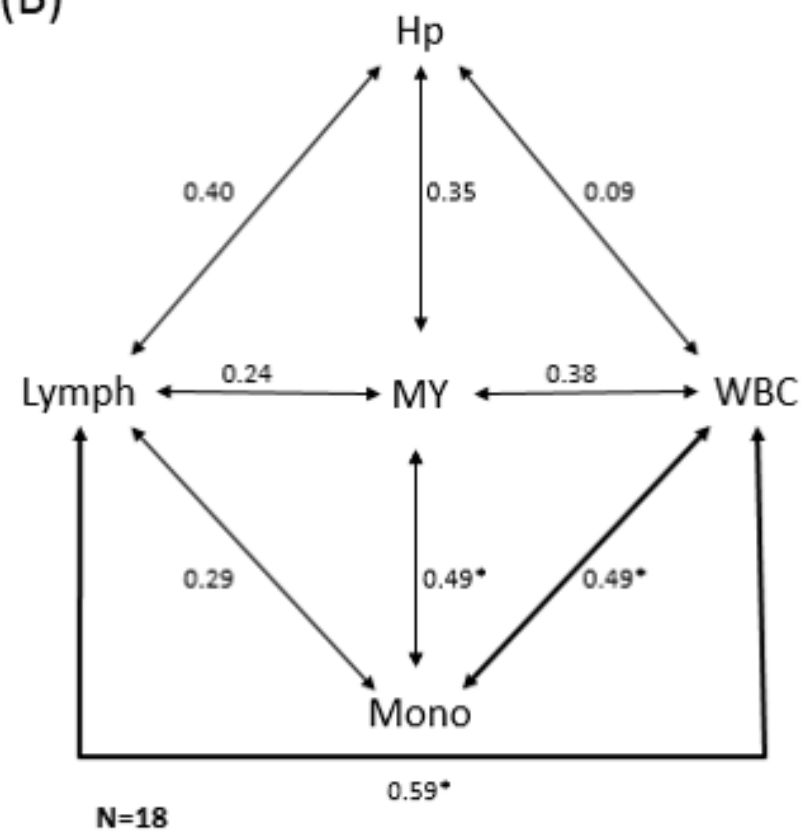

Figure 1: Nonparametric coefficients between blood constituents in dairy cattle at 20-26 DIM that were grouped based on outcome of pregnancy diagnosis at 95 DIM [significant correlation $(p<0.05)$ values indicated (*) and trends indicated $( \pm)] .(A)$ non-pregnant cows; trend in Mono -WBC ( $p<0.08) ;(B)$ pregnant cows. $H p=$ Haptoglobin, $M Y=$ Milk yield, $W B C=$ White blood cells, Lymph = Lymphocytes, Mono = Monocytes (Akers, 2014).

The lack of specificity of Hp as a biological marker comes with advantages and disadvantages. The broad spectrum of stressors resulting in the acute phase response cause an unspecified increase in Hp 50-100 times basal levels (Kim et al., 2011). Combination of APPs (Perterson et al., 2004), body temperature, and clinical exam would improve diagnosis and causation of the acute phase response (Ceron et al., 2005). Huzzey et al. (2009) proposed a sensitivity scale of $\mathrm{Hp}$ to identify cows in need of treatment. A cut off point of $\geq 400 \mu \mathrm{g} / \mathrm{mL}$ of plasma Hp was recommended to identify cows that need further clinical examination to determine disease status. Plasma Hp threshold of $\geq 1400 \mu \mathrm{g} / \mathrm{mL}$ gave necessity for antibiotic treatment. These findings hold promise for the use of APPs not only as a biomarker for disease 
but also fertility in dairy cattle. The endocrine, metabolic, and physical changes that make up the transition period (Goff and Horst, 1997), force the modern dairy cow into a state of altered homeostasis. The characterization and rebalance of homeostasis can give insight into the future immune and fertility status of the lactating dairy cow. The culmination of previous literature provides insight into the proposed pathway of cellular mechanisms between tissues and circulation as shown in Figure 2. 


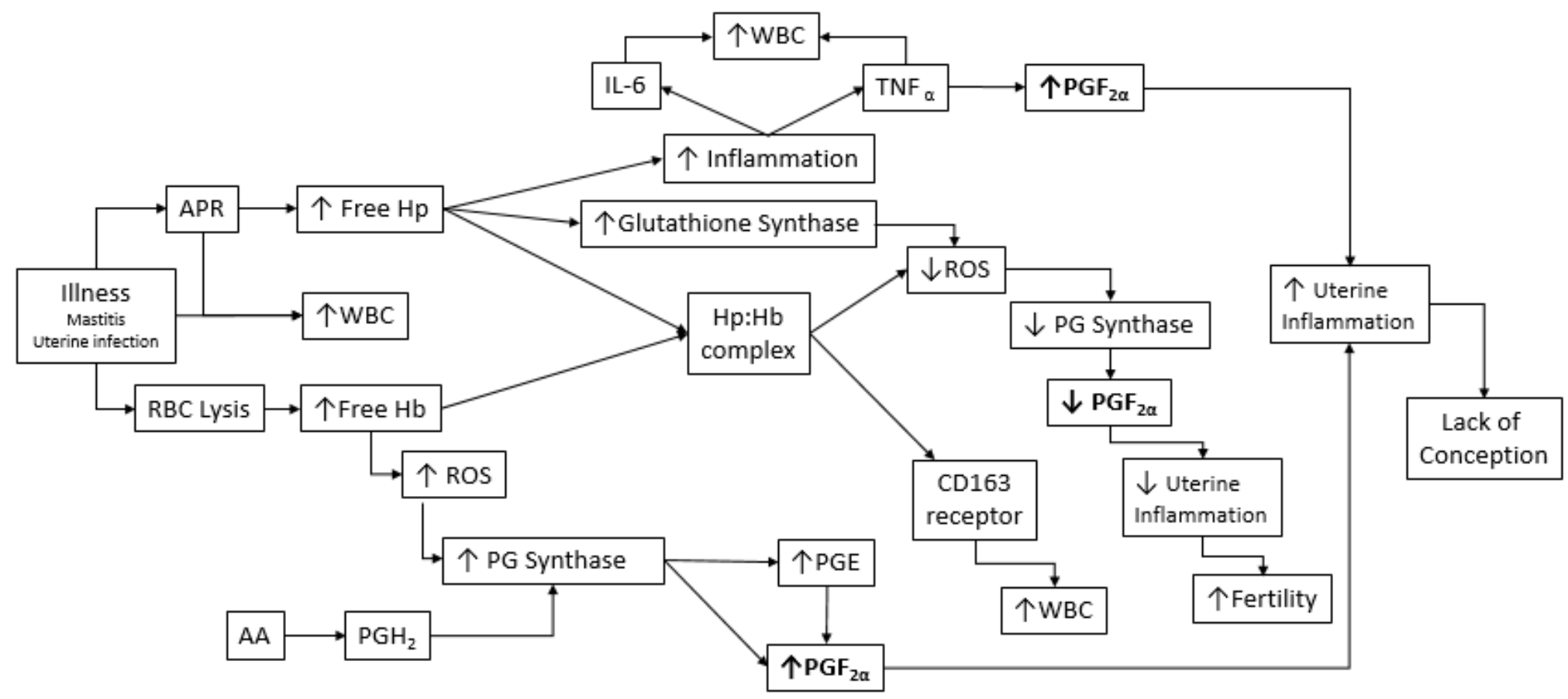

Figure 2: Proposed pathway for the interaction of systemic and local cellular components affecting the outcome of the first service in the lactating dairy cow. APR = Acute Phase Reaction, RBC = Red Blood Cells, WBC = White Blood Cells, Hp=Haptoglobin, Hb= Hemoglobin, Hp:Hb = Haptoglobin Hemoglobin Complex, IL-6 = Interleukin 6, TNF $\alpha=$ Tumor Necrosis Factor alpha, PGF $2 \alpha=$

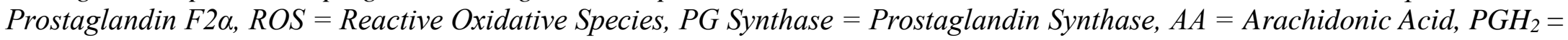
Prostaglandin $\mathrm{H}_{2}, P G E=$ Prostaglandin E. 


\section{Statement of the Problem}

The change in concentrations of hormones in the transition period that induced calving, the physical stress of calving, and the immediate onset of lactation combine to create an immune compromised animal. The decrease in DMI prepartum and the need postpartum for increased energy due to milk production puts the cow in a state of negative energy balance. Because of the high demand for protein, glucose, and fat in the first few weeks post calving, the cow draws these nutrients from her body reserves which opens the animal to clinical and subclinical infections that have the potential to impact health, production, and subsequent fertility. The aim of this study was to use leukocyte counts and Hp concentrations as biomarkers of health status and to associate those biomarkers and milk yield on reproductive success in dairy cattle (Figure 4). Specific objectives included: 1. Examine for relationships among biomarkers in circulation, uterus, and mammary gland milk samples to determine health status as identified through physical symptoms and milk yield, and 2. use biomarkers and milk yield at prebreeding (20-26 DIM) to predict likelihood of becoming pregnant at first insemination (54-60 DIM).

\section{Materials and Methods}

This study was conducted during the winter of 2014 through spring of 2015 at DoVan Farm in Berlin, Pennsylvania (708 m above sea level; 39 $55^{\prime} 12^{\prime \prime} \mathrm{N}, 78^{\circ} 57^{\prime} 0^{\prime \prime} \mathrm{S}$ ), a commercial dairy farm that milks approximately 700 Holstein Friesian cows three times daily at 0400, 1300, and 2200. Cows were housed in free stall barns year round and fed a total mixed ration once daily free choice with push-ups. Rolling herd average of this farm is 10,433 to $10,886 \mathrm{~kg} /$ year with a reproductive cull rate of 5\%,22\% pregnancy rate, and 2.3 services per conception. Conception to first service was $37 \%$ with an average of 115 days open, while maintaining a 13.0 month calving interval. DoVan maintains consistency with timing of the first artificial insemination 
60 DIM whether cows show estrus or are put on an ovulation synchronization protocol and inseminated at a fixed time. Blood and quarter milk samples were collected from 101 postpartum multiparous and 25 postpartum primiparous animals at examination periods: prebreeding (20-26 DIM), breeding (55-60 DIM), and pregnancy (90-95 DIM). Uterine cytology and culture samples were collected at prebreeding check (20-26 DIM; Figure 3). Milk leukocyte differentials were determined using QScout MLD slides in the QScout Farm Lab (Advanced Animal Diagnostics, Morrisville, NC) on farm. Experimental mode hospital cow setting was used to perform complete cell differentials without adjustment for stage of lactation (Figure 4). PCDart Dairy Management Software (Dairy Records Management Systems, Raleigh, NC) was used to collect milk weights, incidences of disease, prebreeding and breeding information, and pregnancy records. Three day milk weights prior to sampling were recorded and averaged. Confirmation of pregnancy and disease status were assessed by an experienced veterinarian.

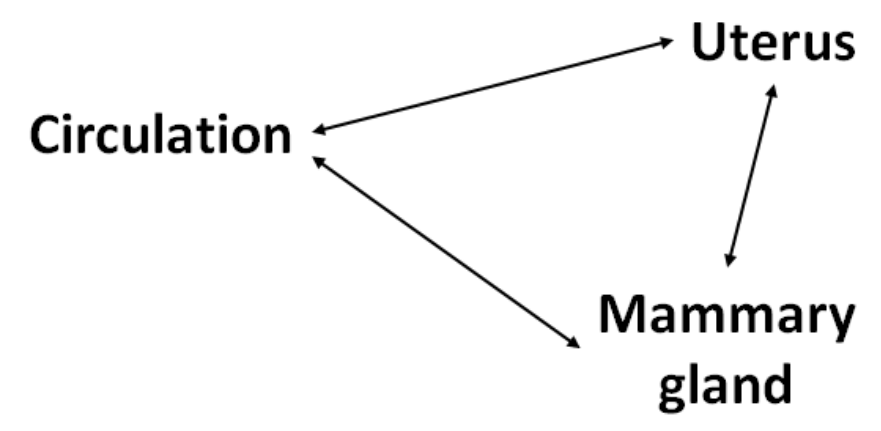

$\begin{array}{lll}\text { Prebreeding Check } & \text { Breeding } & \text { Pregnancy Check } \\ \text { 20-26 DIM } & \text { 54-60 DIM } & \text { 90-96 DIM } \\ \text { - Blood Sample } & \text { - Blood Sample } & \text { - Blood Sample } \\ \text { - Milk Samples/Culture } & \text { - Milk Samples/Culture } & \text { - Milk Samples/Culture } \\ \text { - Uterine Cytology/Culture } & & \end{array}$

Figure 3: Sampling timeline in tissue and circulation. 


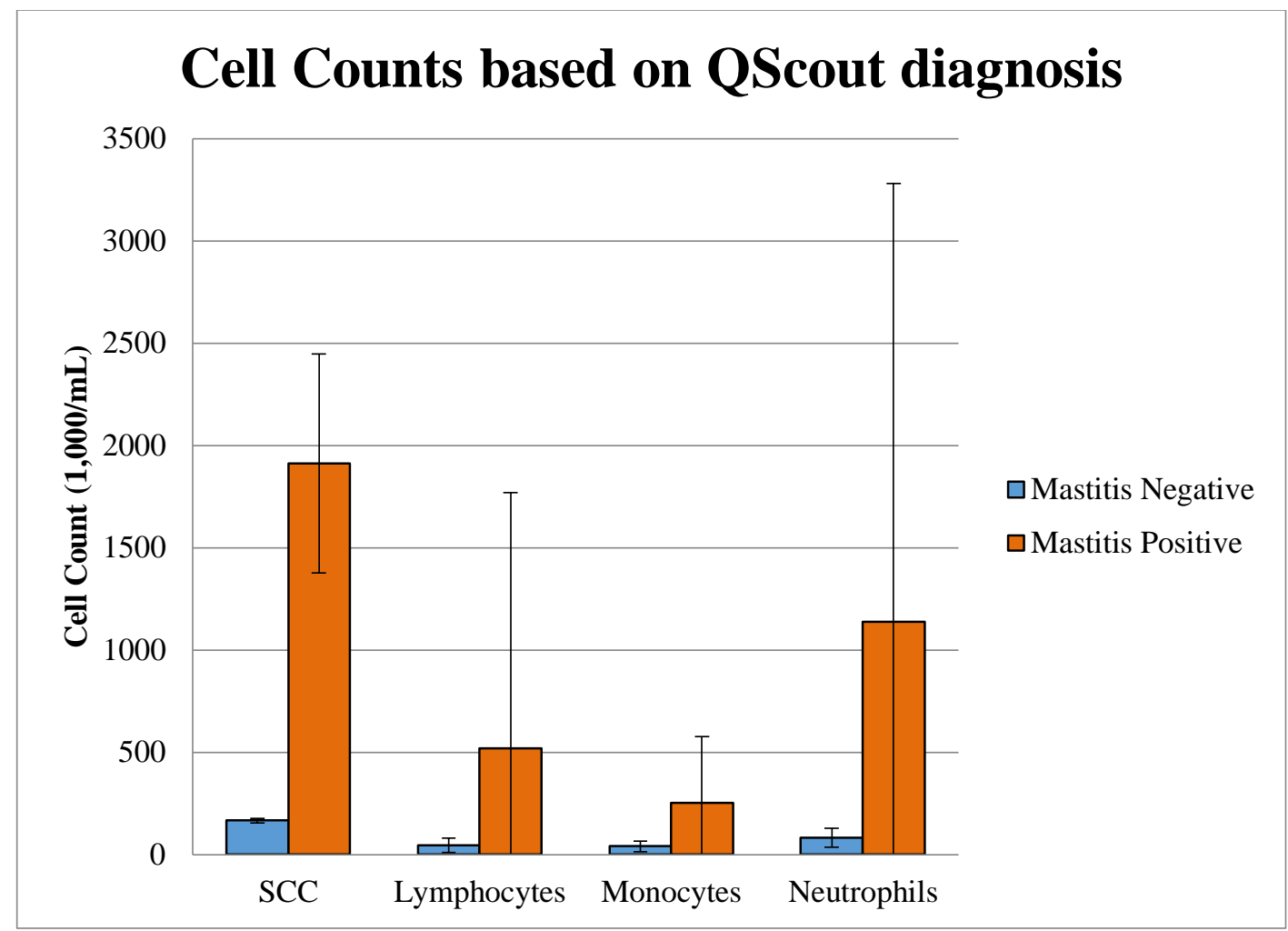

Figure 4: Cell differential counts from QScout Farm Lab set to experimental mode in hospital cow setting for pooled milk samples from cows milking all four quarters, grouped by QScout mastitis diagnosis 20-26 DIM. Positive cows $n=45$, negative cows $n=69$. SCC= somatic cell counts.

\section{Blood Sampling}

The ventral side of the caudal tail vein was disinfected with a $70 \%$ alcohol solution, and blood was collected by venipuncture using a 20 gauge needle into two sterile $10 \mathrm{ml}$ collection tubes containing $0.10 \mathrm{ml}$ EDTA (Coviden, Mansfield, MA) and chilled for transport. One tube of whole blood was sent to Advanced Animal Diagnostics (Durham, NC) for automated cell counts, which were performed within 48 hours of collection. Samples were analyzed on Advia 120 (Siemens, Malvern PA) or CELL-DYN (Abbott Diagnostics, Abbott Park IL) analyzers for white blood cell peroxidase counts or white blood cell optical count and white blood cell impedance count. The remaining tube of blood was transported on ice to the laboratory and centrifuged at 
$1275 \mathrm{xG}$ for 20 minutes at $4^{\circ} \mathrm{C}$. Plasma was removed and stored in aliquots at $-80{ }^{\circ} \mathrm{C}$ until assayed for Hp by enzyme-linked immunosorbent assay (ELISA assay; Life Diagnostics, West Chester PA).

\section{Milk Sampling}

While wearing disposable gloves, the teat end was cleaned and stripped 3 times.

Individual quarter milk samples were collected into the QScout Q4 milk collection tray

(Advanced Animal Diagnostics, Morrisville, NC) and capped immediately. Then beginning with the front teats, sterilized gauze soaked in $70 \%$ ethyl alcohol was used to clean the teat end while applying pressure on the teat in a downward direction to expose the sphincter. After cleaning the rear teats, new gloves were obtained, and sterile milk samples were collected midstream into sterile conical tubes held $45^{\circ}$ perpendicular to the ground. Samples were placed immediately on dry ice for shipment and culture at the Mastitis Laboratory at North Carolina State University Veterinary School (Raleigh, NC). Aliquots of from each quarter were pooled for each cow and frozen for subsequent determination of Hp by ELISA assay (Life Diagnostics, West Chester PA).

\section{Uterine Cytology}

Endometrial cells were obtained via uterine cytology brush for large animal use (Jorgensen Labs Inc., Loveland, Colorado). The sterile rod was guided via rectal palpation into the vagina and to the cervix. The internal sheath was passed through the cervix, and the brush was then guided into the uterus. Endometrial cells were obtained by rolling the brush over the surface of the uterine body and rotating the brush head. The brush was retracted into the rod and removed from the uterus (Kasimanickam et al., 2005). The brush was swabbed with sterile transport swabs and placed in Amies transport medium (Fisher Scientific, Pittsburgh PA) for anaerobic and aerobic bacteria culture by Antech Diagnostics (Medina, $\mathrm{OH}$ ). The brush head was suspended in $5 \mathrm{ml}$ of Roswell Park Memorial Institute 1640 medium (RPMI; Fisher 
Scientific, Pittsburgh PA) for cytological analysis at Antech Diagnostics (Medina, OH). All samples were chilled for overnight shipping. A representative sample (250ul) of the suspended cells was placed on a glass slide for cyto-centrifugation in a Shandon Cytospin 4 (Thermo

Scientific, Waltham MA). Slides were dried and stained by a Wescor Aerospray slider stainer (ELITesch Group, Puteaux, France) and read by a pathologist.

\section{Health Status}

An experienced veterinarian diagnosed disease status at each time point and administered treatment as necessary (Table 2). Diseases were grouped into five categories; metabolic (milk fever, ketosis, digestive, left displaced abomasum, or diarrhea), reproductive (abortion, retained placenta, metritis, calving difficulty, or twin birth), structural hoof root or lameness), and infectious diseases (pneumonia and Salmonella), mammary (mastitis), and QScout Farm Lab mastitis diagnosis [positive cow diagnosis for one or more positive quarters (independent from mammary diagnosis by producer)]. Treatment and disease incidences were entered into PCDart from parturition through 90 DIM or through cull date. QScout leukocyte differentials and mastitis diagnosis were recorded from QStats ${ }^{\mathrm{TM}}$ (Advanced Animal Diagnostics, Morrisville, NC). 
Table 2: Disease frequency by health category at each sampling period.

\begin{tabular}{lcccc}
\hline & $\begin{array}{c}\text { Postpartum } \\
(20-26 \mathrm{DIM}) \\
\mathrm{N}=126\end{array}$ & $\begin{array}{c}\text { Prebreeding } \\
(54-60 \mathrm{DIM}) \\
\mathrm{N}=126\end{array}$ & $\begin{array}{c}\text { Postbreeding } \\
(90-96 \mathrm{DIM}) \\
\mathrm{N}=124\end{array}$ & Total \\
\hline Metabolic & 7 & 1 & 4 & $\mathbf{1 2}$ \\
Reproductive & 46 & 1 & 0 & $\mathbf{4 7}$ \\
Structural & 8 & 13 & 7 & $\mathbf{2 8}$ \\
$\begin{array}{l}\text { Infectious } \\
\text { Mammary }\end{array}$ & 2 & 1 & 1 & $\mathbf{4}$ \\
$\quad$ & & & & \\
$\quad$ Treated & 1 & 2 & 2 & $\mathbf{5}$ \\
$\quad \begin{array}{c}\text { Positive QScout } \\
\text { Farm Lab Mastitis } \\
\text { Diagnosis }\end{array}$ & 51 & 61 & 61 & $\mathbf{1 7 3}$ \\
\hline
\end{tabular}

\section{Reproductive Measurements}

Cows were palpated rectally weekly postpartum for the evaluation of the uterus. Manual uterine massage or "rakes" were performed as necessary. The veterinarian determined the presence of ovarian structures and preformed routine pre-breeding examinations (20-26 DIM). Cows received an injection of $\mathrm{PGF}_{2} \alpha$ analog (Estrumate@ Intervet/Merck Animal Health Summit, NJ) at prebreeding. Pre-synchronization (Pre-synch) was initiated 35-41 DIM with ovulation synchronization (Ovsynch program) 14 days later (49-55 DIM). Tail chalk was used daily as an estrous detection aid and cows were artificially inseminated 12 hours after external signs of estrus by experienced breeders who checked the herd daily. If cows did not show signs of estrus, they were inseminated 48 hours after the second GnRH injection of the Ovsynch program (Pursley et al., 1995). Pregnancy diagnosis was determined via rectal palpation and ultrasound 26 to 32 days post artificial insemination (90-96 DIM). 


\section{Statistical Analysis}

Pregnancy rate was calculated using all cows present during the experiment. Cows that were culled or deceased were recorded as non-pregnant. A power test was conducted based on the results of Akers (2014), revealed that a sample size of 100 cows allowed for a power of greater than $95 \%$.

Data were transformed using $\log 10$ or square root $(\mathrm{x}+1)$ to normally distribute cell counts and percentages, respectfully. Means and standard deviations of untransformed data are used in plots of data. Independent t-tests were performed on quarter samples of milk cell counts with repeated measures. Milk leukocyte data at 20-26 DIM were analyzed beginning with cows milking all four quarters using dependent t-tests performed front and rear quarters and side to side quarters. Finding no significance and difference further analysis used the pooled milk samples within cow. Repeated measures ANOVA was performed on all cell differentials for pooled milk, blood, uterine cytology, and concentrations of Hp in milk and plasma followed by Tukey-Kramer with adjustments for multiple comparisons. Relative risk was calculated for pregnancy prediction models. Multivariate correlations were performed on biomarkers. Analysis of covariance on pregnancy status was performed using GLM procedure of SAS. Logistic regression was systematically used for predictive models of pregnancy in a backward elimination. Due to the large number of variables in the full model, variables were grouped into physiological cohorts. Blood variables included plasma Hp and leukocytes in circulation. Milk variables included milk leukocytes, QScout udder diagnosis, lactation, milk yield, culture status, and milk Hp. Uterine variables included culture status and uterine leukocytes. Health variables included calving difficulty, illness status, treatment status, and individual disease category. Conception rates were analyzed by chi square analysis with Fisher's exact test used when expected count was less than five. Data were analyzed using JMP and SAS software (JMP®, 
Version Pro 11, SAS Institute Inc., Cary, NC, Copyright @ 92013 ; SAS®, Version 9.3, SAS

Institute Inc., Cary, NC,Copyright (C2002-2010). Significance criterion alpha level for all tests was 0.05 .

\section{Results}

\section{Study Statistics}

Animals consisted of 25 first lactation and $1012^{\text {nd }}-4^{\text {th }}$ lactation cows $\left(452^{\text {nd }}\right.$ lactation, 27

$3^{\text {rd }}$ lactation, and $294^{\text {th }}$ lactation). During the study, four cows were culled. The days to first service averaged 72.5 with a $35.7 \%$ conception rate to first service. Average number of days to second service was 113 with second service conception rate being $35.8 \%$. Services per conception averaged 2.3 for pregnant animals and 2.9 overall; conception rates between technicians did not differ significantly. Rolling herd average milk production was $10,433 \mathrm{~kg}$ with a study average of $41.96 \mathrm{~kg} / \mathrm{day}$.

\section{Health Status}

Incidence of health status was based on farm treatment for clinical illness as directed by the veterinarian and diagnosis of mastitis by the QScout Farm Lab. The majority of illnesses treated during the postpartum period were reproductive (abortions, retained placentas, metritis, calving difficulty $\geq 3$, and twin births; $n=46$ ). Over time incidences of reproductive disorders decreased and positive QScout Farm Lab diagnoses increased (Table 3). 
Table 3: Disease frequency with illness count

\begin{tabular}{|c|c|c|c|c|c|c|c|c|}
\hline & Total & Total & & Tre & ated by Far & & & QScout \\
\hline & $\begin{array}{c}\text { IIInesses } \\
\text { Found }\end{array}$ & $\begin{array}{l}\text { Treated } \\
\text { Animals }\end{array}$ & $\begin{array}{l}\text { Metabolic } \\
\text { Disorder }\end{array}$ & $\begin{array}{l}\text { Reproductive } \\
\text { Disorder }\end{array}$ & $\begin{array}{c}\text { Structural } \\
\text { Disorder }\end{array}$ & $\begin{array}{l}\text { Infectious } \\
\text { Disorder }\end{array}$ & $\begin{array}{c}\text { Mammary } \\
\text { Disorder }\end{array}$ & $\begin{array}{c}\text { Diagnosis } \\
\text { Positive }\end{array}$ \\
\hline $\begin{array}{l}\text { Postpartum } \\
\text { (0-26DIM) }\end{array}$ & 88 & 64 & 7 & 46 & 8 & 2 & 1 & 51 \\
\hline $\begin{array}{l}\text { Prebreeding } \\
\text { (26-60 DIM) }\end{array}$ & 67 & 18 & 1 & 1 & 13 & 1 & 2 & 63 \\
\hline $\begin{array}{l}\text { Postbreeding } \\
\text { (60-90 DIM) }\end{array}$ & 66 & 14 & 4 & 0 & 7 & 1 & 2 & 63 \\
\hline Total & 221 & 96 & 12 & 47 & 28 & 4 & 5 & 177 \\
\hline $\begin{array}{l}\text { Diseas } \\
\text { by the } \\
\text { treatme } \\
\text { displac } \\
\text { metriti } \\
\text { infectio } \\
\text { quarter }\end{array}$ & $\begin{array}{l}\text { frequenc } \\
\text { oducer } \\
\text { t by the } \\
\text { d aboma } \\
\text { calving } \\
\text { s (treate } \\
\text { clinicall }\end{array}$ & $\begin{array}{l}\text { over tim } \\
\text { nd positiv } \\
\text { roducer), } \\
\text { um, or dic } \\
\text { ifficulty, } \\
\text { for pneu } \\
\text { infected) }\end{array}$ & $\begin{array}{l}\text { by disorder } \\
\text { QScout Di } \\
\text { netabolic d } \\
\text { rrhea), repr } \\
\text { twin birth, } \\
\text { tonia or sal }\end{array}$ & $\begin{array}{l}n=126 . \text { Tota } \\
\text { agnosis cows), } \\
\text { sorders (treate } \\
\text { oductive (treat } \\
\text {, structural (tr } \\
\text { monella), and }\end{array}$ & $\begin{array}{l}\text { illnesses fo } \\
\text { otal treated } \\
\text { for milk fe } \\
\text { d for abort } \\
\text { ated for ho } \\
\text { ammary }(t r\end{array}$ & $\begin{array}{l}\text { d (inciden } \\
\text { nimals (tot } \\
r \text {, ketosis, } \\
\text { ns, retaines } \\
\text { root or lar } \\
\text { ated due to }\end{array}$ & $\begin{array}{l}\text { es of treatme } \\
\text { l incidences } \\
\text { ligestive, } \\
\text { placentas, } \\
\text { eness), } \\
\text { one or more }\end{array}$ & \\
\hline
\end{tabular}

Healthy animals during the postpartum period had a conception rate of $50 \%$ compared to $30.7 \%$ conception rate for animals with an illness $(\mathrm{p}=0.0387)$. Healthy animals were 1.76 times more likely to become pregnant to the first breeding than treated $(\mathrm{p}=0.0209)$. Primiparous animals were 2.64 times more likely to become pregnant if they did not have an illness in the postpartum period $(\mathrm{p}=0.0227)$. Multiparous cows without postpartum illness had a $40 \%$ conception rate compared to those that did not conceive on the first breeding; however, they were only 1.43 times more likely to become pregnant $(\mathrm{p}=0.194)$.

Animals with a reproductive disease 0-26 DIM, including positive uterine culture, had a $31 \%$ conception rate to the first AI compared to $67 \%$ conception rate in healthy animals $(\mathrm{p}=$ 0.0430). Animals with an infectious, structural, or positive QScout Farm Lab diagnosis had a $54 \%$ conception rate (Figure 5). Cows without calving difficulty had a $42 \%$ conception rate, 
whereas cows needing assistance calving had a $19 \%$ conception rate $(\mathrm{p}=0.0223)$. Cows that did not have a positive uterine culture but had calving difficulty $(n=10)$, had a $20 \%$ conception rate $(\mathrm{p}=0.07)$, compared to cows with a positive uterine culture or calving and calving difficulty.

\section{Pregnancy status by health status grouping}

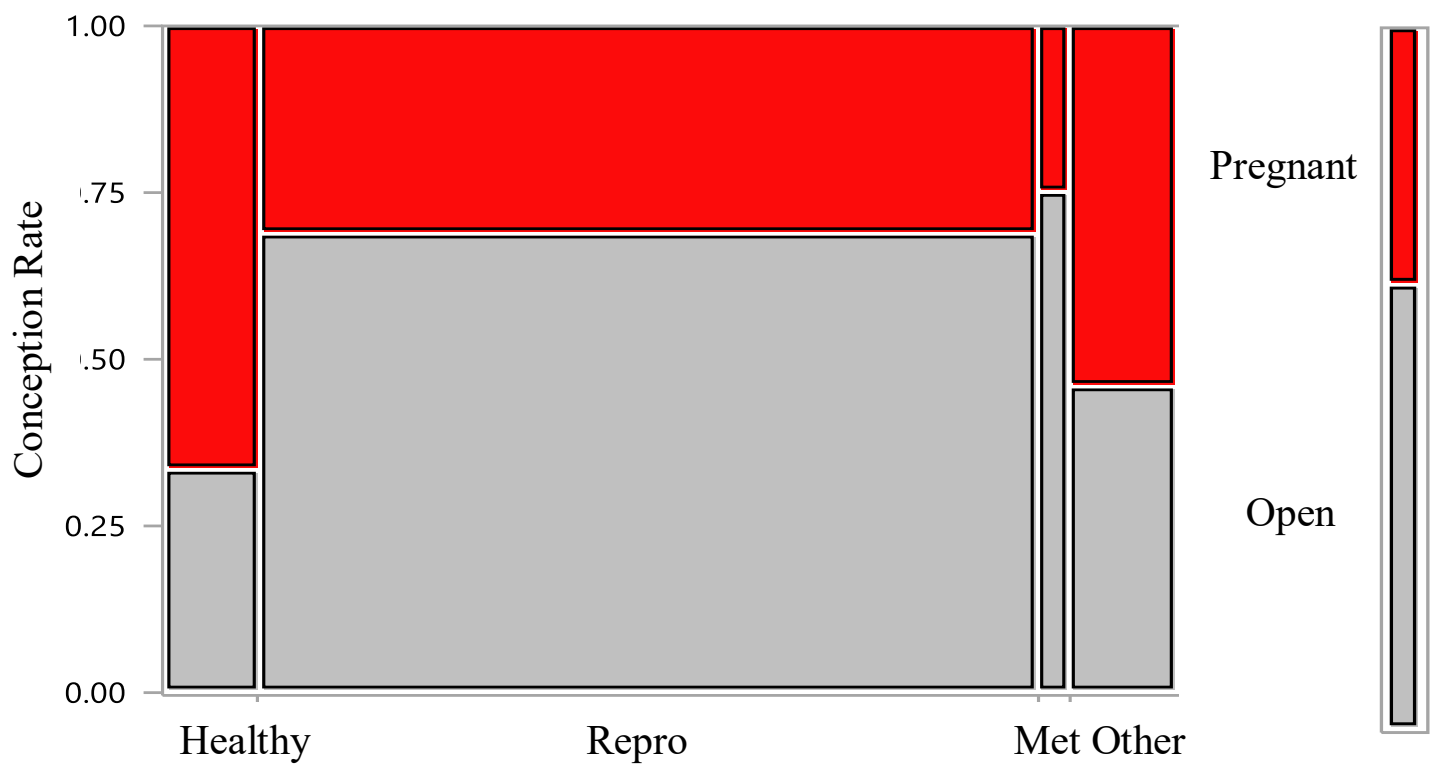

Figure 5: Pregnancy status by health status grouping 20-26 DIM $n=126$. Grouped by healthy $(n=12)$, reproductive disease and positive uterine culture $=$ Repro $(n=97)$, metabolic $=$ Met $(n$ $=4)$, other (infectious, structural, and positive QScout Farm Lab diagnosis; $n=13)(p=$ $0.0430)$.

\section{Milk Analysis}

Mastitis quarter infection rates did not differ between front and rear quarters and left to right. Quarter milk samples had higher cell counts ( $<$ 00.0001) in mastitis positive quarters. Counts for all cell types differed $(\mathrm{p}<0.0001)$ between positively and negatively diagnosed cows. Percent composition of monocytes were higher $(\mathrm{p}=0.032)$ in the front quarters regardless of mastitis status $(\mathrm{p}=0.027)$. No difference was found between front and rear quarters and side to 
side for other quarter leukocyte differentials and, therefore, pooled milk leukocyte counts were used in the remainder of the analyses.

Cell counts increased between 20-26 and 54-60 DIM as well as 20-26 and 90-96 DIM in SCC $(p=0.0330, p=0.0017)$, neutrophils $(p=0.0134, p=0.0007)$, and monocytes $(p=0.0431$, $\mathrm{p}=00.0001)$. Lymphocytes did not change over time $(\mathrm{p}=0.3514, \mathrm{p}=0.1777)$. Lactation significantly affected SCC $(p=0.0027)$, neutrophils $(p=0.0022)$, lymphocytes $(p=0.0187)$, and monocytes $(\mathrm{p}=0.0187)$. Days in milk affected SCC $(\mathrm{p}<.0002)$, neutrophils $(\mathrm{p}<0.0001)$, lymphocytes $(\mathrm{p}=0.0040)$, and monocytes $(\mathrm{p}<0.0001$; Figure 6$)$.

No effect of DIM $(\mathrm{p}=0.9577)$ or lactation $(\mathrm{p}=0.9601)$ were found on milk leukocytes. However, effect of QScout diagnosis positive was found $(\mathrm{p}<0.0001)$ and a time by diagnosis interaction $(\mathrm{p}=0.0038)$ with all leukocyte types (Figure 6). 


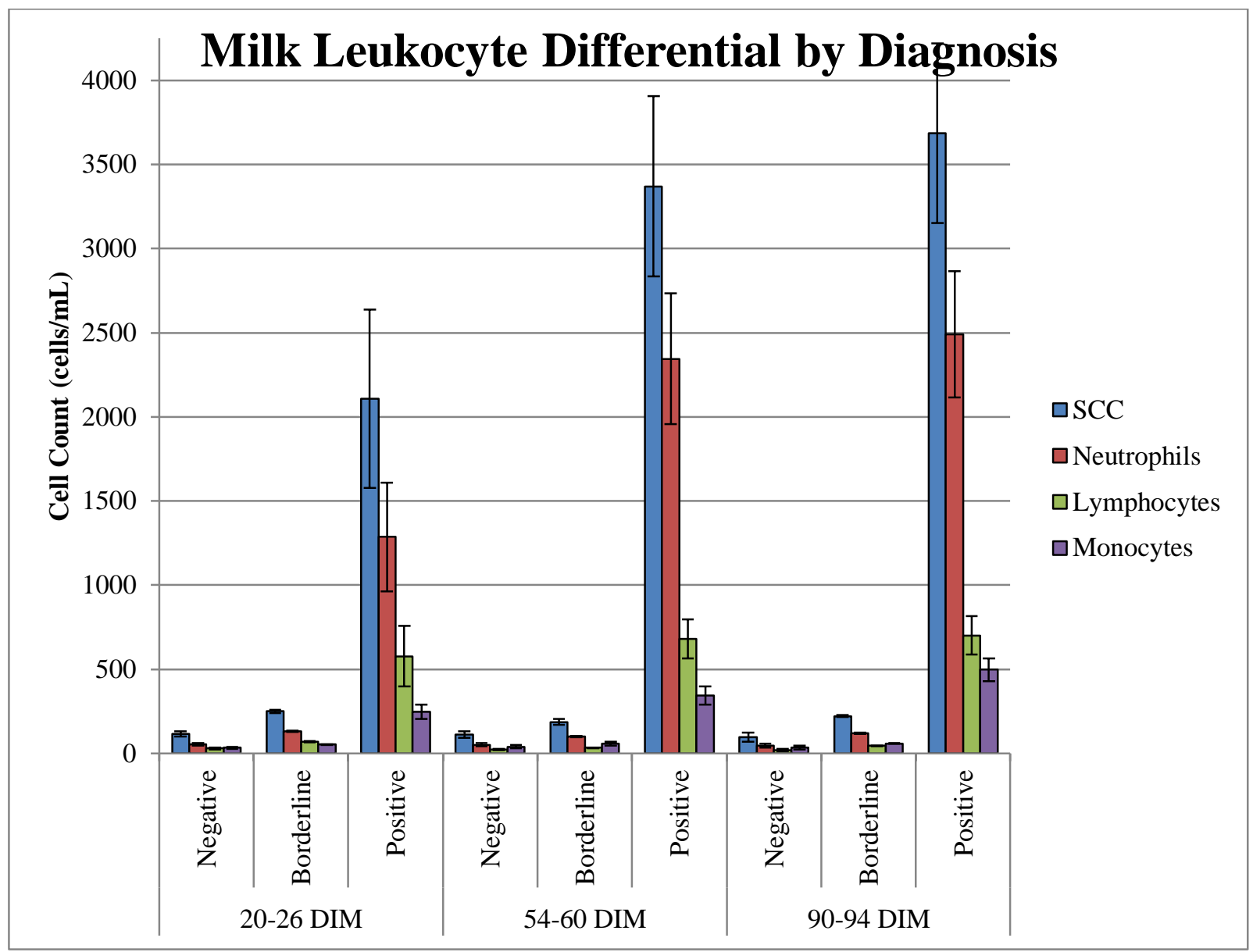

Figure 6: Total somatic cell count and leukocyte differential over time. $N=126$ No effect of time or lactation on cell type $(p=0.9577$ and $p=0.9601)$. Significant main effect of QScout Farm Lab udder diagnosis on all cell types $(p<0.0001)$ and interaction of time and QScout Farm Lab udder diagnosis on all cell types ( $p \leq 0.05)$ were found. No effect of lactation or QScout Farm Lab udder diagnosis was shown.

Days in milk (SCC p $=0.0046$, neutrophils $\mathrm{p}=0.0013$, lymphocytes $\mathrm{p}=0.188$, and monocytes $\mathrm{p}=0.0011)$, illness status $(\mathrm{p}<0.0001)$, and DIM by illness status $(\mathrm{p} \leq .0008)$ affected all pooled milk leukocyte counts when cows were categorized by illness status as healthy or having an illness. No lactation effect was shown $(\mathrm{p}=0.9792)$.

Pooled milk Hp concentration was not affected by lactation $(\mathrm{p}=0.9519)$, illness $(\mathrm{p}=$ 0.9264), or QScout Farm Lab udder diagnosis $(\mathrm{p}=0.4582)$. However, interactions between 
lactation and illness $(\mathrm{p}=0.0323)$ and lactation and QScout Farm Lab udder diagnosis $(\mathrm{p}=$ 0.0049) were significant (Figure 7). Pooled milk Hp concentration increased with increasing SCC $(p<0.0001)$ and milk neutrophils $(p<0.0001 ; n=63)$.

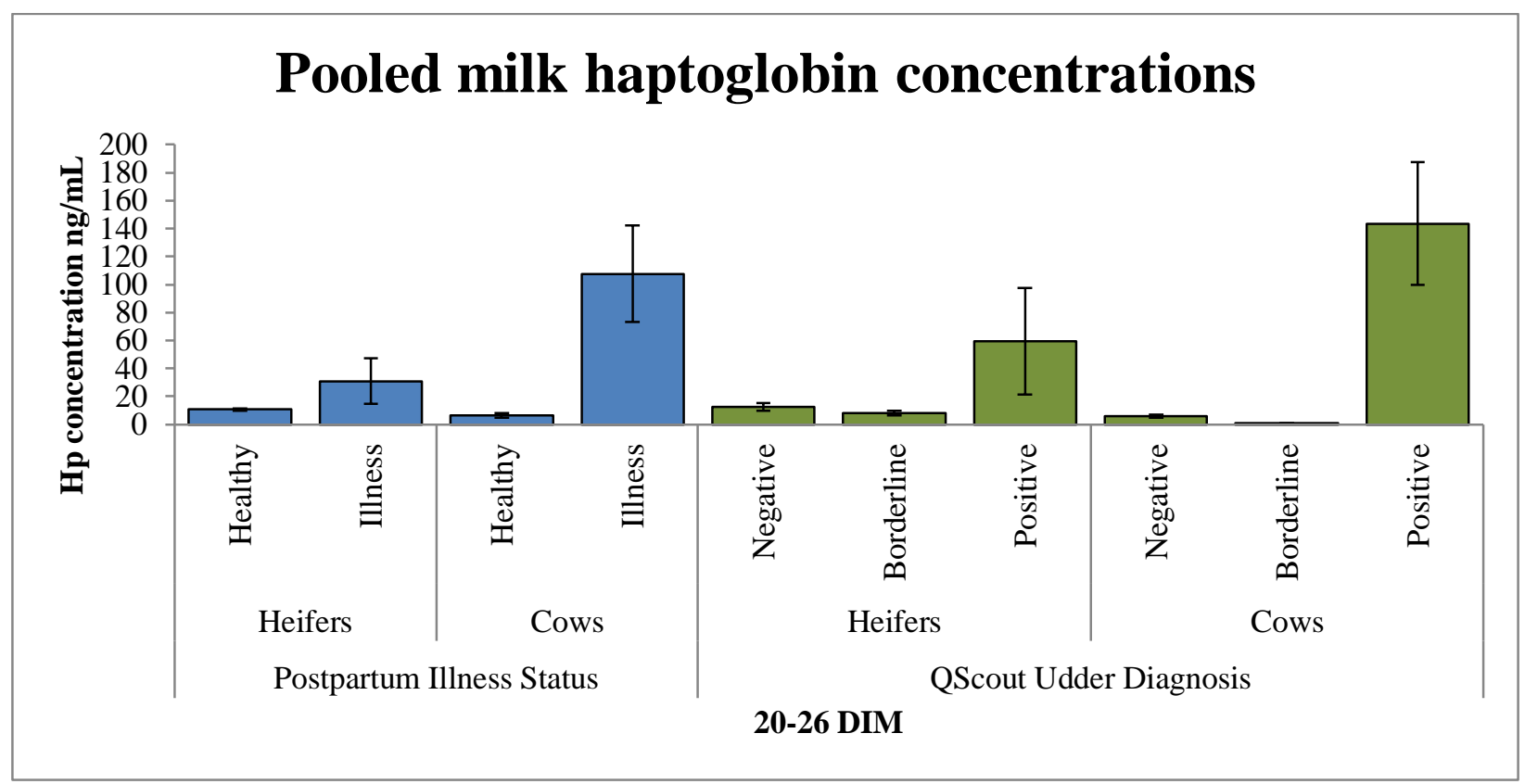

Figure 7: Pooled milk haptoglobin concentrations $N=63$. Lactation $(p=0.9510)$, illness $(p=$ $0.9264)$, lactation $*$ illness ( $p=0.0323)$, QScout Farm Lab udder diagnosis $(p=0.4582)$, and lactation*QScout Farm Lab udder diagnosis $(p=0.0049)$.

\section{Blood Leukocyte Analysis}

Main effects of lactation, DIM, QScout diagnosis, illness, and their interactions on total leukocytes in blood were examined. Days in milk affected concentrations of neutrophils, monocytes, eosinophils, and basophils $(\mathrm{p} \leq .01)$ when included with lactation, QScout udder diagnosis, and their interactions. No other effects of lactation or interactions were found (Figure 8). Days in milk affected TLC, neutrophils, monocytes, eosinophils, basophils ( $\leq \leq .01)$ 
when modeled with illness status, lactation and their interactions. Lactation was only significant with monocytes $(\mathrm{p}=0.02)$ and basophils $(\mathrm{p}=0.018)$ modeled with health status.

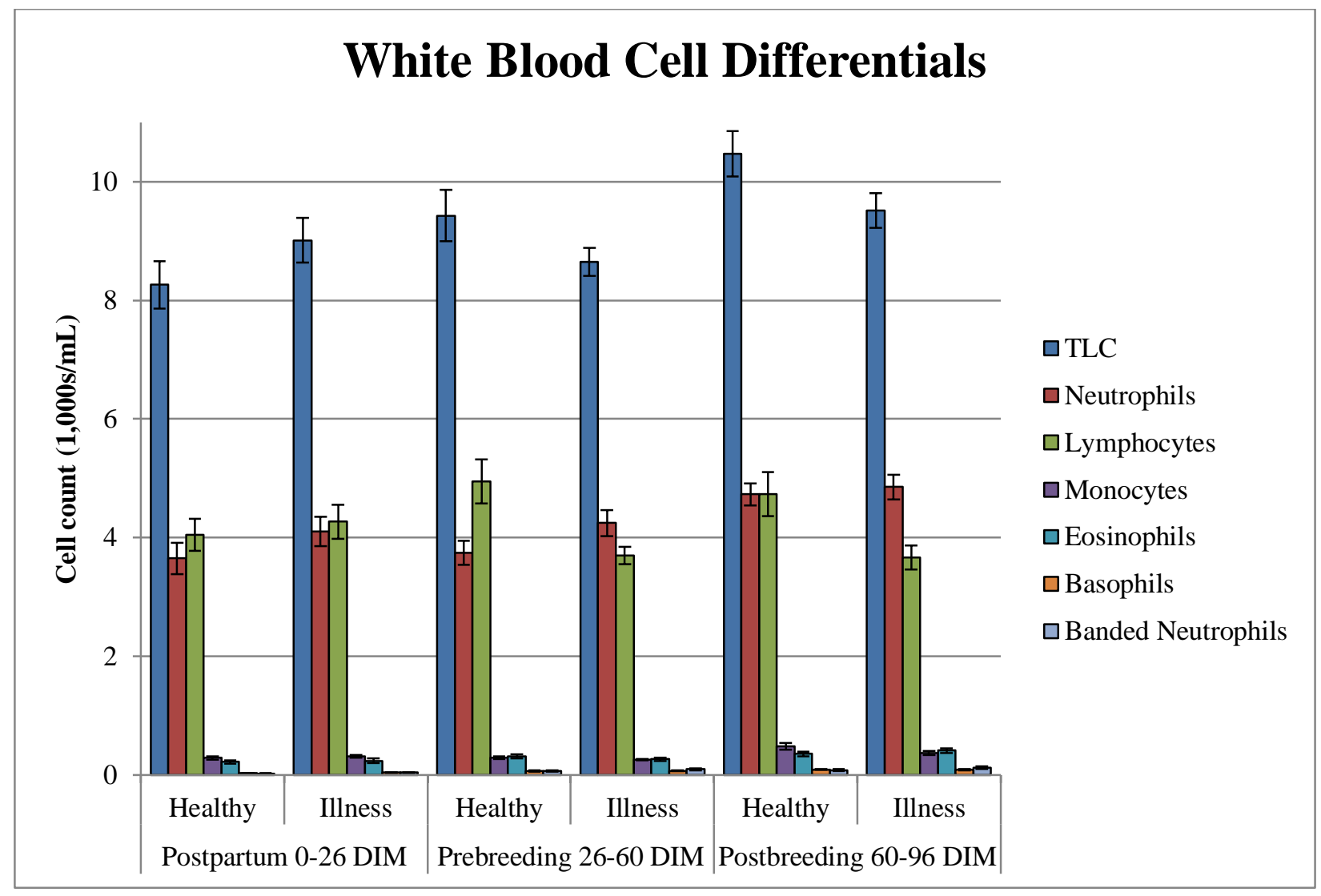

Figure 8: White blood cell differentials over time by illness status (QScout Farm Lab positive udder diagnosis and cows treated by the producer for illness) $N=126$. Cows were considered ill if they were treated in the period prior to sample collection or tested positive with the QScout Farm Lab on collection day. A main effect of time was found (neutrophils $p=0.013$, monocytes $p=0.0052$, eosinophils $p=0.0034$, basophils $p=0.0003$ ) with no overall lactation effect.

Blood leukocytes were correlated with milk leukocytes for all animals over all time points. All milk leukocytes were correlated with total SCC ( $\mathrm{p}<0.05)$; all leukocytes in circulation were correlated with WBC in circulation with no evident pattern $(\mathrm{p}<0.05 ; \mathrm{n}=375$; Table 4). Milk neutrophils were correlated with blood neutrophils $(\mathrm{p}=0.004)$, blood lymphocytes $(\mathrm{p}=0.0018)$, blood monocytes $(\mathrm{p}=0.011)$, and blood banded neutrophils $(\mathrm{p}<$ 
0.0001). Milk lymphocytes were correlated with blood neutrophils $(\mathrm{p}=0.001)$, blood lymphocytes $(\mathrm{p}=0.0008)$, blood monocytes $(\mathrm{p}=0.013)$, and blood banded neutrophils $(\mathrm{p}<$ 0.0001). Milk monocytes were correlated with blood lymphocytes $(\mathrm{p}=0.0068)$, blood eosinophils $(\mathrm{p}=0.009)$, and blood banded neutrophils $(\mathrm{p}<0.0001)$. 
Table 4: Correlations between blood and milk leukocytes all animals 20-90 DIM

\begin{tabular}{|c|c|c|c|c|c|c|c|c|c|c|c|}
\hline & U & $\begin{array}{l}\bar{\Xi} \\
\overline{0} \\
\Sigma\end{array}$ & 胥 & $\sum_{\Sigma}^{\stackrel{O}{0}}$ & $\sum_{3}^{0}$ & $\underset{\Xi}{\overrightarrow{0}}$ & 妾 & $\sum_{\infty}^{\stackrel{0}{0}}$ & $\begin{array}{c}\tilde{0} \\
\tilde{I} \\
\tilde{\varphi}\end{array}$ & $\begin{array}{l}0 \\
\tilde{E} \\
\tilde{D} \\
\infty\end{array}$ & 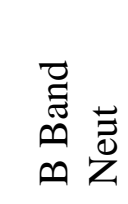 \\
\hline $\mathrm{SCC}$ & 1 & & & & & & & & & & \\
\hline M Neut & $0.993 *$ & 1 & & & & & & & & & \\
\hline M Lymph & $0.952 *$ & $0.924 *$ & 1 & & & & & & & & \\
\hline M Mono & $0.792 *$ & $0.751 *$ & $0.686^{*}$ & 1 & & & & & & & \\
\hline WBC & -0.029 & -0.025 & -0.025 & -0.052 & 1 & & & & & & \\
\hline B Neut & $0.152 *$ & $0.15 *$ & $0.174 *$ & 0.0662 & $0.573 *$ & 1 & & & & & \\
\hline B Lymph & -0.172 & $-0.165 *$ & $-0.177 *$ & $-0.143 *$ & $0.724 *$ & $-0.128 *$ & 1 & & & & \\
\hline B Mono & $-0.131 *$ & $-0.134 *$ & $-0.131 *$ & -0.065 & $0.247 *$ & $0.249 *$ & -0.015 & 1 & & & \\
\hline B Eos & 0.087 & 0.082 & 0.066 & 0.137 & $0.253 *$ & $0.123^{*}$ & 0.072 & 0.0636 & 1 & & \\
\hline B Baso & -0.008 & 0.005 & -0.0427 & -0.015 & $0.222 *$ & 0.123* & 0.08 & 0.216 & $0.283^{*}$ & 1 & \\
\hline $\begin{array}{l}\text { B Band } \\
\text { Neut }\end{array}$ & $0.331 *$ & $0.341 *$ & $0.275^{*}$ & $0.274 *$ & $0.213 *$ & 0.233* & 0.006 & -0.0008 & 0.1003 & 0.218* & 1 \\
\hline
\end{tabular}


Blood and milk leukocyte correlations were analyzed for cows treated by the producer (Table 5; $\mathrm{n}=5$ ) again, there was no clear pattern. Milk neutrophils were correlated with SCC (p $=0.0002)$ and milk lymphocytes $(\mathrm{p}=0.0002)$ with milk lymphocytes and SCC being correlated $(\mathrm{p}<0.0001)$. Blood eosinophils were correlated with SCC $(\mathrm{p}=0.031)$, milk neutrophils $(\mathrm{p}=$ 0.014), and milk lymphocytes ( $\mathrm{p}=0.013)$. Blood basophils were correlated with WBC in circulation $(\mathrm{p}=0.028)$. 
Table 5: Cows treated for mammary infection combined 0-96 DIM

\begin{tabular}{|c|c|c|c|c|c|c|c|c|c|c|c|}
\hline & $\underset{\mho}{U}$ & $\begin{array}{l}\vec{\Xi} \\
\stackrel{0}{Z} \\
\Sigma\end{array}$ & $\begin{array}{l}\text { 竞 } \\
\text { 方 } \\
\text { 主 }\end{array}$ & $\frac{\stackrel{O}{\Xi}}{\sum}$ & $\sum_{\substack{n \\
j}}^{n}$ & $\begin{array}{l}\overrightarrow{0} \\
\vec{D}_{\infty}\end{array}$ & 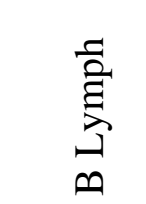 & $\sum_{n}^{\stackrel{o}{0}}$ & 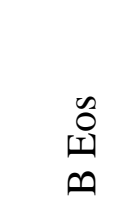 & 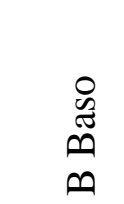 & \\
\hline SCC & 1 & & & & & & & & & & \\
\hline M Neut & $0.997 *$ & 1 & & & & & & & & & \\
\hline M Lymph & $0.996 *$ & 0.999* & 1 & & & & & & & & \\
\hline M Mono & 0.790 & 0.7413 & 0.7382 & 1 & & & & & & & \\
\hline WBC & -0.001 & -0.084 & -0.081 & 0.677 & 1 & & & & & & \\
\hline B Neut & 0.813 & 0.816 & 0.802 & 0.554 & -0.173 & 1 & & & & & \\
\hline B Lymph & -0.614 & -0.651 & -0.635 & -0.149 & 0.561 & -0.905 & 1 & & & & \\
\hline B Mono & -0.403 & -0.445 & -0.427 & 0.036 & 0.635 & -0.803 & 0.969 & 1 & & & \\
\hline B Eos & $-0.968 *$ & $-0.986 *$ & $-0.986 *$ & -0.522 & 0.242 & -0.797 & 0.6985 & 0.506 & 1 & & \\
\hline B Baso & 0.113 & 0.03 & 0.0275 & 0.773 & $0.972 *$ & 0.038 & 0.3615 & 0.4375 & 0.136 & 1 & \\
\hline $\begin{array}{l}\text { B Band } \\
\text { Neut }\end{array}$ & 0.597 & 0.5532 & 0.5365 & 0.803 & 0.388 & 0.808 & -0.538 & -0.455 & -0.444 & 0.589 & 1 \\
\hline
\end{tabular}

Correlations between blood and milk leukocytes in animals treated for mammary infections 20-90 DIM. Repeated measures as pairwise correlations between pooled milk and blood constituents shown in 5 animals. SCC =somatic cell count, Neut=neutrophils, Lymph =lymphocytes, Mono =monocytes, WBC =total blood leukocytes, B =blood, Eos = eosinophils, Baso = basophils, Band Neut =banded neutrophils. Benjimini-Hochberg critical value was used to adjust the alpha level due to multiple comparisons. Correlations shown with $p \leq 0.05$ indicated as *. 


\section{Plasma Haptoglobin Concentration}

Plasma Hp concentration was affected by DIM ( $p<0.0001)$, QScout Farm Lab udder diagnosis ( $p<0.0001)$, illness status ( $p<0.0001)$, and interactions of DIM by QScout Farm Lab udder diagnosis $(\mathrm{p}=0.0002)$ and DIM by illness status $(\mathrm{p}<0.0001)$. A three way interaction was also shown in DIM by lactation and illness status $(\mathrm{p}=0.0384$; Figure 9$)$. Analysis of plasma Hp concentration across lactation by illness status indicated differences at 54-60 DIM and 90-96 DIM ( $\mathrm{p}<0.0001)$ with no difference at 20-26 DIM ( $\mathrm{p}=0.2906)$. 


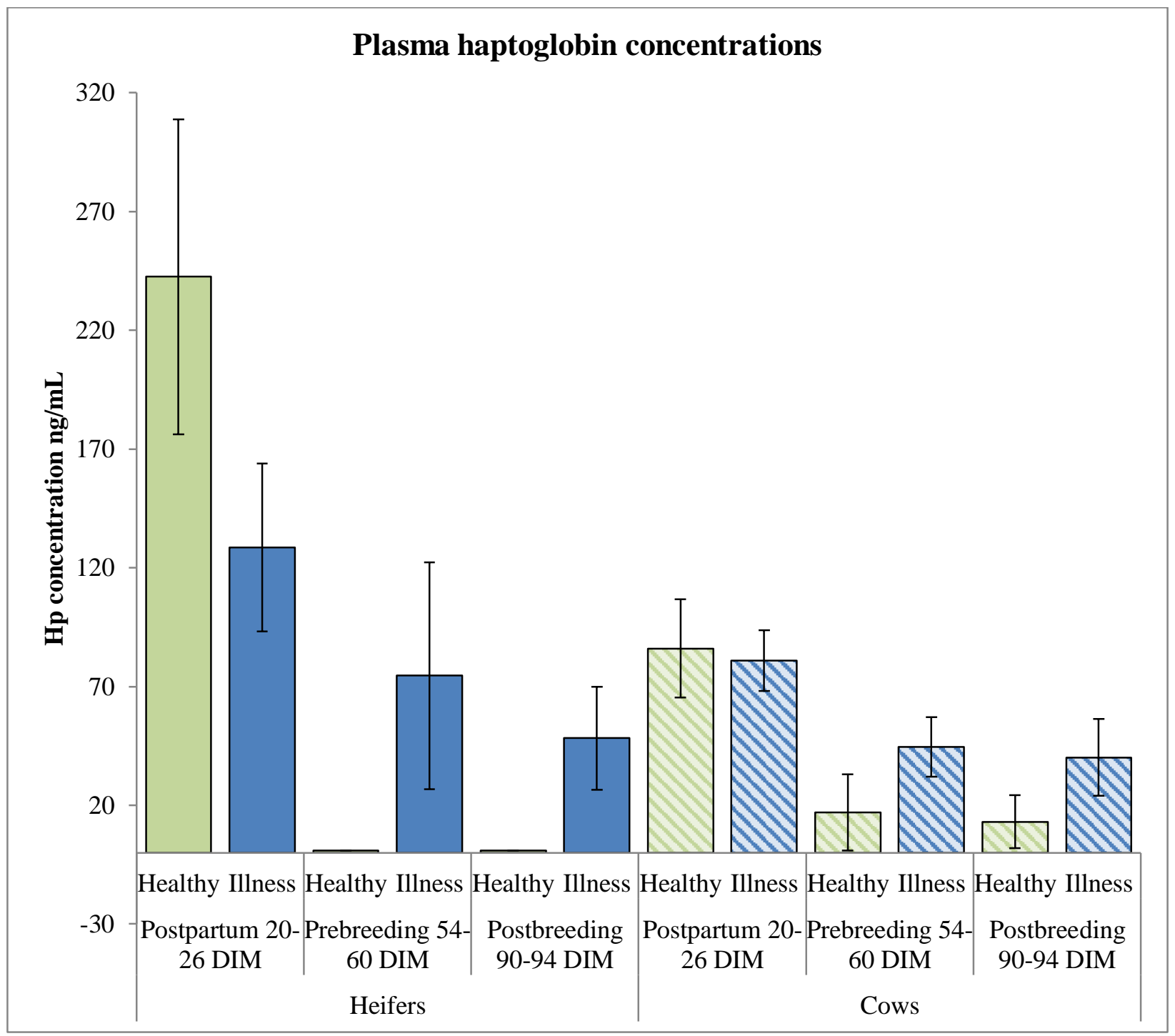

Figure 9: Plasma haptoglobin concentrations over time by illness status (QScout Farm Lab positive udder diagnosis and cows treated by the producer for illness) $N=124$. Main effects of time ( $p<0.0001)$, QScout Farm Lab udder diagnosis $(p<0.0001)$, and illness $(p<0.0001)$ with a time*lactation interaction $(p=0.0384)$. Postpartum 20-26 DIM $(p=0.2906)$, prebreeding 54$60 \operatorname{DIM}(p<0.0001)$, and postbreeding 90-96 DIM $(p<0.0001)$.

Plasma Hp concentration was plotted by parity over time against SCC. Type three fixed effects were evaluated for SCC with differences in lactation (heifers vs cows) $(p=0.0027)$, DIM $(\mathrm{p}=0.0002)$, and plasma Hp concentration $(\mathrm{p}=00.0001)$. No interaction of DIM by lactation was found ( $\mathrm{p}=0.646$; Figure 10). A difference between heifer and cow plasma Hp 
concentration was found at 20-26 DIM $(\mathrm{p}=0.043)$ but not at 54-60 $(\mathrm{p}=0.50)$ or 90-94 DIM $(\mathrm{p}=$ $0.50)$.

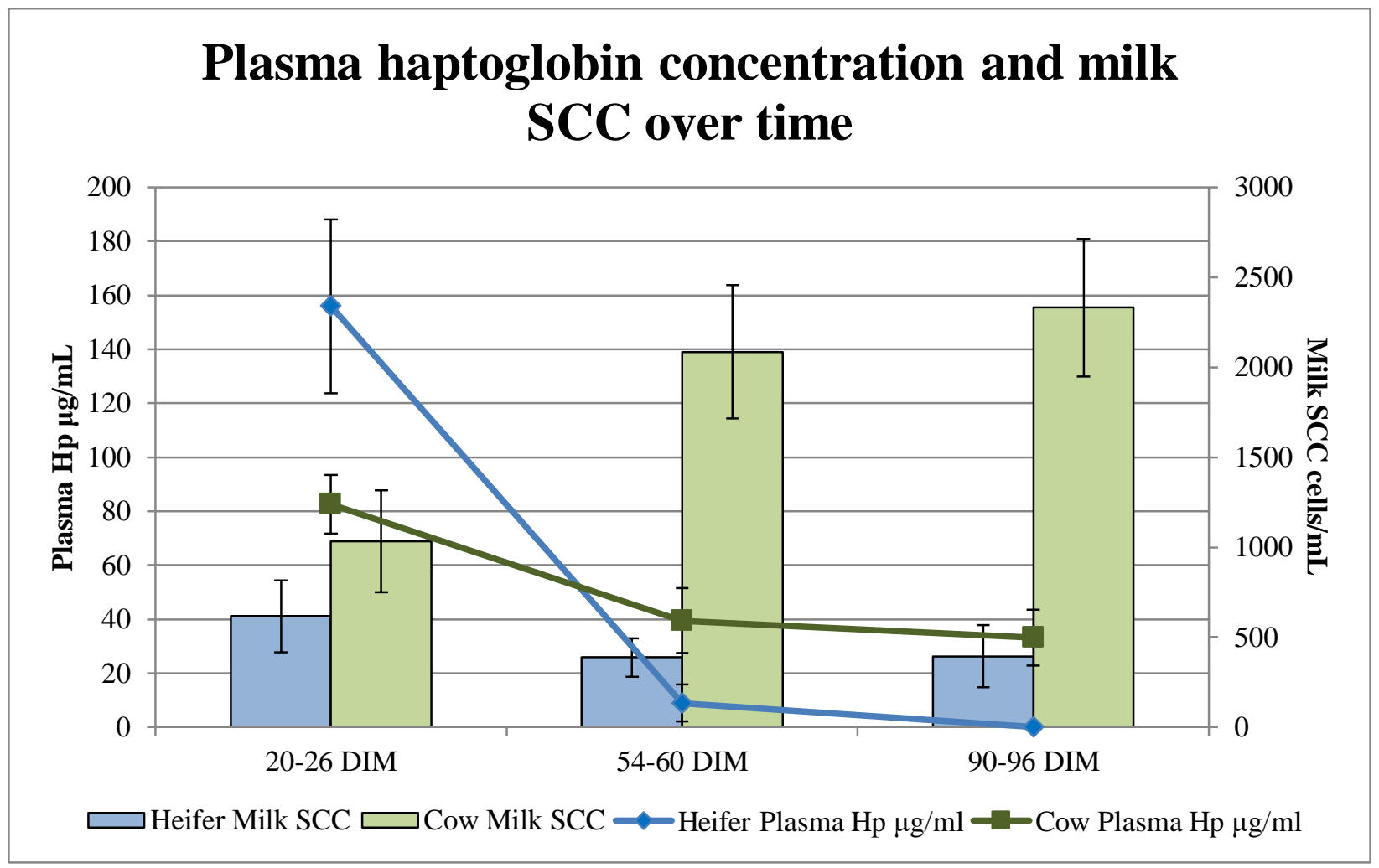

Figure 10: Plasma haptoglobin concentration and milk somatic cell count over time by parity. A difference in parity $(p=0.0027)$ and time $(p=0.0002)$ but no interaction $(p=0.65)$ for SCC was found. Plasma Hp was different between parities at 20-26 DIM $(p=0.043)$ but not at other times $(p=0.50)$.

\section{Pregnant vs. Open Cows}

Multivariate correlations were examined at 20-26 DIM with pregnancy status at 90-94 DIM showing no discernable pattern. In pregnant cows WBC were positively correlated with circulating lymphocytes $(\mathrm{p}<0.0001)$, circulating neutrophils $(\mathrm{p}=0.0027)$, and negatively with milk yield $(\mathrm{p}=0.041)$. In addition to neutrophils, milk yield in pregnant cows was also negatively correlated with plasma Hp concentration $(\mathrm{p}=0.0128)$, neutrophils $(\mathrm{p}=0.0288)$, and banded neutrophils $(\mathrm{p}=0.0212)$. Neutrophils in pregnant cows were correlated with banded 
neutrophils $(\mathrm{p}=0.0238)$, monocytes $(\mathrm{p}=0.0086)$, and plasma Hp concentration $(\mathrm{p}=0.0004)$.

Nonsignificant correlations existed between milk Hp concentration and plasma Hp concentration $(\mathrm{p}=0.09)$, milk Hp concentration and circulating banded neutrophils $(\mathrm{p}=0.50)$, basophils and lymphocytes $(\mathrm{p}=0.933)$ and monocytes $(\mathrm{p}=0.352)$. Milk Hp concentration was correlated with plasma Hp concentration $(\mathrm{p}=0.051)$ and banded neutrophils $(\mathrm{p}=0.02)$ were correlated in open cows. In open cows WBC were correlated with lymphocytes $(\mathrm{p}<0.0001)$, neutrophils $(\mathrm{p}<$ 0.0001) and monocytes $(\mathrm{p}=0.089)$. Basophils were correlated with lymphocytes $(\mathrm{p}=0.0375)$ and monocytes $(\mathrm{p}=0.0214$; Table 6$)$.

Table 6: Correlations at 20-26 DIM by pregnancy diagnosis

\begin{tabular}{|c|c|c|c|c|c|c|c|c|c|}
\hline & 올 & $\underline{\underline{z}}$ & 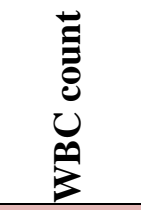 & 㿣 & 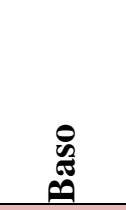 & 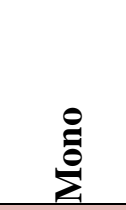 & $\begin{array}{l}\bar{\Xi} \\
\text { Zे }\end{array}$ & 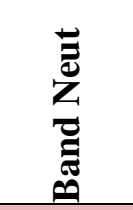 & $\sum$ \\
\hline Milk Hp & & $0.326 \mp$ & 0.036 & 0.003 & -0.293 & -0.175 & 0.045 & $0.474 *$ & -0.194 \\
\hline PI Hp & 0.324 & & -0.052 & 0.17 & 0.005 & 0.145 & -0.092 & 0.025 & -0.132 \\
\hline $\begin{array}{l}\text { WBC } \\
\text { count }\end{array}$ & -0.092 & 0.229 & & $0.601 *$ & 0.206 & $0.213 T$ & $0.855 *$ & 0.09 & -0.007 \\
\hline Lymph & -0.306 & -0.09 & $0.717 *$ & & $0.258 *$ & 0.078 & 0.173 & -0.077 & 0.078 \\
\hline Baso & 0.082 & 0.009 & -0.062 & -0.013 & & $0.285^{*}$ & 0.078 & -0.059 & 0.219 \\
\hline Mono & 0.037 & 0.297 & 0.213 & 0.023 & 0.149 & & 0.14 & -0.136 & -0.101 \\
\hline Neut & 0.233 & 0.528* & $0.457 *$ & -0.162 & -0.112 & $0.405^{*}$ & & 0.133 & 0.039 \\
\hline Band Neut & 0.145 & 0.09 & 0.018 & -0.232 & -0.072 & 0.263 & $0.352 *$ & & -0.18 \\
\hline MY & 0.071 & $-0.364 *$ & $-0.321 *$ & -0.125 & 0.109 & -0.002 & $-0.341 *$ & $-0.358^{*}$ & \\
\hline
\end{tabular}

Multivariate correlations blood, milk yield, and haptoglobin values at 20-26 DIM based on 9096 DIM pregnancy status of open (red cells) and pregnant (blue cells) animals. Spearmen $\rho$ values shown with $p \leq 0.05$ indicated with $*$ and trends of $p \leq 0.09$ indicated with T. Milk Hp (pooled milk haptoglobin concentration), Pl Hp (plasma haptoglobin concentration), WBC count (total leukocyte count in blood), lymph (blood lymphocyte count), baso (blood basophil count), mono (blood monocyte count), neut (blood neutrophil count), band neut (blood banded neutrophil count), MY (milk yield). 


\section{Correlations by Pregnancy Diagnosis}

Milk yield alone did not affect conception rate $(\mathrm{p}=0.8140)$. Mean plasma $\mathrm{Hp}$

concentrations and mean milk yield were examined with cows producing higher than the average milk yield by time point (low milk $=<41.95 \mathrm{~kg}$ and high milk $=>41.95 \mathrm{~kg}$ ) and above or below average $\log 10 \mathrm{Hp}($ low $=<1.5$, high $=>1.5$ at $\mathrm{T} 1$; low $=<0$, high $=>33 \mathrm{~T} 2$ and T3). Haptoglobin concentration and milk categories were analyzed by pregnancy status over time. At 20-26 DIM no difference was found in conception rates between groups (Figure 11). Conception rate at 5460 DIM showed no difference between groups (Figure 12).

\section{Contingency analysis of haptoglobin/milk category at 20-26 DIM by pregnancy status}

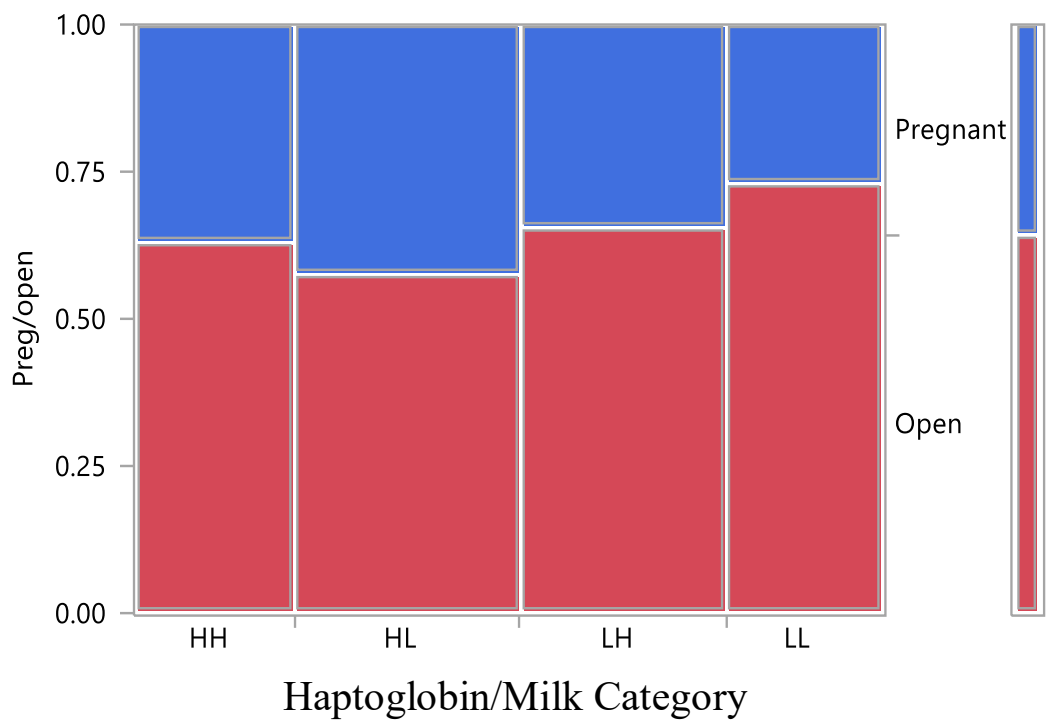

Figure 11: Contingency analysis of haptoglobin/milk production category at 20-26 DIM by pregnancy at 90-96 DIM $(n=126)$. Haptoglobin is based on average log10 concentration by time point (1.5). Milk production is based on average production low milk $=<41.95 \mathrm{~kg}$ and high milk $=>41.95 \mathrm{~kg}$. Pregnancy rates: $\mathrm{HH}=37.04 \%(n=27), \mathrm{HL}=42.11 \%(n=39), \mathrm{LH}=$ $34.29 \%(n=35)$, and $L L=30.77 \%(n=25 ; p=0.6587)$. 


\section{Contingency analysis of haptoglobin/milk category at 54-60 DIM by pregnancy status}

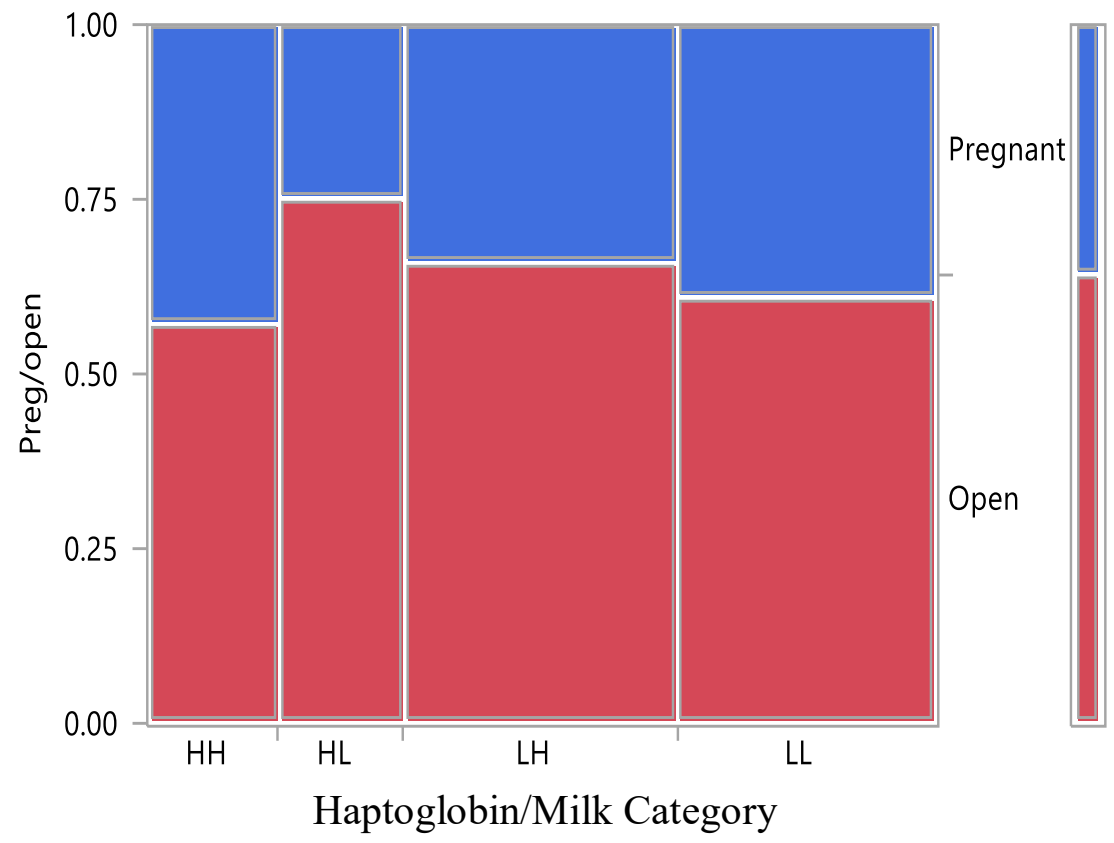

Figure 12: Contingency analysis of haptoglobin/milk production category at 54-60 DIM by pregnancy at 90-96 DIM $(n=126)$. Haptoglobin is based on average log 10 concentration by time point (0). Milk production is based on average production low milk $=<41.95 \mathrm{~kg}$ and high milk $=>41.95 \mathrm{~kg}$. Pregnancy rates: $\mathrm{HH}=42.86 \%(n=20), H L=25 \%(n=19), L H=34.09 \%$ $(n=44)$, and $L L=39.02 \%(n=43 ; p=0.6341)$.

Analysis of Hp/milk categories by illness status showed that at 20-26 DIM there was a tendency for $\mathrm{Hp}$ concentration and milk production to be related to illness status ( $\mathrm{p}=0.0615$; Figure 13). At 54-60 DIM high Hp was related to illness status regardless of milk production ( $\mathrm{p}$ $<0.0001$; Figure 14). 


\section{Contingency analysis of haptoglobin/milk category at 20-26 DIM by illness status}

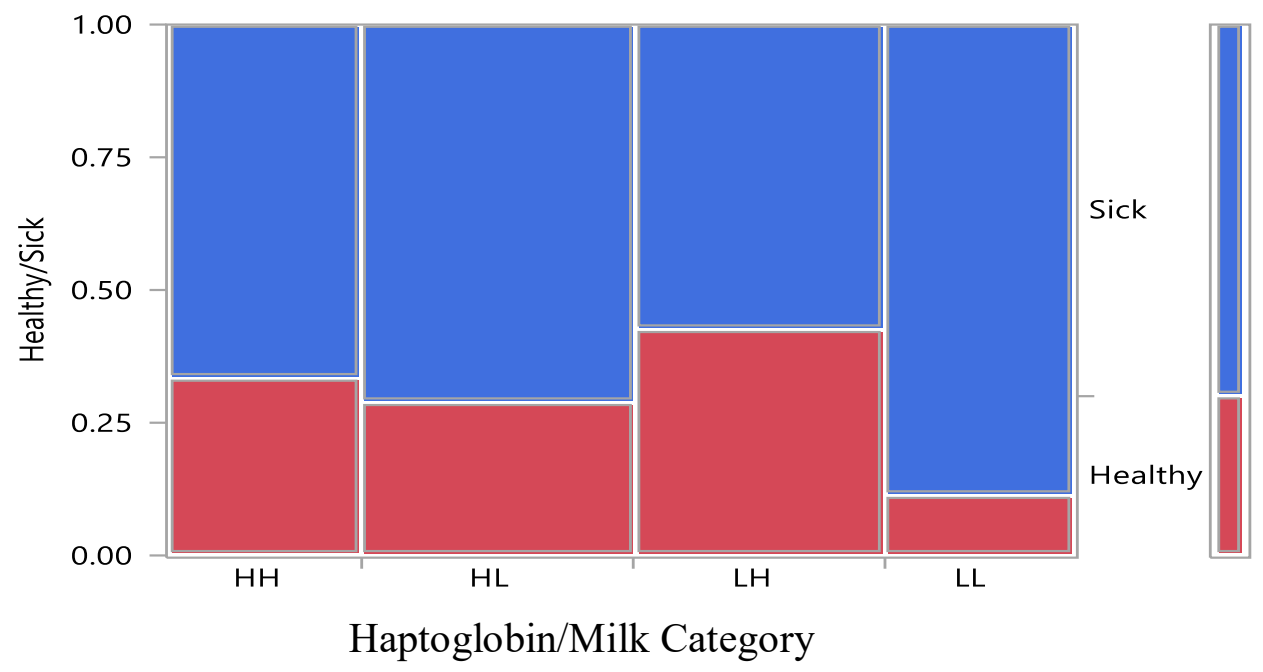

Figure 13: Contingency analysis of haptoglobin/milk production category at 20-26 DIM by illness status 0-26 DIM $(n=126)$. Haptoglobin is based on average log 10 concentration by time point $(1.5 \mathrm{ng} / \mathrm{mL})$. Milk production is based on average production low milk $=<41.95 \mathrm{~kg}$ and high milk $=>41.95 \mathrm{~kg}$. Illness rates: $\mathrm{HH}=66.67 \%(n=27), H L=69 \%(n=39), \mathrm{LH}=57.14 \%$ $(n=35)$, and $L L=88 \%(n=25 ; p=0.0615)$.

\section{Contingency analysis of haptoglobin/milk category at 54-60 DIM by illness status}

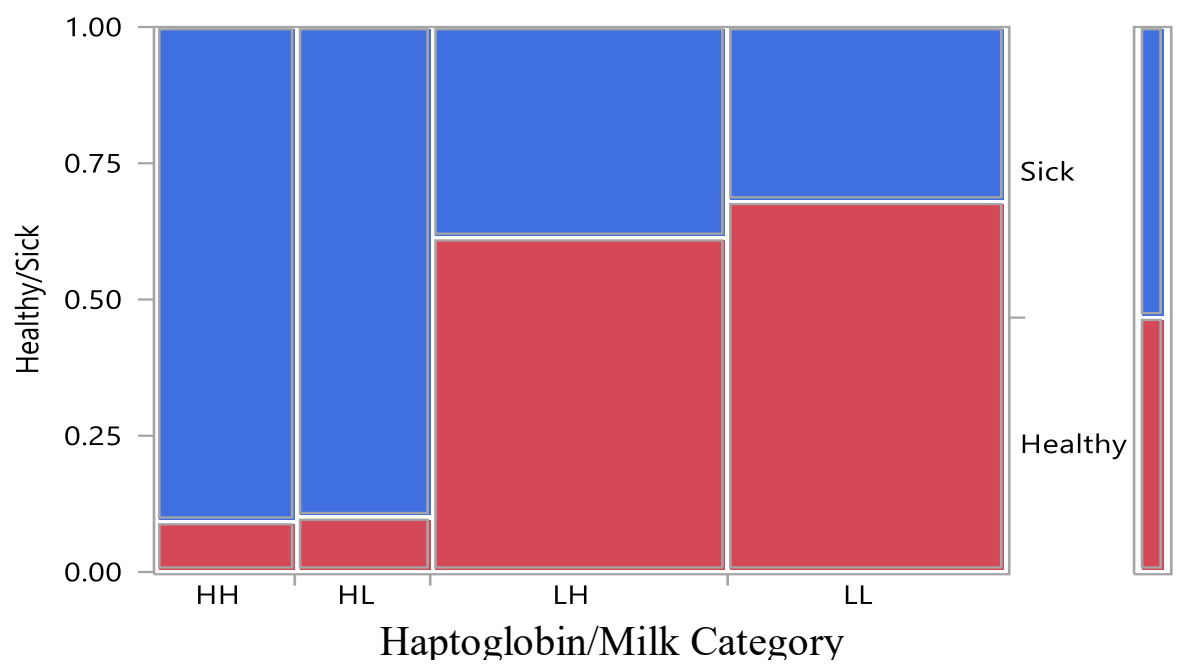

Figure 14: Contingency analysis of haptoglobin/milk production category at 54-60 DIM by illness status 26-60 DIM $(n=126)$. Haptoglobin is based on average log10 concentration by time point $(0 \mathrm{ng} / \mathrm{mL})$. Milk production is based on average production low milk $=<41.95 \mathrm{~kg}$ and high milk $=>41.95 \mathrm{~kg}$. Illness rate: $\mathrm{HH}=95 \%(n=21), H L=89.47 \%(n=19), L H=36.36 \%$ $(n=44)$, and $L L=34.88 \%(n=43 ; p<0.0001)$. 


\section{Uterine Cytology Analysis}

Uterine leukocyte count was affected by udder diagnosis $(\mathrm{p}=0.024)$. The interaction of udder diagnosis and lactation $(\mathrm{p}=0.018)$ is due to the interaction of lactation and udder diagnosis borderline $(\mathrm{p}=0.00067)$ with no heifers in this group. Cell types did not differ between illness statuses at 20-26 DIM; total leukocytes, monocytes/macrophages, lymphocytes, and neutrophils (Figure 15). Total leukocyte count did not differ between treatment $(\mathrm{p}=0.1609)$ or reproductive disease $(\mathrm{p}=0.5378 ; \mathrm{n}=85)$.

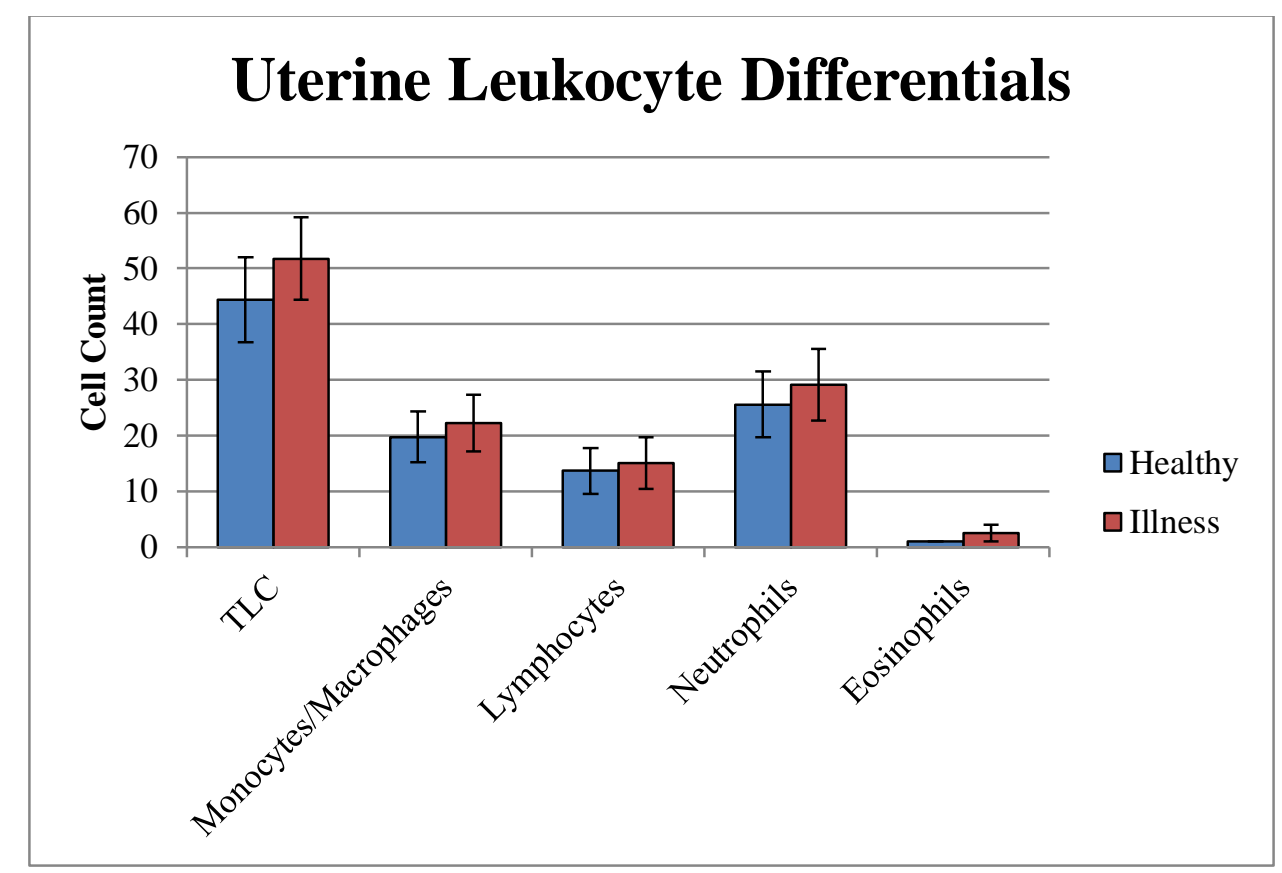

Figure 15: Uterine cytology white blood cell differentials. Cell counts from uterine cytology differentials performed 20-26 DIM by illness status, regardless of lactation.

\section{Uterine Culture Analysis}

Of the 126 animals $34 \%$ had negative uterine cultures $(n=43)$ and $42 \%$ were positively cultured for a single bacterial species Bacillus $(\mathrm{n}=53)$. Five additional animals cultured positive for Bacillus in addition to a second or third bacterial species. The remaining animals presented 
with positive cultures of one or multiple bacterial species (Figure 16). Odds ratio showed if an animal had a negative uterine culture they were 1.9 times more likely to become pregnant to the first service having a 48.3\% conception rate $(\mathrm{p}=0.04$; Figure 17$)$.

\section{Frequency of Bacterial Species}

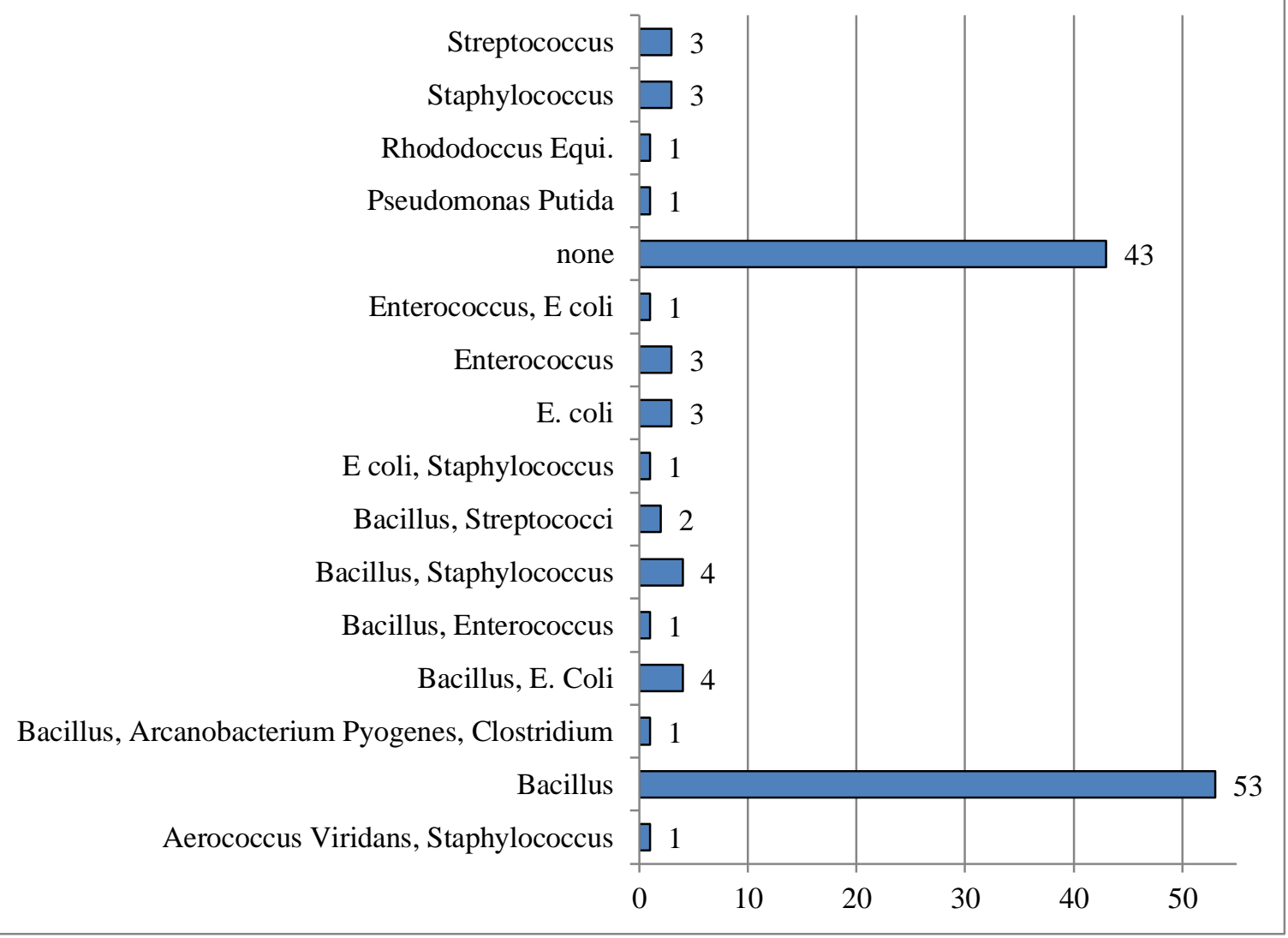

Figure 16: Frequency of bacterial species in uterine culture $n=126$. 


\section{Uterine culture by pregnancy status}

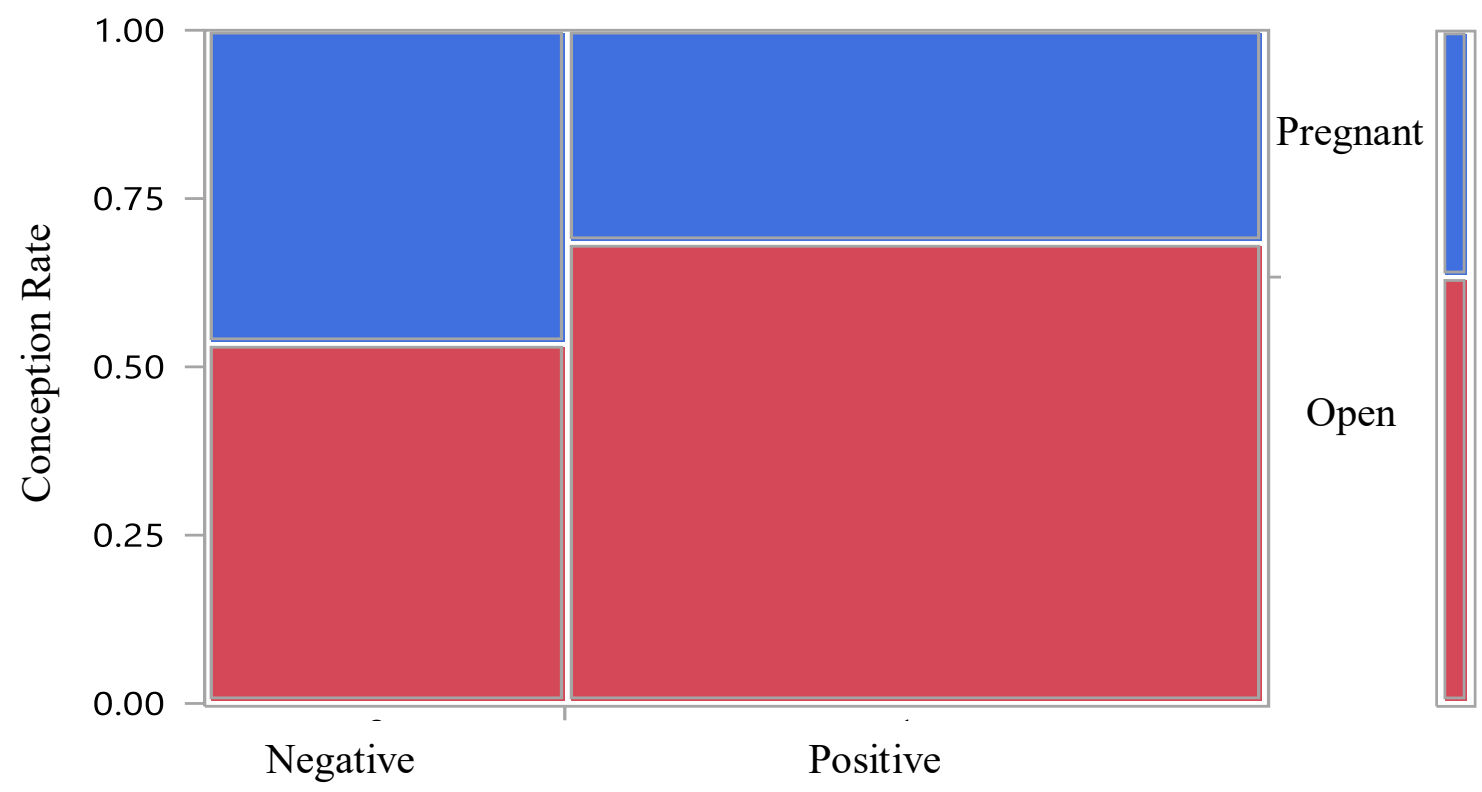

Figure 17: Contingency table of negative or positive uterine culture at 20-26 DIM by pregnancy status at 54-90 DIM $n=126(p=0.055)$.

\section{Health and Pregnancy Status}

Cows treated for a postpartum illness had lower conception to the first AI than those animals not treated for a clinical illness ( $\mathrm{p}=0.00123$; Figure 18). Regardless of lactation, healthy cows had 5.60 times more likely to become pregnant to first AI than those with both an illness and positive uterine culture $(\mathrm{p}=0.030)$, and 3.99 times the odds of pregnancy to the first AI than those with one insult (illness or positive uterine culture; $p=0.031$ ). Cows with one insult (illness or uterine culture) were 1.89 times more likely to become pregnant first AI compared to cows with an illness and positive uterine culture $(\mathrm{p}=0.030$; Table 7$)$. Calving difficulty affected conception to the first AI $(\mathrm{p}=0.0223)$ but was not related to total uterine leukocytes $(\mathrm{p}=0.960)$ or uterine culture (positive, negative; $p=0.8067$ ). 


\section{Conception by postpartum treatment}

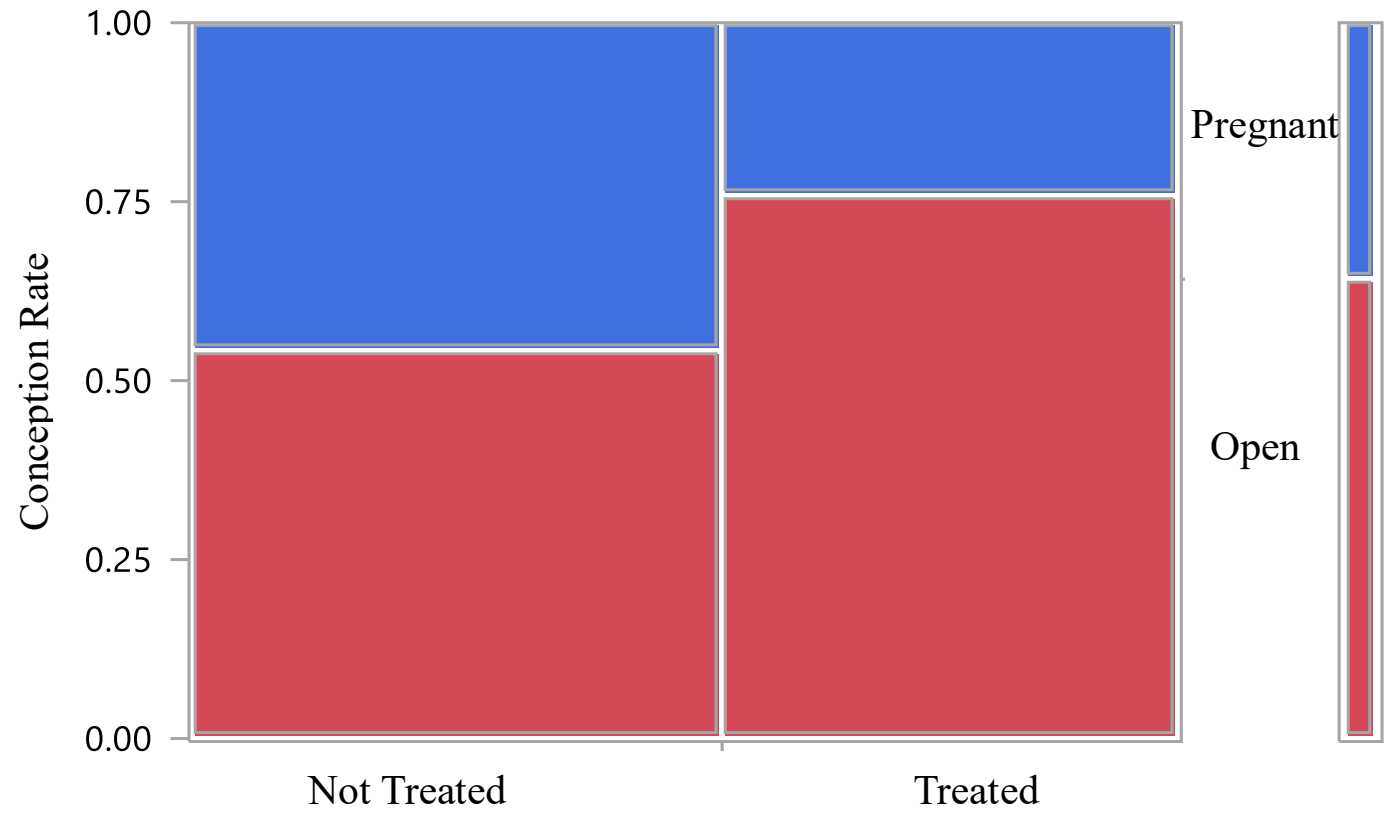

Figure 18: Contingency analysis of pregnancy by postpartum treatment 0-26 DIM (not treated/healthy, treated/ill) $n=126$ with open cows $(n=80)$ and pregnant cows $(n=46 ; p=$ $0.00123)$. 
Table 7: Illness, uterine, and mastitis status 20-26 DIM

\begin{tabular}{|c|c|c|}
\hline & Illness Status 20-26 DIM & $\mathrm{N}$ \\
\hline Healthy & & 12 \\
\hline & Metabolic & 2 \\
\hline & Reproductive & 8 \\
\hline Illne & Structural & 2 \\
\hline mimess & Infectious & 1 \\
\hline & Metabolic and Reproductive & 1 \\
\hline & Reproductive and Mammary & 1 \\
\hline Positive uterir & culture & 27 \\
\hline & Metabolic & 2 \\
\hline & Reproductive & 17 \\
\hline & Structural & 1 \\
\hline & Reproductive and Structural & 1 \\
\hline $\begin{array}{l}\text { Positive } \\
\text { Uterine }\end{array}$ & QScout Positive & 20 \\
\hline Culture and & Reproductive and QScout positive & 11 \\
\hline & Structural and QScout positive & 1 \\
\hline & Infectious and QScout positive & 1 \\
\hline & $\begin{array}{l}\text { Reproductive, structural, and QScout } \\
\text { positive }\end{array}$ & 2 \\
\hline QScout Positi & & 10 \\
\hline QScout & Metabolic & 2 \\
\hline Positive and & Structural & 4 \\
\hline
\end{tabular}

Illness, uterine, and mastitis status based on QScout Farm Lab diagnosis 20-26 DIM. Count of animals shown with single or multiple insults determined by an experienced veterinarian and culture.

\section{Predictive Models}

Linear regression analysis was performed on all cell types between tissues. Total leukocytes, lymphocytes, and monocytes in milk and circulation at all time points indicated a negative regression from circulation to milk with significance found for lymphocytes of pregnant cows $(\mathrm{p} \leq 0.05)$. Neutrophils showed no significance with negative regression from circulation 
to milk and milk to the uterus. Haptoglobin concentrations in circulation and milk concurrently increased regardless of pregnancy status with a significant rise in open cows ( $\leq \leq 0.05$; Table 8).

Table 8: Linear regression of cell types by tissue and pregnancy

Circulation by Milk

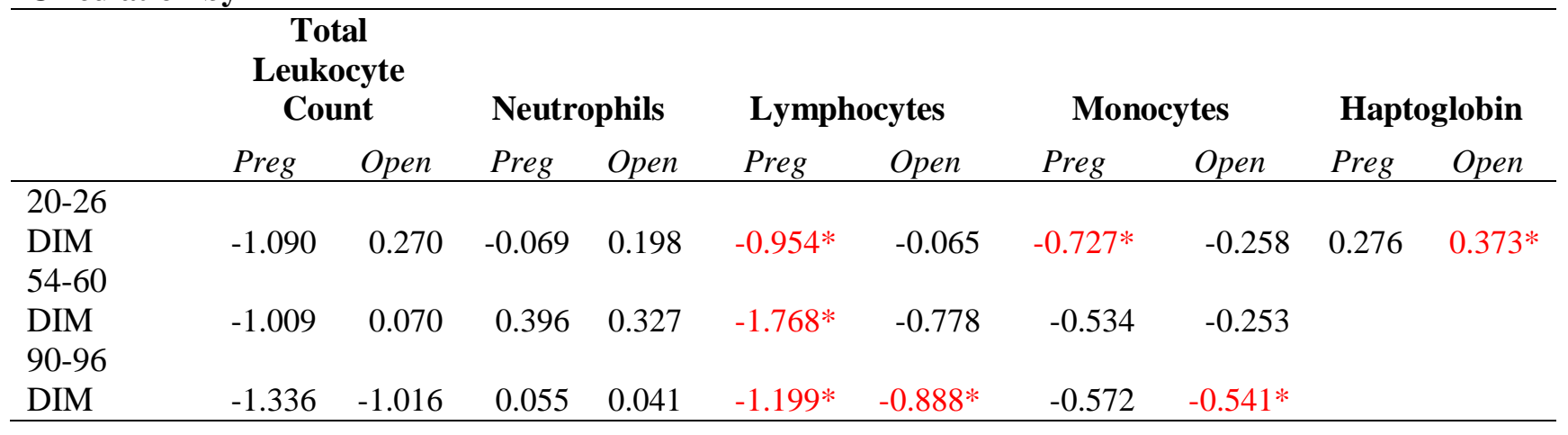

20-26 DIM

\begin{tabular}{|c|c|c|c|c|c|c|c|c|c|c|}
\hline & \multicolumn{2}{|c|}{$\begin{array}{c}\text { Total } \\
\text { Leukocyte } \\
\text { Count }\end{array}$} & \multicolumn{2}{|c|}{ Neutrophils } & \multicolumn{2}{|c|}{ Lymphocytes } & \multicolumn{2}{|c|}{ Monocytes } & \multicolumn{2}{|c|}{ Haptoglobin } \\
\hline & Preg & Open & Preg & Open & Preg & Open & Preg & Open & Preg & Open \\
\hline $\begin{array}{l}\text { Circulation } \\
\text { by Milk }\end{array}$ & -1.090 & 0.270 & -0.069 & 0.198 & $-0.954 *$ & -0.065 & $-0.727 *$ & -0.258 & 0.276 & $0.373 *$ \\
\hline $\begin{array}{l}\text { Circulation } \\
\text { by Uterus } \\
\text { Milk by }\end{array}$ & 66.7 & 42.63 & 0.168 & 0.271 & 0.546 & -0.178 & 0.402 & $1.087 \Phi$ & & \\
\hline Uterus & -18.54 & -8.289 & -0.222 & 0.020 & -0.104 & 0.051 & -0.407 & -0.111 & & \\
\hline
\end{tabular}

Linear regression of cell types by tissue and pregnancy. Slopes shown with $p \leq 0.05$ indicated as * and trends of $p \leq 0.09$ indicated with T, Preg= pregnant.

\section{Logistic Regression by Pregnancy}

Pregnancy was set as the outcome with variables taken out systematically based on significance level. Partial model results were combined to a main model with the variables illness status, uterine culture, plasma Hp concentration, QScout Farm Lab udder diagnosis, blood basophils, milk neutrophils and lymphocytes, and calving difficulty. The most predictive 
variable is shown as illness status $(\mathrm{p}=0.0408)$ when used in the model alone. The combination of illness status $(\mathrm{p}=0.0333)$ and uterine culture $(\mathrm{p}=0.0764)$ was the second most predictive model (Table 9).

Table 9: Predictive equations generated by logistic procedure: Partial models

\begin{tabular}{lr} 
Pregnancy Status $=$ Milk Neuts + Lymphs + QScout Udder \\
Diagnosis + Lact + MY + Hp/MY Cat + SCC + Monos + \\
Culture + Milk Hp & Pr > Chi Sq \\
Milk Partial Model & $0.0259^{*}$ \\
\hline \hline Neutrophils & $0.0357^{*}$ \\
+ Lymphocytes & 0.199 \\
+ Udder Diagnosis & \\
& \\
\hline Pregnancy Status = Plasma Hp + Basos + TLC + Neuts + \\
Lymphs + Band Neuts + Monos + Eos \\
Circulation Partial Model & Pr > Chi Sq \\
\hline \hline Plasma Hp & $0.0854 T^{2}$ \\
+ Basophils & $0.0738 T$
\end{tabular}

Pregnancy Status $=$ Uterine TLC + Monos + Lymphs + Neuts + Culture

Uterine Partial Model

$\mathrm{Pr}>\mathrm{Chi} \mathrm{Sq}$

Uterine Culture 0.2476

Pregnancy Status $=$ Calving difficulty + Illness Stat + Trt + Repo + Met + Struc

Health Partial Models

$\mathrm{Pr}>\mathrm{Chi} \mathrm{Sq}$

Calving difficulty $0.0266^{*}$

Illness Status $0.0408^{*}$


Predictive equations generated by logistic procedure continued: Overall Model

\begin{tabular}{|c|c|}
\hline \multicolumn{2}{|c|}{$\begin{array}{l}\text { Pregnancy Status = Illness stat + Ut Culture + Plasma Hp + } \\
\text { QScout Udder Diagnosis + Blood Basos + Milk Neuts + } \\
\text { Milk Lymphs + Calving Diff }\end{array}$} \\
\hline Overall Models & $\operatorname{Pr}>$ Chi Sq \\
\hline Illness status & 0.1119 \\
\hline+ Uterine culture & $0.0022 *$ \\
\hline + Plasma Hp & 0.216 \\
\hline + Udder Diagnosis & $0.0307 *$ \\
\hline Illness status & $0.0378 *$ \\
\hline+ Uterine culture & $0.0704 \uparrow$ \\
\hline + Plasma Hp & 0.2689 \\
\hline Illness status & $0.0333^{*}$ \\
\hline+ Uterine culture & $0.0764 \mathrm{~T}$ \\
\hline Illness status & $0.0408 *$ \\
\hline
\end{tabular}

Predictive modeling for pregnancy based on status at 20-26 DIM using systematic logistic procedure. Values shown with $p \leq 0.05$ indicated as $*$ and trends of $p \leq 0.09$ indicated with $\Phi$. Milk Neuts = milk neutrophils, Lymphs = lymphocytes, Lact $=$ lactation, $M Y=$ milk yield, $\mathrm{Hp} / \mathrm{MY} \mathrm{Cat}=$ high or low Hp and high or low milk category, SCC = somatic cell count, Monos = monocytes, Basos =basophils, TLC =total leukocyte count, Band Neuts = banded neutrophils, Eos $=$ eosinophils, Illness Stat $=$ illness status, $T r t=$ treatment, Repo $=$ reproductive, Met $=$ metabolic, Struc $=$ structural .

Repeated measures ANOVA in "proc mixed" form was performed to predict pregnancy status 90-94 DIM due to illness status and plasma Hp at 20-26 DIM and 54-60 DIM. Postpartum illness was different $(p=0.0487)$ with plasma Hp concentration $(p=0.4007)$, time $(p=0.9620)$, and milk weight $(\mathrm{p}=0.5587)$ were not different. No interaction between time and illness was found $(\mathrm{p}=0.2651)$ (Table 10). A predictive model was formed based on the pregnancy outcome by the health status of the animal ( $\mathrm{p}=0.1199$; Equation 1$)$. 
Table 10: Plasma Hp by illness status

\begin{tabular}{lcccccc}
\hline & \multicolumn{2}{c}{ 20-26 DIM } & \multicolumn{2}{c}{$\mathbf{5 4 - 6 0 ~ D I M ~}$} \\
& \multicolumn{1}{c}{ Plasma Hp } & Pregnancy & & Plasma Hp & Pregnancy \\
& $\mathbf{N}$ & ng/mL & Rate & N & ng/mL & Rate \\
\hline Healthy & 38 & $110.67 \pm 22.0$ & $50 \%$ & 59 & $13.75 \pm 13.06$ & $37.30 \%$ \\
Ill & 88 & $91.21 \pm 12.7$ & $29.50 \%$ & 67 & $50.82 \pm 13.9$ & $34.33 \%$ \\
\hline
\end{tabular}

Plasma Hp concentration by illness status at 20-26 DIM and 54-60 DIM $n=126$. Illness status and pregnancy rates are time independent.

\section{Prediction of pregnancy based on illness and plasma Hp 20-26 DIM}

logit(Pregnancy in healthy cattle $)=0.27+0.14(\log 10$ of blood Hp$)$

$\operatorname{logit}($ Pregancy in cattle with an illness $)=0.25+0.04(\log 10$ of blood Hp$)$

Equation 1: Regression prediction of pregnancy based on health status and plasma Hp concentration at 20-26 DIM $n=126 . P=0.1199$.

\section{Discussion}

Differences in concentrations occurred in cellular biomarkers in blood, the uterus, and mammary gland; however, concentrations were not correlated between the mammary gland and uterus or blood and the uterus. Concentration of milk leukocytes differed with diagnoses of mastitis by QScout but did not change over time or between lactations. Concentrations of circulating leukocytes did not differ between healthy and sick animals at any time. This indicates that subclinical infections in a tissue do not affect other systems. However, leukocyte infiltration into the mammary gland during bacterial infection (Nickerson and Heald, 1982) as well as leukocyte diapedesis into circulation from the mammary gland has occurred in severe cases of coliform mastitis (Sordillo et al., 1988). Severity of infection may be the cause of the lack of leukocyte by illness difference in this study. Animals were treated for clinical infections immediately after symptoms appeared. 
There was a negative relationship between number of blood and mammary gland lymphocytes indicating the decrease of lymphocytes in milk with the increase in circulating lymphocytes. This relationship was significant for pregnant cows when they were 20-26 and 5460 DIM. Furthermore, it was significant for all animals at 90-96 DIM; at this time a pregnancy would have already been established. The difference in lymphocytes from blood and milk between pregnant animals indicates the use of mastitis status as a predictor of pregnancy. Increase in SCC proportionally increases neutrophils, lymphocytes, and monocytes. It has been shown that parity increases mastitis incidences and SCC (Batra et al., 1977; Archer et al., 2013), which was confirmed in this study with average SCC increasing with parity. Somatic cell count was not significantly related to pregnancy status; however, milk neutrophil and lymphocyte concentrations related to pregnancy status in partial pregnancy prediction models. Increase in neutrophils and lymphocytes in milk were correlated with mastitis status. Thus, the increasing severity of mastitis status can be negatively related to conception rate.

Milk neutrophils were related to pooled milk Hp concentrations as well as QScout mastitis diagnosis and illness status. Hence, pooled milk Hp concentration at 20-26 DIM was an indicator of mastitis status that is related to prediction of conception to the first insemination. The lack of interaction between cellular biomarkers in any tissue and mastitis on conception rate affirms the use of mastitis to model inflammatory events in cattle and their subsequent impact on reproductive success (Barker et al., 1998; Schrick et al., 2001; Santos et al., 2004).

Haptoglobin has been shown in numerous cases to be an inflammatory marker for cattle (Ceron et al., 2005; Peterson et al., 2004; Ekersall et al., 2001; Sheldon et al., 2001; Lipperheide et al., 1997; Nakagawa et al., 1997) with concentrations increasing during bacterial challenges (Lai et al., 2007; Petersen et al., 2004). Elevated milk and plasma Hp concentrations were 
shown in animals with an illness; however, elevated plasma Hp concentrations were also exhibited in healthy postpartum animals. Haptoglobin becomes a more accurate predictor of conception rate later in lactation, after the peak 20-26 DIM (Saremi et al., 2012; Ametaj, 2005; Humblet et al., 2006; Hachenberg et al., 2007). Previous studies have found that primiparous animals exhibit a higher acute phase reaction when compared to multiparous animals (Cullens, 2005; Saremi et al., 2012). Speculation has been made that this increase during the periparturent period is due to the physical stress on the reproductive tract during calving (Saremi et al., 2012; Hachenberg et al., 2007). Hoffmann et al. (1973) described endocrine changes surrounding parturition, including the rise of glucocorticoids. These endocrine changes stimulate relaxation of the cervix and uterine contractions inducing release of proinflammatory cytokines (van Engelen et al., 2009) and increasing the acute phase response and subsequently plasma $\mathrm{Hp}$ concentration.

After the initial peak at 20-26 DIM, plasma Hp concentration declined rapidly in healthy animals having values below assay sensitivity in primiparous animals while the value was 20 $\mathrm{ng} / \mathrm{mL}$ in multiparous animals, resulting in a time by lactation interaction. Multiparous animals may not respond to physical stresses of parturition as markedly as primiparous animals, indicated by lower Hp at 20-26 DIM. Elevated plasma Hp concentration after the transition period may be a reflection of the increase incidences of clinical and subclinical disease in multiparous animals (Akers, 2014). Speculation that Hp is elevated during a negative energy balance (Crawford et al., 2005) can also account for this increase early postpartum. Due to the peak in plasma Hp production early postpartum, the use of plasma Hp concentration as the sole indicator of health status (Horoadagoda et al., 1999) should be used with caution. 
The combination of milk production and plasma $\mathrm{Hp}$ concentration demonstrates a more complete picture of health status as relating to future fertility of the dairy cow; reflected in the Hp/milk categories at 54-60 DIM by illness status. Demetrio et al. (2007) demonstrated a negative correlation between milk production and conception rate to AI of lactating dairy cows. At breeding (54-60 DIM) animals with high plasma Hp concentration did not conceive to the first insemination regardless of milk production. However, illness status by 54-60 DIM is not a predictor of pregnancy to the first AI, indicating cows were able to overcome an illness obtained after the transition period and conceive to the first AI.

Illness status at 20-26 DIM was a predictor of pregnancy to the first insemination with a $50 \%$ conception rate of healthy cattle. Reproductive insults were found to have the most negative influence on first service conception. This is in agreement with Braun and Smith (1980) who demonstrated lower first service conception rates correlated with increasing reproductive disorders like calving difficulty, retained placenta, uterine infection, and cystic ovaries. In the current study cows that had a positive uterine culture were less likely to conceive. The combination of an illness status and positive uterine culture lowed pregnancy rates further. With progesterone having an immune suppressive function on the uterus, the luteal phase allows for a period of susceptibility of infection if contaminated with bacteria (Seals et al., 2002; Lewis 2003a).

In the transition cow, once parturition occurs there are physical changes to the reproductive tract (Sheldon et al., 2014; Senger 2012). An increase in calving difficulty can cause these changes to become physical damage to the cow that take more time to repair postpartum. Calving difficulty can be related to size or position of the calf. Calving difficulty $(\geq 3)$ was shown to decrease conception rate to the first AI postpartum with no interaction of 
uterine culture. This indicates that assisted calving decreases probability of conception to the first AI due to physical damage of the reproductive tract not due to infection introduced by bacterial contamination. Having physical damage to the reproductive tract lengthens the time to involution (Gier and Marion, 1968; Senger 2012) delaying subsequent conception.

The combination of calving difficulty, illness status by clinical signs, uterine culture, and plasma Hp after the transition period allows producers a more accurate picture of a postpartum dairy cow's fertility to the first AI around 60 DIM. The low frequency of E. coli in the uterine cultures indicates proper sampling procedures and lack of contamination of the uterus while passing the cytology rod. The most frequent bacterial species found was the facultative anaerobic gram-positive Bacillus. Bacillus spp. are typically found in decaying tissue like the lochia of a uterus during involution. The use of best management practices, such as performing uterine rakes during the early postpartum period allowing any lochia to be emptied more rapidly, on this commercial farm allowed cattle to overcome certain fertility challenges. The practice of using a presynch protocol to set up cattle to cycle prior to Ovsynch for breeding primes the estrous cycle to cycle, further expelling any remaining loci. Exogenous $\mathrm{PGF}_{2 \alpha}$ administered 14 days prior to initiating an Ovsynch or other timed AI protocol helped ensure the cows were day 5 through 12 or their estrous cycle for optimum fertility. Exogenous $\mathrm{PGF}_{2 \alpha}$ increased lymphocyte proliferation in vitro (Seals et al., 2002), which suppresses the action of P4 to allow leukocytes to fight infection while lysing the CL. After intrauterine infusion of $100 \mu \mathrm{g}$ of LPS at estrus, repeat breeder cows had flushing solutions containing $80 \%$ neutrophils 6 to 72 hours post flush and $75 \%$ of cows treated with intrauterine infusion of LPS conceived to the following AI (Singh et al., 2000). Singh suggested that the challenge stimulated the immune response to overcome the bacterial contamination and metritis that was previously maintained over several estrous cycles. 
An additional study measuring acute phase response by plasma $\mathrm{Hp}$ in dairy cattle concluded higher acute phase responses is characterized by the innate immune response and reduced mitogen-induced IFN- $\gamma$ secretion which resulted in decreased reproductive efficiency for cows with high concentrations of serum Hp (Nightingale et al., 2015).

The use of cellular biomarkers to predict fertility of dairy cattle would allow producers a chute side test to negate the costs of breeding cattle that are not in the proper state to support a pregnancy. Proper management of transition cows is the most important factor. Detection of clinical and subclinical illness has continued to be the number one predictor of pregnancy (Akers, 2014). The combination of calving difficulty, clinical signs of illness, uterine culture, and Hp plasma concentration (after 26 DIM) for the culmination of most predictive indication of fertility.

\section{Future Implications}

Due to the numerous illness categories in this study various illnesses could not be broken down to examine specific leukocyte and Hp interactions for these groups. A larger number of animals would be necessary for this to occur. Additionally, testing animals in the same stage of lactation over two to three years would give a more accurate picture of how each animal copes with the physical stress of calving and any illnesses they acquire. This would allow the Hp concentration parity effect to be further examined.

It is known that $\mathrm{Hp}$ is released due to the acute phase response; this is a protective mechanism from oxidation as well as a positive and negative inflammatory mediator. The levels of Hp in the body are known to be influenced through cellular levels, increasing the circulating levels in a postpartum dairy cow exogenously could help stimulate immune activation to 
overcome a latent or subclinical infection in order for conception to the first service to be successful. Exogenous haptoglobin given to Hp knockout cells restored cell migration in an inflammatory arthritis model (Smeets et al., 2003). It has been shown that feeding certain types of grains like barley (Emmanuel et al., 2008) stimulate an inflammatory response. The use of feeds to alter the $\mathrm{pH}$ balance of the rumen for a short time could potentially increase acute phase proteins in circulation to overcome an immune challenge. Emmanuel et al. (2008) showed an increase in serum amyloid A and LPS-binding protein that have shorter half-lives than Hp and bind endotoxins in circulation drawing leukocytes to the complex.

Additional research should focus on the production of cellular products produced as a result of an acute phase response. These products would include molecules like interferon gamma and bilirubin. These molecules are further down the signaling cascade and would indicate the APR is initiated and the innate immune response has been activated fighting the immune challenge causing reduced conception rates. 


\section{Appendix}

Table 11: Milk somatic cell summary by QScout Farm Lab diagnosis

\begin{tabular}{|c|c|c|c|c|c|c|c|c|}
\hline & & Time & $\mathbf{N}$ & Negative & $\mathbf{N}$ & Borderline & $\mathbf{N}$ & Positive \\
\hline \multirow{12}{*}{ SCC } & Left Front & $\mathrm{T} 1$ & 83 & 34 & 17 & 89 & 20 & 558 \\
\hline & Left Rear & $\mathrm{T} 1$ & 86 & 38 & 17 & 77 & 19 & 1163 \\
\hline & Right Rear & T1 & 79 & 35 & 16 & 72 & 27 & 1742 \\
\hline & Right Front & $\mathrm{T} 1$ & 87 & 34 & 18 & 82 & 19 & 1168 \\
\hline & Left Front & $\mathrm{T} 2$ & 73 & 32 & 15 & 87 & 34 & 1681 \\
\hline & Left Rear & $\mathrm{T} 2$ & 80 & 29 & 12 & 89 & 28 & 1401 \\
\hline & Right Rear & $\mathrm{T} 2$ & 78 & 29 & 9 & 94 & 35 & 1318 \\
\hline & Right Front & $\mathrm{T} 2$ & 81 & 25 & 14 & 64 & 29 & 2232 \\
\hline & Left Front & T3 & 73 & 28 & 14 & 85 & 30 & 2742 \\
\hline & Left Rear & $\mathrm{T} 3$ & 79 & 32 & 17 & 102 & 24 & 1872 \\
\hline & Right Rear & $\mathrm{T} 3$ & 72 & 28 & 10 & 94 & 38 & 1389 \\
\hline & Right Front & $\mathrm{T} 3$ & 82 & 29 & 13 & 76 & 26 & 1790 \\
\hline \multirow{3}{*}{ SCC } & Heifers & T1 & 10 & 150 & 6 & 300 & 9 & 1345 \\
\hline & Heifers & $\mathrm{T} 2$ & 9 & 84 & 3 & 175 & 13 & 4957 \\
\hline & Heifers & T3 & 8 & 67 & 4 & 228 & 12 & 3037 \\
\hline \multirow{3}{*}{ SCC } & Cows & $\mathrm{T} 1$ & 39 & 105 & 20 & 234 & 42 & 2283 \\
\hline & Cows & $\mathrm{T} 2$ & 39 & 117 & 12 & 190 & 50 & 2957 \\
\hline & Cows & T3 & 34 & 103 & 14 & 218 & 51 & 3840.86 \\
\hline
\end{tabular}

Mean milk Total Leukocyte Summary by QScout Farm Lab Diagnosis over time. All cell counts performed on QScout Farm Lab on hospital cow setting shown in cells $/ \mathrm{mL}$ of pooled milk. T1 =20-26 DIM, T2 =54-60 DIM, T3 =90-96 DIM. 
Table 12: Milk total leukocyte summary by QScout Farm Lab diagnosis

\begin{tabular}{cccccccc} 
& Time & N & Negative & N & Borderline & N & Positive \\
\hline \multirow{3}{*}{ Neutrophils } & T1 & 49 & 53 & 26 & 129 & 51 & 1286 \\
& T2 & 48 & 51 & 15 & 99 & 63 & 2345 \\
& T3 & 42 & 46 & 18 & 119 & 63 & 2491 \\
\hline \multirow{3}{*}{ Lymphocytes } & T1 & 49 & 28 & 26 & 69 & 51 & 576 \\
& T2 & 48 & 21 & 15 & 32 & 63 & 680 \\
& T3 & 42 & 18 & 18 & 44 & 63 & 700 \\
\hline \multirow{3}{*}{ Monocytes } & T1 & 49 & 33 & 26 & 52 & 51 & 247 \\
& T2 & 48 & 40 & 15 & 56 & 63 & 344 \\
& T3 & 42 & 33 & 18 & 58 & 63 & 497 \\
\hline
\end{tabular}

Mean milk leukocyte summary by QScout Farm Lab Diagnosis over time. All cell counts performed on QScout Farm Lab on hospital cow setting shown in cells/mL of pooled milk. T1 =20-26 DIM, T2 =54-60 DIM, T3 =90-96 DIM. 
Table 13: Blood leukocyte summary by QScout Farm Lab diagnosis

\begin{tabular}{cccccccc|c} 
& Time & N & Negative & N & Borderline & N & Positive & $\mathbf{p}$ \\
\hline \multirow{2}{*}{ Total Leukocyte } & T1 & 41 & 8.67 & 21 & 8.92 & 44 & 8.79 & 0.952 \\
Count & T2 & 48 & 8.97 & 15 & 10.31 & 62 & 8.73 & 0.1241 \\
& T3 & 42 & 10.39 & 18 & 10.29 & 63 & 9.55 & 0.2431 \\
\hline \multirow{3}{*}{ Neutrophils } & T1 & 41 & 3.65 & 21 & 3.95 & 44 & 4.25 & 0.3622 \\
& T2 & 48 & 3.65 & 15 & 3.96 & 62 & 4.3 & 0.125 \\
& T3 & 42 & 4.78 & 18 & 4.47 & 63 & 4.87 & 0.6364 \\
\hline \multirow{5}{*}{ Lymphocytes } & T1 & 41 & 4.44 & 21 & 4.34 & 44 & 3.9 & 0.5046 \\
& T2 & 48 & 4.6 & 15 & 5.62 & 62 & 3.72 & 0.0051 \\
& T3 & 42 & 4.59 & 18 & 4.85 & 63 & 3.67 & 0.0528 \\
\hline \multirow{3}{*}{ Monocytes } & T1 & 41 & 0.32 & 21 & 0.294 & 44 & 0.3 & 0.8509 \\
& T2 & 48 & 0.298 & 15 & 0.262 & 62 & 0.257 & 0.3525 \\
& T3 & 42 & 0.465 & 18 & 0.484 & 63 & 0.384 & 0.3814 \\
\hline \multirow{3}{*}{ Eosinophils } & T1 & 41 & 0.196 & 21 & 0.252 & 44 & 0.255 & 0.6255 \\
& T2 & 48 & 0.301 & 15 & 0.324 & 62 & 0.271 & 0.6973 \\
& T3 & 42 & 0.355 & 18 & 0.369 & 63 & 0.415 & 0.5685 \\
\hline \multirow{3}{*}{ Basophils } & T1 & 41 & 0.036 & 21 & 0.037 & 44 & 0.04 & 0.9145 \\
& T2 & 48 & 0.068 & 15 & 0.061 & 62 & 0.072 & 0.809 \\
& T3 & 42 & 0.102 & 18 & 0.071 & 63 & 0.088 & 0.2358 \\
\hline \multirow{2}{*}{ Banded } & T1 & 41 & 0.028 & 21 & 0.048 & 44 & 0.039 & 0.1886 \\
Neutrophils & T2 & 48 & 0.063 & 15 & 0.071 & 62 & 0.101 & 0.2654 \\
& T3 & 42 & 0.091 & 18 & 0.049 & 63 & 0.12 & 0.2529 \\
\hline Blood leukocyte summary by QScout Farm Lab Udder Diagnosis. Mean counts in 1,000/mL. T1 \\
$=$ 20-26 DIM, T2 =54-60 DIM, T3 =90-96 DIM. & & & & &
\end{tabular}


Table 14:Mean uterine leukocyte summary by QScout Farm Lab diagnosis

\begin{tabular}{lccccccc} 
Cell type & $\mathbf{N}$ & Negative & $\mathbf{N}$ & Borderline & $\mathbf{N}$ & Positive & $\mathbf{p}$ \\
\hline Total Leukocyte & & & & & & & \\
Count & 35 & 44 & 19 & 54.42 & 31 & 51.41 & 0.7402 \\
\hline Neutrophils & 28 & 25 & 13 & 20.23 & 26 & 35.04 & 0.4597 \\
\hline Lymphocytes & 28 & 9.5 & 16 & 28.81 & 25 & 11.16 & 0.0577 \\
\hline Monocytes & 26 & 22 & 11 & 24.27 & 21 & 19.19 & 0.8783 \\
\hline Eosinophils & 1 & 1 & 2 & 2.5 & 1 & 1 & 0.8165 \\
\hline
\end{tabular}

Mean uterine leukocyte summary by QScout Farm Lab udder diagnosis at 20-26 DIM. Mean cell counts are given. 
Table 15: Average milk yield summary by QScout Farm Lab diagnosis

\begin{tabular}{|c|c|c|c|c|c|c|c|c|c|}
\hline & & Time & $\mathbf{N}$ & Negative & $\mathbf{N}$ & Borderline & $\mathbf{N}$ & Positive & $\mathbf{p}$ \\
\hline & \multicolumn{9}{|l|}{ Milk } \\
\hline & Weight & $\mathrm{T} 1$ & 49 & 40.48 & 26 & 40.03 & 51 & 40.89 & 0.9267 \\
\hline & Milk & & & & & & & & \\
\hline & Weight & $\mathrm{T} 2$ & 48 & 45.57 & 15 & 43.10 & 63 & 59.55 & 0.6654 \\
\hline & Milk & & & & & & & & \\
\hline & Weight & $\mathrm{T} 3$ & 42 & 42.46 & 18 & 39.37 & 63 & 41.72 & 0.3196 \\
\hline \multirow{3}{*}{$\begin{array}{l}\text { Milk } \\
\text { Yield }\end{array}$} & Heifers & $\mathrm{T} 1$ & 10 & 29.09 & 6 & 27.90 & 9 & 29.70 & 0.9028 \\
\hline & Heifers & $\mathrm{T} 2$ & 11 & 36.69 & 3 & 38.01 & 13 & 46.82 & 0.5043 \\
\hline & Heifers & $\mathrm{T} 3$ & 9 & 35.22 & 8 & 33.86 & 12 & 43.65 & 0.6073 \\
\hline \multirow{3}{*}{$\begin{array}{l}\text { Milk } \\
\text { Yield }\end{array}$} & Cows & $\mathrm{T} 1$ & 39 & 43.40 & 20 & 43.67 & 42 & 43.29 & 0.9824 \\
\hline & Cows & $\mathrm{T} 2$ & 37 & 48.21 & 12 & 44.38 & 53 & 45.15 & 0.2393 \\
\hline & Cows & T3 & 33 & 44.44 & 10 & 43.78 & 56 & 42.33 & 0.3568 \\
\hline
\end{tabular}

Average Milk Yield Summary by QScout Farm Lab Diagnosis over time in kgs. Average milk yield calculated by three consecutive days yield prior to sampling day. T1 =20-26 DIM, T2 =5460 DIM, T3 =90-96 DIM. 
Table 16: Disease status by QScout Farm Lab diagnosis

\section{Total}

With

\begin{tabular}{|c|c|c|c|c|c|c|c|c|}
\hline Disease & Time & $\begin{array}{c}\text { With } \\
\text { Disease }\end{array}$ & $\mathbf{N}$ & Negative & $\mathbf{N}$ & Borderline & $\mathbf{N}$ & $\begin{array}{c}\text { Positiv } \\
\text { e }\end{array}$ \\
\hline \multirow{3}{*}{ Metabolic } & $\mathrm{T} 1$ & 7 & 2 & $4.08 \%$ & 3 & $11.54 \%$ & 2 & $3.92 \%$ \\
\hline & $\mathrm{T} 2$ & 1 & - & - & - & - & 1 & $1.59 \%$ \\
\hline & $\mathrm{T} 3$ & 2 & - & - & - & - & 2 & $3.23 \%$ \\
\hline \multirow{4}{*}{ Reproductive } & & & & & 1 & & 1 & \\
\hline & $\mathrm{T} 1$ & 46 & 18 & $42.31 \%$ & 1 & $36.73 \%$ & 7 & $33.33 \%$ \\
\hline & $\mathrm{T} 2$ & 1 & - & - & - & - & 1 & $1.59 \%$ \\
\hline & $\mathrm{T} 3$ & - & - & - & - & - & - & - \\
\hline \multirow{3}{*}{ Mammary } & $\mathrm{T} 1$ & 1 & - & - & 1 & $3.85 \%$ & - & - \\
\hline & $\mathrm{T} 2$ & 2 & - & - & 1 & $6.67 \%$ & 1 & $1.59 \%$ \\
\hline & $\mathrm{T} 3$ & 2 & - & - & - & - & 2 & $3.23 \%$ \\
\hline \multirow{3}{*}{ Structural } & $\mathrm{T} 1$ & 8 & 2 & $4.08 \%$ & 2 & $7.69 \%$ & 4 & $7.84 \%$ \\
\hline & $\mathrm{T} 2$ & 13 & 4 & $8.33 \%$ & 0 & $0 \%$ & 9 & $14.29 \%$ \\
\hline & $\mathrm{T} 3$ & 7 & 3 & $7.14 \%$ & 1 & $5.56 \%$ & 3 & $4.48 \%$ \\
\hline \multirow{3}{*}{ Infectious } & $\mathrm{T} 1$ & 2 & - & - & 1 & $3.85 \%$ & 1 & $1.96 \%$ \\
\hline & $\mathrm{T} 2$ & 1 & - & - & - & - & 1 & $1.53 \%$ \\
\hline & T3 & 1 & - & - & - & - & 1 & $1.61 \%$ \\
\hline
\end{tabular}

Summary of disease status by QScout Farm Lab diagnosis over time. Diseases status was determined by experienced veterinarian and clinical symptoms treated by producer; disease percent is percent of animals positive for disease and QScout category out of all possible animals. $T 1=20-26$ DIM, T2 =54-60 DIM, T3 =90-96 DIM. 
Table 17: Conception rates to first AI by QScout Farm Lab diagnosis

\begin{tabular}{|c|c|c|c|c|c|c|c|c|c|}
\hline & & Time & $\mathbf{N}$ & Negative & $\mathbf{N}$ & Borderline & $\mathbf{N}$ & Positive & p \\
\hline & $\begin{array}{l}\text { Pregnancy } \\
\text { at } 90 \text { DIM }\end{array}$ & $\mathrm{T} 1$ & 49 & $32.65 \%$ & 26 & $30.77 \%$ & 51 & $41.18 \%$ & 0.5656 \\
\hline & $\begin{array}{l}\text { Pregnancy } \\
\text { at } 90 \text { DIM }\end{array}$ & $\mathrm{T} 2$ & 48 & $39.58 \%$ & 15 & $40.00 \%$ & 63 & $31.75 \%$ & 0.6489 \\
\hline & $\begin{array}{l}\text { Pregnancy } \\
\text { at } 90 \text { DIM }\end{array}$ & $\mathrm{T} 3$ & 42 & $42.86 \%$ & 18 & $38.89 \%$ & 63 & $31.75 \%$ & 0.3748 \\
\hline \multirow{3}{*}{$\begin{array}{l}\text { Pregnancy } \\
\text { at } 90 \text { DIM }\end{array}$} & Heifers & $\mathrm{T} 1$ & 10 & $50.00 \%$ & 6 & $33.33 \%$ & 9 & $44.44 \%$ & 0.8090 \\
\hline & Heifers & $\mathrm{T} 2$ & 11 & $45.45 \%$ & 4 & $50.00 \%$ & 10 & $40.00 \%$ & 0.9357 \\
\hline & Heifers & $\mathrm{T} 3$ & 9 & $33.33 \%$ & 8 & $75.00 \%$ & 7 & $28.57 \%$ & 0.1720 \\
\hline \multirow{3}{*}{$\begin{array}{l}\text { Pregnancy } \\
\text { at } 90 \text { DIM }\end{array}$} & Cows & $\mathrm{T} 1$ & 39 & $28.21 \%$ & 20 & $30 \%$ & 42 & $40.48 \%$ & 0.4692 \\
\hline & Cows & $\mathrm{T} 2$ & 37 & $37.84 \%$ & 11 & $36.36 \%$ & 53 & $30.19 \%$ & 0.7367 \\
\hline & Cows & $\mathrm{T} 3$ & 33 & $45.45 \%$ & 10 & $10 \%$ & 56 & $32.14 \%$ & 0.1308 \\
\hline
\end{tabular}

Conception rates to first AI by QScout Farm Lab udder diagnosis over time. T1 =20-26 DIM, T2 =54-60 DIM, T3 =90-96 DIM. 
Pregnancy by postpartum illness

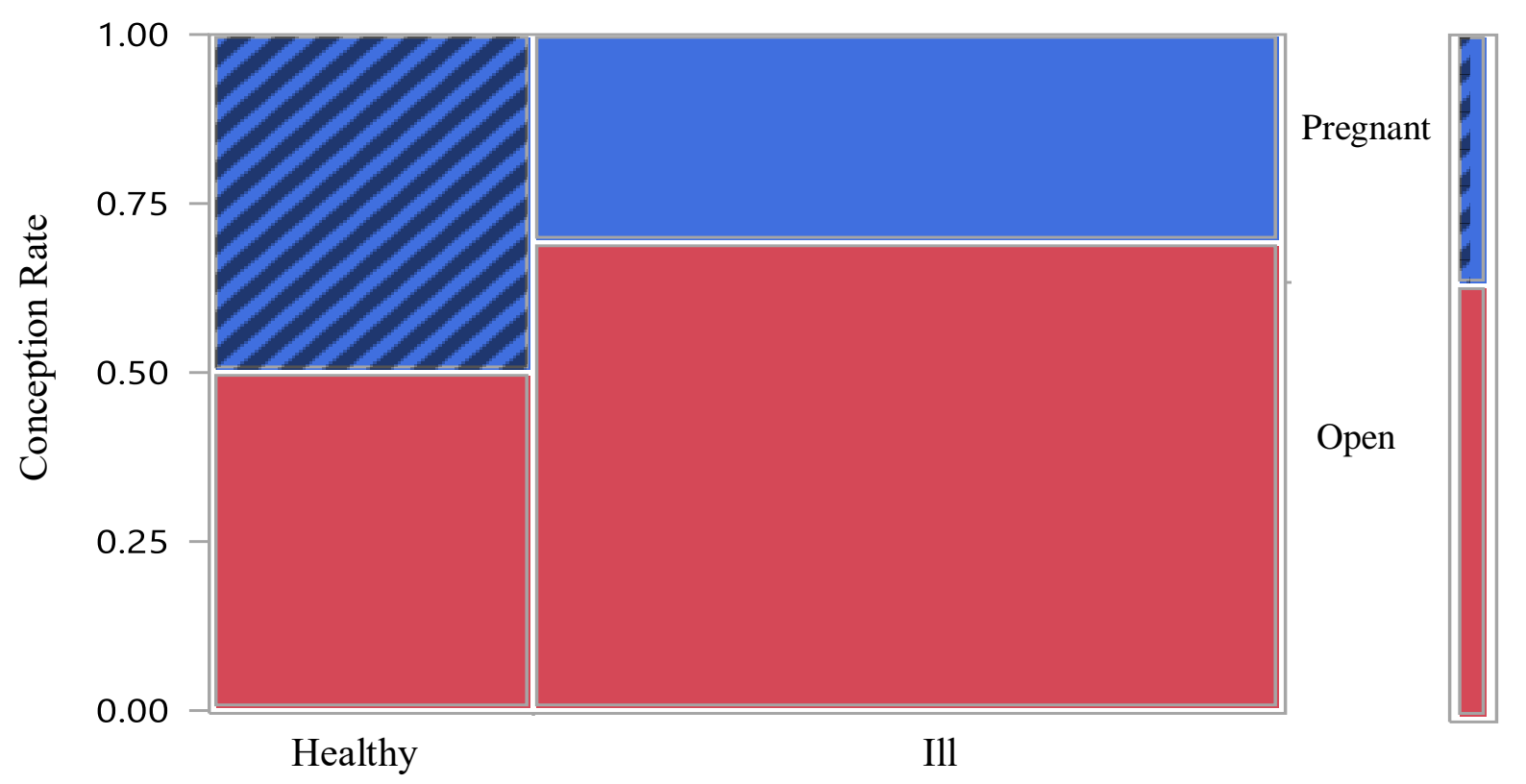

Figure 19: Contingency analysis of pregnancy by postpartum illness $n=126$ with open animals $(n=80)$ and pregnant animals $(n=46)$ Chi square $p=0.0387$. 
Pregnancy status by calving difficulty

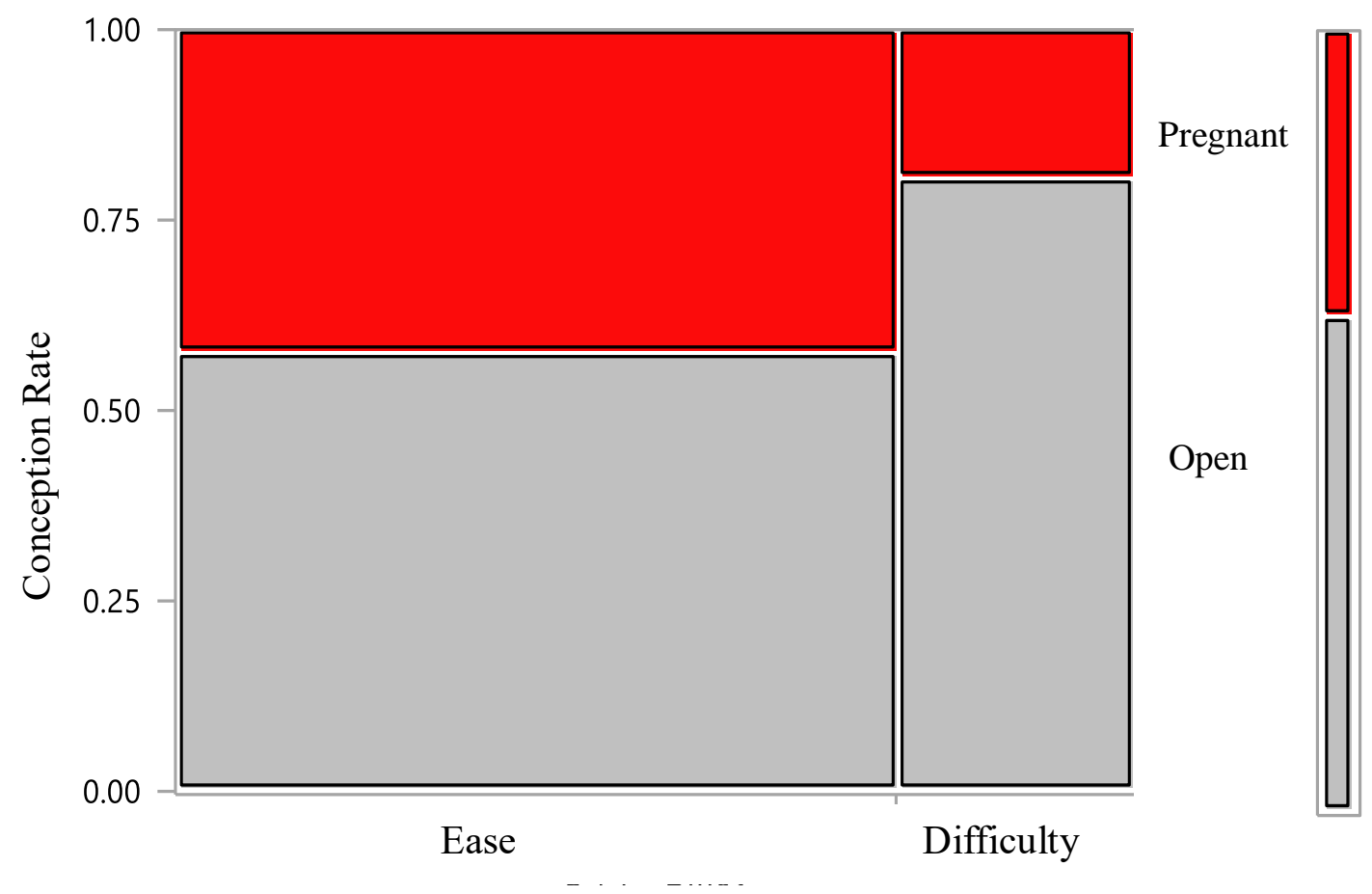

Figure 20: Pregnancy status by calving difficulty $n=126$. Calving score of $\leq 2=0(n=95)$ and calving score $\geq 3=1(n=31)$. Calving score $1=$ unassisted delivery. $2=$ little difficulty, assistance given by hand and may have not been required. $3=$ moderate difficulty, calf jack used and pull duration less than 10 minutes. $4=$ major difficulty with calf jack used; pull duration longer than 10 minutes $(p=0.0223)$.

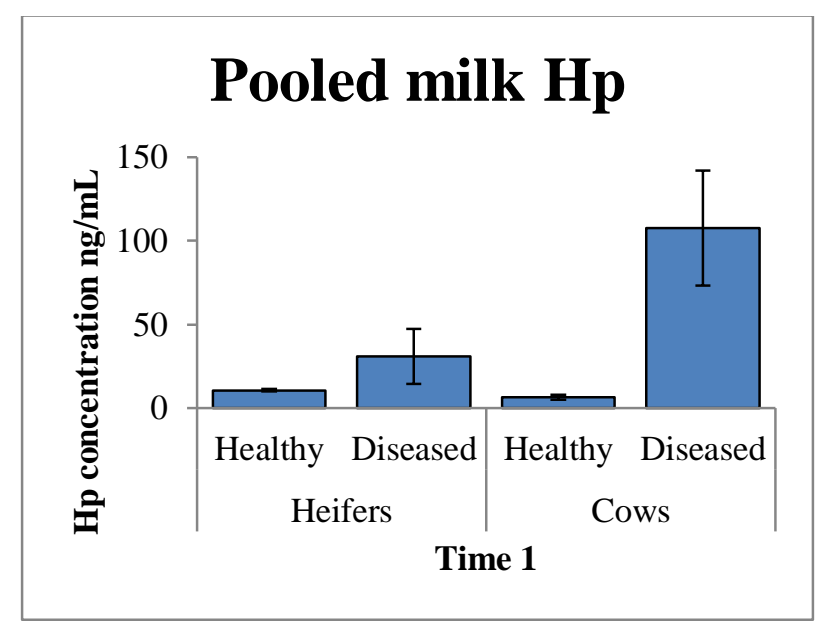

Figure 21: Pooled milk Hp concentrations at 20-26 DIM of healthy and diseased animals by parity. 
Table 18: Repeated measures ANOVA of WBC type by QScout diagnosis and time Model: Log10cell type $=$ Time + QScout Diagnosis + Time*QScout Diagnosis

\begin{tabular}{|c|c|c|c|c|}
\hline & SCC & Neutrophils & Lymphocytes & Monocytes \\
\hline Time & 0.0680 & 0.1275 & $<0.0001$ & 0.1279 \\
\hline $\begin{array}{l}\text { QScout } \\
\text { Diagnosis }\end{array}$ & $<0.0001$ & $<0.0001$ & $<0.0001$ & 0.0056 \\
\hline $\begin{array}{l}\text { Time*QScout } \\
\text { Diagnosis }\end{array}$ & 0.0047 & 0.0008 & 0.0275 & 0.0430 \\
\hline
\end{tabular}

Table 19: Autoregressive contrasts $\operatorname{Pr}>$ F

\begin{tabular}{lcccc}
\hline & SCC & Neutrophils & Lymphocytes & Monocytes \\
\hline $\begin{array}{l}\text { Negative vs } \\
\text { borderline and } \\
\text { positive }\end{array}$ & $<0.0001$ & $<0.0001$ & $<0.0001$ & 0.0537 \\
$\begin{array}{l}\text { Borderline vs } \\
\text { positive }\end{array}$ & $<0.0001$ & $<0.0001$ & $<0.0001$ & 0.0445 \\
\hline
\end{tabular}

Autoregressive contrasts by WBC type by QScout diagnosis and time. Contrasts: Negative vs. borderline and positive $(1,-0.5,-0.5)$ and borderline vs. positive $(-1,1)$. 
Table 20: Milk culture by QScout Farm Lab positive udder diagnosis

\begin{tabular}{|c|c|c|c|c|c|c|c|c|c|}
\hline \multirow[b]{2}{*}{$\begin{array}{l}\mathrm{N} \\
\% \\
\text { Row\% }\end{array}$} & \multicolumn{3}{|c|}{ Time 1} & \multicolumn{3}{|c|}{ Time 2} & \multicolumn{3}{|c|}{ Time 3} \\
\hline & 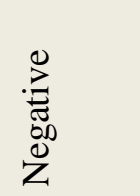 & 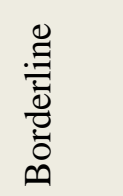 & $: \sum_{\substack{0 \\
0}}^{0}$ & 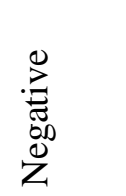 & 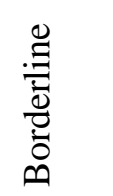 & $: \stackrel{0}{:}$ & 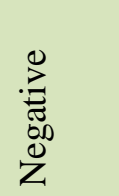 & 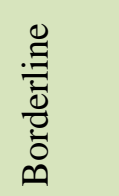 & $: \begin{array}{l}0 \\
: \\
0 \\
0 \\
0\end{array}$ \\
\hline Negative & 21 & 9 & 4 & 12 & 10 & 15 & 23 & 10 & 19 \\
\hline milk & 24.42 & 10.47 & 4.65 & 11.32 & 9.43 & 14.15 & 19.49 & 8.47 & 16.10 \\
\hline culture & 61.76 & 26.47 & 11.76 & 32.43 & 27.03 & 40.54 & 44.23 & 19.23 & 36.54 \\
\hline Positive & 12 & 7 & 33 & 25 & 4 & 40 & 18 & 7 & 41 \\
\hline milk & 13.95 & 8.14 & 38.37 & 23.58 & 3.77 & 37.74 & 15.25 & 5.93 & 34.75 \\
\hline culture & 23.08 & 13.46 & 63.46 & 36.23 & 5.80 & 57.97 & 27.27 & 10.61 & 62.12 \\
\hline & 33 & 16 & 37 & 37 & 14 & 55 & 41 & 17 & 60 \\
\hline Total & 38.37 & 18.60 & 43.02 & 34.91 & 13.21 & 51.89 & 34.75 & 14.41 & 50.85 \\
\hline Chi Sq & $<0.0001$ & & & 0.0077 & & & 0.0218 & & \\
\hline
\end{tabular}

Milk culture by udder diagnosis Chi square by time. Nonparametric ANOVA means scores shown using Mantel-Haenszel Methodology were row mean score differ $<0.0001$. 
Table 21: McNemars test of agreement: Milk culture and QScout Farm Lab positive udder diagnosis

\begin{tabular}{|c|c|c|c|c|c|c|}
\hline \multirow{2}{*}{$\begin{array}{l}\mathrm{N} \\
\% \\
\text { Row\% }\end{array}$} & \multicolumn{2}{|l|}{ Time 1} & \multicolumn{2}{|l|}{ Time 2} & \multicolumn{2}{|l|}{ Time 3} \\
\hline & Negative & Positive & Negative & Positive & Negative & Positive \\
\hline Negative & 30 & 4 & 22 & 15 & 33 & 19 \\
\hline \multirow[t]{2}{*}{ Culture } & 34.88 & 4.65 & 20.75 & 14.15 & 27.97 & 16.10 \\
\hline & 88.24 & 11.76 & 59.46 & 40.54 & 63.46 & 36.54 \\
\hline Positive & 19 & 33 & 29 & 40 & 25 & 41 \\
\hline \multirow[t]{2}{*}{ Culture } & 22.09 & 38.37 & 27.36 & 37.74 & 21.88 & 34.75 \\
\hline & 36.54 & 63.46 & 42.03 & 57.97 & 37.88 & 62.12 \\
\hline McNemar's & \multicolumn{2}{|c|}{$\begin{array}{c}0.0018 \\
\text { (Disagree) }\end{array}$} & \multicolumn{2}{|c|}{$\begin{array}{c}0.0348 \\
\text { (Disagree) }\end{array}$} & \multicolumn{2}{|c|}{$\begin{array}{c}0.3657 \\
\text { (Agree) }\end{array}$} \\
\hline
\end{tabular}

McNemars test of agreement of milk culture and udder diagnosis based on QScout Farm Lab. Borderline animals are combined with negative udder diagnosis. Significance was determined on the difference of the two dependent variables. Over all analysis: row mean scores differ $<0.0001$. Kappa coefficient $=0.3033$. 
Table 22: DoVan treated mastitic cows by QScout Farm Lab positive udder diagnosis

\begin{tabular}{|c|c|c|c|c|c|c|c|c|c|}
\hline \multirow[b]{2}{*}{$\begin{array}{l}\mathrm{N} \\
\% \\
\text { Row\% }\end{array}$} & \multicolumn{3}{|c|}{ Time 1} & \multicolumn{3}{|c|}{ Time 2} & \multicolumn{3}{|c|}{ Time 3} \\
\hline & 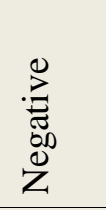 & 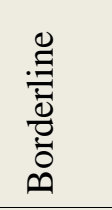 & 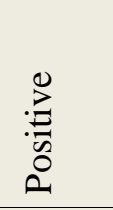 & 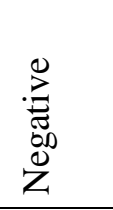 & 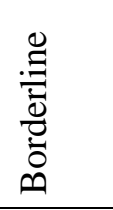 & $\stackrel{0}{:}$ & 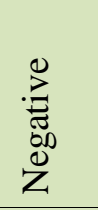 & 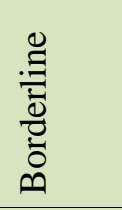 & $\begin{array}{l}0 \\
: \\
0 \\
0 \\
0\end{array}$ \\
\hline Non- & 49 & 25 & 51 & 48 & 14 & 62 & 42 & 18 & 60 \\
\hline treated & 38.89 & 19.84 & 40.48 & 38.10 & 11.11 & 49.21 & 34.43 & 14.75 & 49.18 \\
\hline & 39.20 & 20.00 & 40.80 & 38.71 & 11.29 & 50.00 & 35.00 & 15.00 & 50.00 \\
\hline \multirow[t]{4}{*}{ Treated } & 0 & 1 & 0 & 0 & 1 & 1 & 0 & 0 & 2 \\
\hline & 0 & 0.79 & 0 & 0 & 0.79 & 0.79 & 0 & 0 & 1.64 \\
\hline & 0 & 100 & 0 & 0 & 50.00 & 50.00 & 0 & 0 & 100 \\
\hline & 49 & 26 & 51 & 48 & 15 & 63 & 42 & 18 & 62 \\
\hline Total & 38.89 & 20.63 & 40.48 & 38.10 & 11.90 & 50.00 & 34.43 & 14.75 & 50.82 \\
\hline $\begin{array}{c}\text { Fisher's } \\
\text { exact }\end{array}$ & & 0.206 & & & 0.1200 & & & 0.2562 & \\
\hline
\end{tabular}

DoVan treated mastitic cows by QScout Farm Lab positive udder diagnosis. Mantel-Henszel Methodology with Fisher's exact test used. Overall analysis: row mean scores differ $p=0.2353$. 
Table 23: McNemars test of agreement: DoVan treated cows by QScout Farm Lab positive udder diagnosis

\begin{tabular}{|c|c|c|c|c|c|c|}
\hline \multirow{2}{*}{$\begin{array}{l}\mathrm{N} \\
\% \\
\text { Row\% }\end{array}$} & \multicolumn{2}{|c|}{ Time 1} & \multicolumn{2}{|c|}{ Time 2} & \multicolumn{2}{|c|}{ Time 3} \\
\hline & Negative & Positive & Negative & Positive & Negative & Positive \\
\hline \multirow{3}{*}{$\begin{array}{l}\text { Non- } \\
\text { treated }\end{array}$} & 74 & 51 & 62 & 62 & 60 & 60 \\
\hline & 58.73 & 40.48 & 49.21 & 49.21 & 49.18 & 49.18 \\
\hline & 59.20 & 40.80 & 50.00 & 50.00 & 50.00 & 50.00 \\
\hline \multirow[t]{3}{*}{ Treated } & 1 & 0 & 1 & 1 & 0 & 2 \\
\hline & 0.79 & 0 & 0.79 & 0.79 & 0 & 1.64 \\
\hline & 100 & 0 & 50.00 & 50.00 & 0 & 100.00 \\
\hline McNemar's & \multicolumn{2}{|c|}{$\begin{array}{c}<0.0001 \\
\text { (Disagree) }\end{array}$} & \multicolumn{2}{|c|}{$\begin{array}{c}<0.0001 \\
\text { (Disagree) }\end{array}$} & \multicolumn{2}{|c|}{$\begin{array}{c}<0.0001 \\
\text { (Disagree) }\end{array}$} \\
\hline
\end{tabular}

McNemars test of agreement with DoVan treated cows by QScout Farm Lab positive udder diagnosis. Borderline cows are combined with negative udder diagnosis cows. Significance was determined on the difference of the two dependent variables. Overall analysis: Row means score differ $=0.6021$. Kappa coefficient $=0.2179$. 
Table 24: Milk and blood correlations 20-26 DIM

\begin{tabular}{|c|c|c|c|c|c|c|c|c|c|c|c|}
\hline & U & 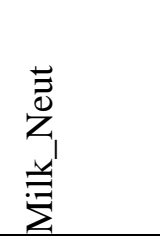 & 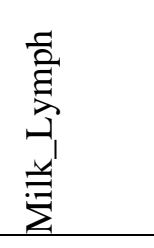 & 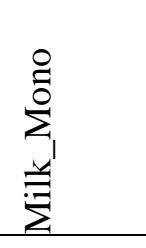 & $\sum_{3}^{0}$ & $\begin{array}{l}\vec{z}_{0} \\
\vec{z}_{1} \\
\infty^{\prime}\end{array}$ & 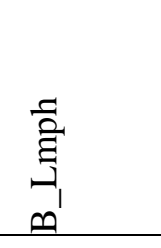 & $\sum_{\infty}^{\stackrel{0}{0}}$ & 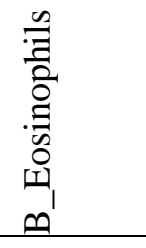 & 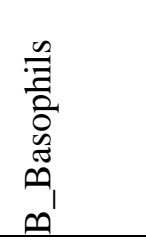 & 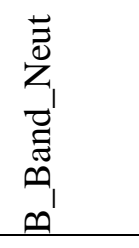 \\
\hline $\begin{array}{l}\text { SCC } \\
\text { Milk }\end{array}$ & 1 & 0.9979* & $0.9852 *$ & 0.7401* & 0.005 & 0.1734 & -0.1314 & -0.1336 & -0.036 & -0.1011 & 0.1043 \\
\hline $\begin{array}{l}\text { Neut } \\
\text { Milk }\end{array}$ & 0.9979* & 1 & $0.9795 *$ & $0.7221 *$ & 0.0052 & 0.1713 & -0.1297 & -0.1322 & -0.0329 & -0.0954 & 0.0967 \\
\hline $\begin{array}{l}\text { Lymph } \\
\text { Milk }\end{array}$ & $0.9852 *$ & $0.9795 *$ & 1 & $0.6417 *$ & 0.0222 & 0.2039 & -0.1315 & -0.1383 & -0.0554 & -0.1269 & 0.1021 \\
\hline Mono & $0.7401 *$ & $0.7221 *$ & $0.6417 *$ & 1 & -0.071 & 0.009 & -0.1047 & -0.0854 & 0.0339 & -0.0048 & 0.1416 \\
\hline WBC & 0.005 & 0.0052 & 0.0222 & -0.071 & 1 & $0.6536^{*}$ & $0.7156 *$ & $0.2391 *$ & $0.307 *$ & 0.1379 & 0.0659 \\
\hline B Neut & 0.1734 & 0.1713 & 0.2039 & 0.009 & $0.6536 *$ & 1 & -0.047 & 0.3018* & 0.1043 & -0.006 & 0.1976 \\
\hline B Lymph & -0.1314 & -0.1297 & -0.1315 & -0.1047 & $0.7156 *$ & -0.047 & 1 & -0.0383 & 0.1843 & 0.1146 & -0.1086 \\
\hline B Mono & -0.1336 & -0.1322 & -0.1383 & -0.0854 & 0.2391* & 0.3018* & -0.0383 & 1 & -0.0013 & 0.1621 & 0.0295 \\
\hline B Eosi & -0.036 & -0.0329 & -0.0554 & 0.0339 & $0.307 *$ & 0.1043 & 0.1843 & -0.0013 & 1 & $0.3394 *$ & -0.0041 \\
\hline $\begin{array}{l}\text { B Baso } \\
\text { B Band }\end{array}$ & -0.1011 & -0.0954 & -0.1269 & -0.0048 & 0.1379 & -0.006 & 0.1146 & 0.1621 & $0.3394 *$ & 1 & -0.0335 \\
\hline Neut & 0.1043 & 0.0967 & 0.1021 & 0.1416 & 0.0659 & 0.1976 & -0.1086 & 0.0295 & -0.0041 & -0.0335 & 1 \\
\hline
\end{tabular}

Milk and blood correlations 20-26 DIM. Pairwise correlation between pooled milk and blood constituents. SCC =somatic cell count, Neut $=$ neutrophils, Lymph =lymphocytes, Mono =monocytes, $W B C=$ total blood leukocytes, $B=b l o o d$, Eosi $=e o s i n o p h i l s$, Baso $=$ basophils, Band Neut =banded neutrophils. Benjimini-Hochberg critical value was used to adjust the alpha level due to multiple comparisons. Correlations shown with $p \leq 0.05$ indicated as $*$. 
Table 25: Milk and blood correlations 54-60 DIM

\begin{tabular}{|c|c|c|c|c|c|c|c|c|c|c|c|}
\hline & $\begin{array}{l}u \\
U \\
0\end{array}$ & 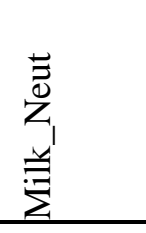 & 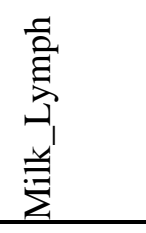 & 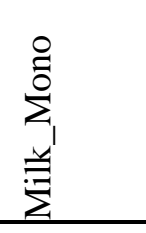 & $\sum_{3}^{0}$ & $\begin{array}{l}\vec{z}_{0} \\
z_{1} \\
\varphi_{1}\end{array}$ & 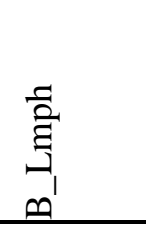 & $\begin{array}{l}\stackrel{0}{0} \\
\sum_{1}^{0} \\
\varrho^{\prime}\end{array}$ & $\begin{array}{l}\bar{v} \\
0 \\
\dot{I} \\
\underline{m}\end{array}$ & 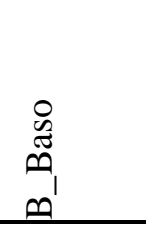 & 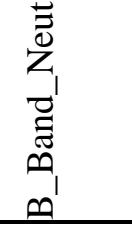 \\
\hline $\begin{array}{l}\text { SCC } \\
\text { Milk }\end{array}$ & 1 & $0.995 *$ & $0.983 *$ & 0.758* & -0.043 & $0.205^{*}$ & $-0.213 *$ & -0.1225 & -0.0949 & -0.0157 & $0.441 *$ \\
\hline $\begin{array}{l}\text { Neut } \\
\text { Milk }\end{array}$ & $0.995 *$ & 1 & $0.970 *$ & $0.699 *$ & -0.039 & $0.207 *$ & $-0.209 *$ & -0.1296 & -0.0962 & 0.0031 & $0.434 *$ \\
\hline $\begin{array}{l}\text { Lymph } \\
\text { Milk }\end{array}$ & $0.983 *$ & $0.970 *$ & 1 & 0.7337 & -0.0199 & $0.243^{*}$ & $-0.214 *$ & -0.1203 & -0.0911 & -0.05 & $0.450 *$ \\
\hline Mono & 0.758* & $0.699 *$ & 0.7337 & 1 & -0.1084 & 0.044 & -0.1734 & -0.0376 & -0.0639 & -0.0737 & $0.331 *$ \\
\hline WBC & -0.043 & -0.039 & -0.0199 & -0.1084 & 1 & $0.504 *$ & 0.7589 & $0.334 *$ & $0.197 *$ & $0.258 *$ & $0.297 *$ \\
\hline $\begin{array}{l}\text { B Neut } \\
\text { B }\end{array}$ & $0.205^{*}$ & $0.207 *$ & $0.243 *$ & 0.044 & $0.504 *$ & 1 & -0.1658 & 0.1033 & 0.0085 & -0.0564 & $0.330 *$ \\
\hline $\begin{array}{l}\text { Lymph } \\
\text { B }\end{array}$ & $-0.213 *$ & $-0.209 *$ & $-0.214 *$ & -0.1734 & 0.7589 & -0.1658 & 1 & $0.242 *$ & 0.114 & $0.29 *$ & 0.0405 \\
\hline Mono & -0.1225 & -0.1296 & -0.1203 & -0.0376 & $0.334 *$ & 0.1033 & $0.242 *$ & 1 & 0.029 & $0.227 *$ & 0.0975 \\
\hline B Eosi & -0.0949 & -0.0962 & -0.0911 & -0.0639 & $0.197 *$ & 0.0085 & 0.114 & 0.029 & 1 & 0.1254 & 0.0118 \\
\hline $\begin{array}{l}\text { B Baso } \\
\text { B Band }\end{array}$ & -0.0157 & 0.0031 & -0.05 & -0.0737 & $0.258 *$ & -0.0564 & $0.29 *$ & $0.227 *$ & 0.1254 & 1 & 0.122 \\
\hline Neut & $0.441 *$ & $0.434 *$ & $0.450 *$ & $0.331 *$ & $0.297 *$ & $0.330 *$ & 0.0405 & 0.0975 & 0.0118 & 0.122 & 1 \\
\hline
\end{tabular}

Milk and blood correlations 54-60 DIM. Pairwise correlation between pooled milk and blood constituents. SCC =somatic cell count, Neut $=$ neutrophils, Lymph =lymphocytes, Mono =monocytes, $W B C=$ total blood leukocytes, $B=$ blood, Eosi $=$ eosinophils, Baso $=$ basophils, Band Neut =banded neutrophils. Benjimini-Hochberg critical value was used to adjust the alpha level due to multiple comparisons. Correlations shown with $p \leq 0.05$ indicated as *. 
Table 26: Milk and blood correlations 90-96 DIM

\begin{tabular}{|c|c|c|c|c|c|c|c|c|c|c|c|}
\hline & U & $\begin{array}{l}\overrightarrow{\overline{0}} \\
\vec{z}_{1} \\
\bar{z} \\
\dot{z}\end{array}$ & 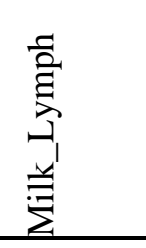 & 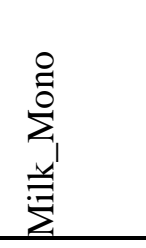 & $\sum_{z}^{0}$ & $\begin{array}{l}\vec{z}_{0} \\
z_{1} \\
n_{1}\end{array}$ & 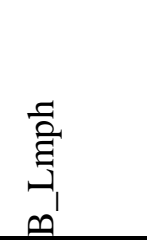 & $\begin{array}{l}0 \\
\sum_{1}^{0} \\
\infty\end{array}$ & 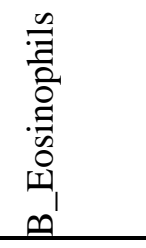 & 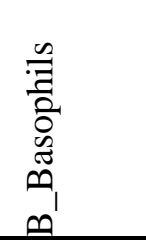 & 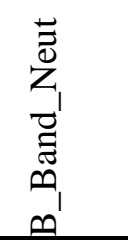 \\
\hline $\mathrm{SCC}$ & 1 & 0.9941 & 0.9606 & 0.8534 & -0.0957 & 0.0452 & -0.165 & -0.1902 & 0.2722 & -0.0669 & 0.288 \\
\hline $\begin{array}{l}\text { Milk Neut } \\
\text { Milk }\end{array}$ & 0.9941 & 1 & 0.9395 & 0.8104 & -0.0876 & 0.0427 & -0.1515 & -0.1942 & 0.2526 & -0.0646 & 0.2947 \\
\hline $\begin{array}{l}\text { Lymph } \\
\text { Milk }\end{array}$ & 0.9606 & 0.9395 & 1 & 0.7793 & -0.1161 & 0.0486 & -0.1966 & -0.1805 & 0.312 & -0.0404 & 0.2657 \\
\hline Mono & 0.8534 & 0.8104 & 0.7793 & 1 & -0.0834 & 0.0431 & -0.1479 & -0.1382 & 0.2484 & -0.1061 & 0.2179 \\
\hline WBC & -0.0957 & -0.0876 & -0.1161 & -0.0834 & 1 & 0.501 & 0.7474 & 0.1798 & 0.1656 & 0.1448 & 0.1803 \\
\hline B Neut & 0.0452 & 0.0427 & 0.0486 & 0.0431 & 0.501 & 1 & -0.1712 & 0.2364 & 0.1271 & 0.2473 & 0.1762 \\
\hline B Lymph & -0.165 & -0.1515 & -0.1966 & -0.1479 & 0.7474 & -0.1712 & 1 & -0.1049 & -0.0414 & -0.1052 & 0.0082 \\
\hline B Mono & -0.1902 & -0.1942 & -0.1805 & -0.1382 & 0.1798 & 0.2364 & -0.1049 & 1 & 0.0202 & 0.1678 & -0.086 \\
\hline B Eosi & 0.2722 & 0.2526 & 0.312 & 0.2484 & 0.1656 & 0.1271 & -0.0414 & 0.0202 & 1 & 0.2643 & 0.1208 \\
\hline $\begin{array}{l}\text { B Baso } \\
\text { B Band }\end{array}$ & -0.0669 & -0.0646 & -0.0404 & -0.1061 & 0.1448 & 0.2473 & -0.1052 & 0.1678 & 0.2643 & 1 & 0.2265 \\
\hline Neut & 0.288 & 0.2947 & 0.2657 & 0.2179 & 0.1803 & 0.1762 & 0.0082 & -0.086 & 0.1208 & 0.2265 & 1 \\
\hline
\end{tabular}

Milk and blood correlations 90-96 DIM. Pairwise correlation between pooled milk and blood constituents. SCC =somatic cell count, Neut = neutrophils, Lymph =lymphocytes, Mono =monocytes, WBC =total blood leukocytes, $B=$ blood, Eosi $=$ eosinophils, Baso $=$ basophils, Band Neut =banded neutrophils. Benjimini-Hochberg critical value was used to adjust the alpha level due to multiple comparisons. Correlations shown with $p \leq 0.05$ indicated as * . 


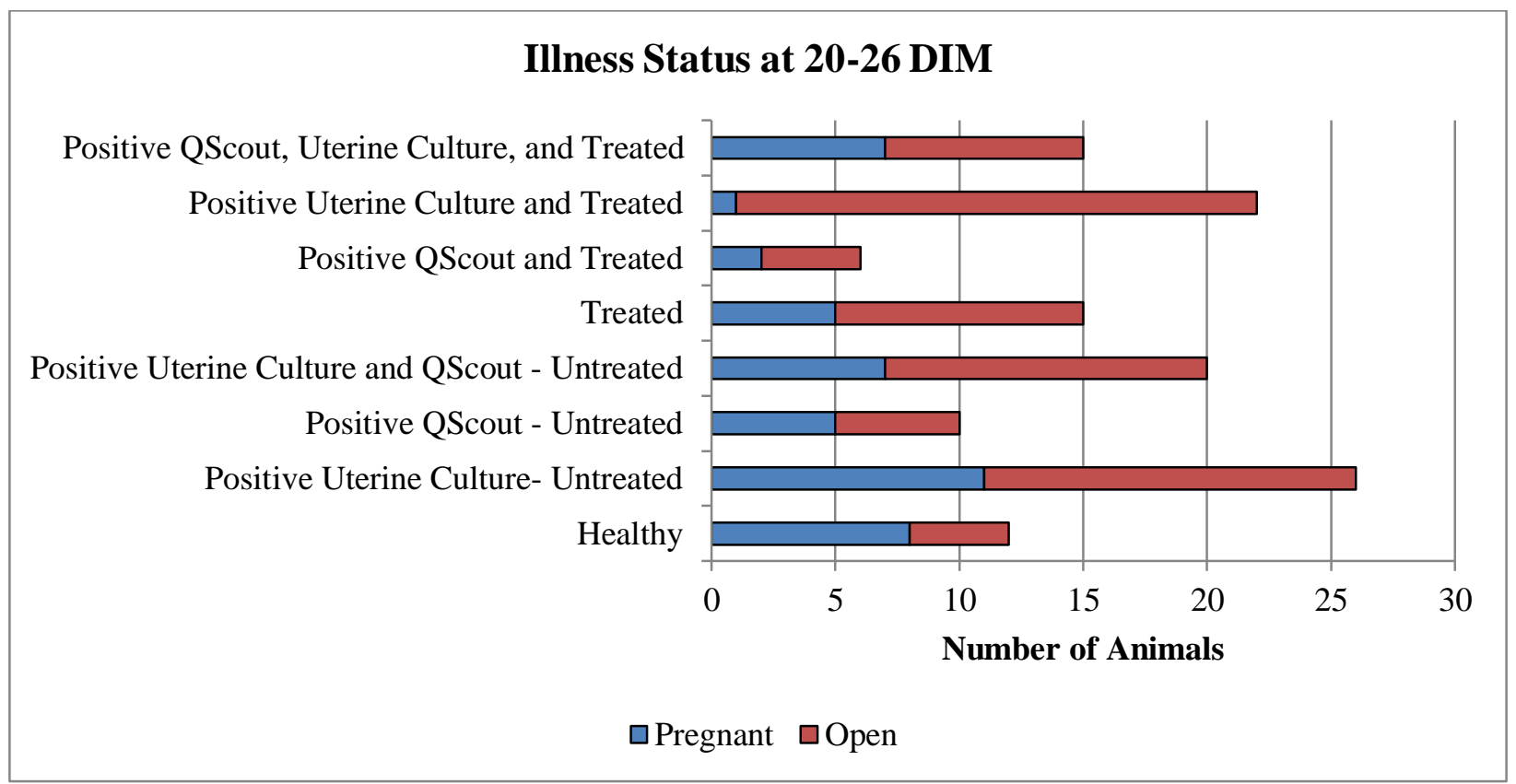

Figure 22: Illness Status 20-26 DIM by pregnancy status to first AI. Positive QScout = Positive diagnosis from QScout Farm Lab, Treated = cow treated by producer for one or multiple illnesses (structural, mammary, metabloic, reproductive, and infectious). 


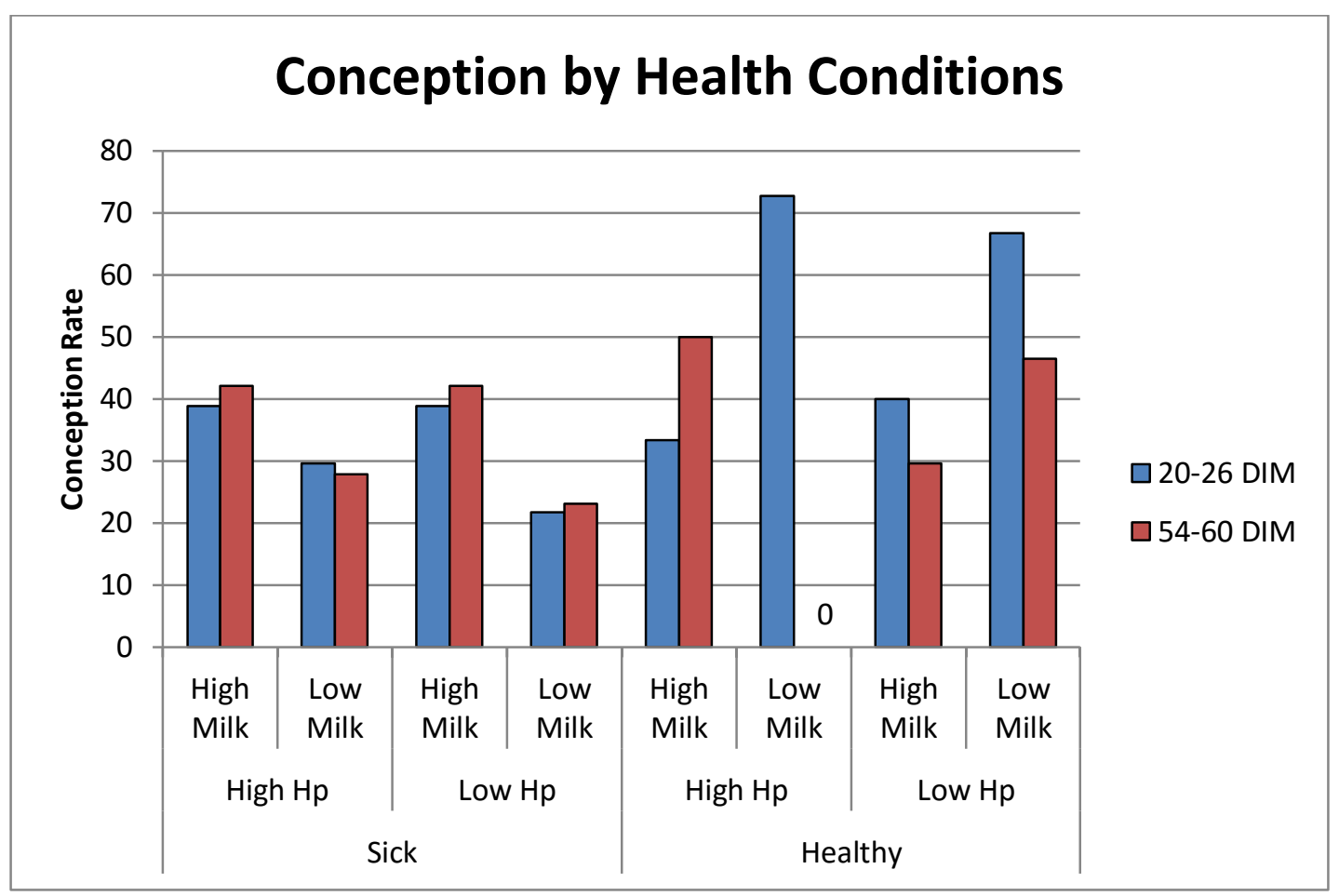

Figure 23: Conception rate by health factors clinical disease, plasma Hp concentration, and milk production. 20-26 DIM sick cattle High Hp/High Milk $n=18$, High Hp/Low Milk $n=27$, Low Hp/High Milk $n=20$, and Low Hp/Low Milk $n=23$. Healthy cattle High Hp/High Milk $n$ = 9, High Hp/Low Milk n= 11, Low Hp/High Milk $n=15$, and Low Hp/Low Milk n= 3. 54-60 DIM sick cattle High Hp/High Milk $n=19$, High Hp/Low Milk $n=18$, Low Hp/High Milk $n=$ 17, and Low Hp/Low Milk $n=13$. Healthy cattle High Hp/High Milk $n=2$, High Hp/Low Milk $n=2$, Low Hp/High Milk $n=27$, and Low Hp/Low Milk $n=28$. 


\section{References}

1922. The Dairy Business is Booming. Holstein-Friesian World, 21, 2249.

2008. NAHMS; National Animal Health Monitoring System Dairy 2007 study: part I. United States Department of Agriculture Animal and Plant Health Inspection Service.

2015. U.S. milk production and related data (quarterly). In: Hoskin, R. \& Cessna, J. (eds.) NASS Agricultural Prices and ERS Calculations. Livestock, Dairy, and Poultry Outlook.

Akers, K. A. 2014. Changes in body condition from prepartum to postpartum on health and reproduction in dairy cattle. Davis College of Agricultural, Natural Resource and Design. West Virginia University.

Alberts, B., Johnson, A., Lewis, J., Raff, M., Roberts, K. \& Walte, P. 2002. B Cells and Antibodies, 4th edn. Garland Science, New York.

Alluwamimi, A. M. 2004. The cytokine of bovine mammary gland: prospects for diagnosis and therapy. Research Veterinary Science, 711, 211-222.

Alsemgeest, S. P. M., Horadagoda, A., Hulskamp-Koch, C. K., Tooten, P. C. J., Kim, D. H., Niewold, T. H. A. \& Gruys, E. 1995. First evidence for the existence of multiple isoforms of bovine serum amyloid-A. Scand. Journal of Immunology, 41, 407-413.

Ametaj, B. N. 2005. A new understanding of the causes of fatty liver in dariy cows. Adv. Dairy Technol., 17, 97-112.

Archer, S. C., McCoy, F., Wapenaar, W. \& Green, M. J. 2013. Association between somatic cell count after first parturition and cumulative milk yeild in dairy cows. 173, 316.

Aronowski, J. \& Zhao, X. 2011. Molecular pathophysiology of cerebral hemorrhage: secondary brain injury. Stroke, 42, 1781-6.

Atamna, H. 2004. Heme, iron, and the mitochondrial decay of ageing. Ageing Research Reviews, 3, 303-318.

Banerjee, S., Jia, Y., Parker Siburt, C. J., Abraham, B., Wood, F., Bonaventura, C., Henkens, R., Crumbliss, A. L. \& Alayash, A. I. 2012. Haptoglobin alters oxygenation and oxidation of hemoglobin and decreases propagation of peroxide-induced oxidative reactions. Free Radical Biology and Medicine, 53, 1317-1326.

Barker, A. R., Schrick, F. N., Lewis, M. J., Dowlen, H. H. \& Oliver, S. P. 1998. Influence of clinical mastitis during early lactation on reproductive performance of Jersey cows. $J$ Dairy Sci, 81, 1285-90.

Barros, C. M., Betts, J. G., Thatcher, W. W., Hansen, P. J. 1992. Possible mechanisms for reduction of circulating concentrations of progesterone by interferon- $\alpha$ in cows: effects on hyperthermia, luteal cells, metabolism of progesterone and secretion of LH. $J$. Endocrinol. 133:175-182

Battaglia, D. F., J. M. Bowen, H. B. Krasa, L. A. Thrun, C. Viguie, and F. J. Karsch. 1996. 
Immune stress and reproductive neuroendocrine function: physiologic evidence for profound inhibition of GnRH secretion. Biol. Reprod. 54(Suppl. 1): 93.(Abstr.)

Battaglia,_D. F., Beaver, A. B., Harris, T. G., Tanhehco, E., Viguié, C. \& Karsch, F. J. 1999. Endotoxin Disrupts the Estradiol-Induced Luteinizing Hormone Surge: Interference with Estradiol Signal Reading, Not Surge Release. Endocrinology.

Battaglia, D. F., Krasa, H. B., Padmanabhan, V., Viguie, C. \& Karsch, F. J. 2000. Endocrine alterations that underlie endotoxin-induced disruption of the follicular phase in ewes. Biol Reprod, 62, 45-53.

Batra, T. R., Nonnechke, B. J., Newbould, F. H. S. \& Hacker, R. R. 1977. Incidence of Clinical Mastitis in a Herd of Holstein Cattle1. Journal of Dairy Science, 60, 1169-1172.

Bauman, D. E., B. W. Currie. 1980. Partitioning of Nutrients During Pregnancy and Lactation: A Review of Mechanisms Involving Homeostasis and Homeorhesis. Journal of Dairy Science, 63, 1514-1529.

Baumann, H. \& Gauldie, J. 1994. The acute phase response. Immunology Today, 15, 74-80.

Bertics, S. J., Grummer, R. R., Cadorniga-Valino, C. \& Stoddard, E. E. 1992. Effect of prepartum dry matter intake on liver triglyceride concentration and early lactation. $J$ Dairy Sci, 75, 1914-22.

Bertoni, G., Trevisi, E., Han, X., Bionaz, M. 2008. Effects of inflammatory conditions on liver activity in puerperium period and consequences for performance in dairy cows. J. Dairy Science, 91(9): 3300-3310.

Beutler, B. A. 2009. TLRs and innate immunity. Blood, 113, 1399-1407.

Bicalho, M. L. S., Machado, V. S., Oikonomou, G., Gilbert, R. O. \& Bicalho, R. C. 2012. Association between virulence factors of Escherichia coli, Fusobacterium necrophorum, and Arcanobacterium pyogenes and uterine diseases of dairy cows. Veterinary Microbiology, 157, 125-131.

Blum, J. W., Dosogne, H., Hoeben, D., Vangroenweghe, F., Hammon, H. M., Bruckmaier, R. M. \& Burvenich, C. 2000. Tumor necrosis factor-alpha and nitrite/nitrate responses during acute mastitis induced by Escherichia coli infection and endotoxin in dairy cows. Domest Anim Endocrinol, 19, 223-35.

Bochsler, P. N. \& Slauson, D. O. 2002. Inflammation and repair of tissue. In: Slauson, D. O. \& Cooper, B. J. (eds.) Mechanisms of disease: A textbook of comparative general pathology. Third ed. Mosby, St. Louis.

Bondurant, R. H. 1999. Inflammation in the bovine female reproductive tract. Journal of animal science, 77 Suppl 2, 101-110.

Bonnett, B. N., Martin, S. W., Gannon, V. P., Miller, R. B. \& Etherington, W. G. 1991. Endometrial biopsy in holsein-Friesian dairy cows. III. Bacteriological analysis and correlations with histological findings. Canadian Journal of Veterinary Research, 55, 
Bouchard, L., Blais, S., Desrosiers, C., Zhao, X. \& Lacasse, P. 1999. Nitric oxide production during endotoxin-induced mastitis in the cow. J Dairy Sci, 82, 2574-81.

Boutinaud, M. \& Jammes, H. 2002. Potential uses of milk epithelial cells: a review. Reprod Nutr Dev, 42, 133-47.

Bradley, A. 2002. Bovine mastitis: an evolving disease. Vet J, 164, 116-28.

Bradley, A. \& Green, M. 2005. Use and interpretation of somatic cell count data in dairy cows. In Practice, 27, 310-315.

Braun, R. K., Smith, R. D. 1980. Effect of calving and post-calving reproductive disorders on conception rate. Factors affecting conception rate. Dairy Integrated Reproductive Management, IRM-10.

Buehler, P. W., Abraham, B., Vallelian, F., Linnemayr, C., Pereira, C. P., Cipollo, J. F., Jia, Y., Mikolajczyk, M., Boretti, F. S., Schoedon, G., Alayash, A. I. \& Schaer, D. J. 2009. Haptoglobin preserves the CD163 hemoglobin scavenger pathway by shielding hemoglobin from peroxidative modification. Blood, 113, 2578-86.

Buford, W. I., Ahmad, N., Schrick, F. N., Butcher, R. L., Lewis, P. E. \& Inskeep, E. K. 1996. Embryotoxicity of a regressing corpus luteum in beef cows supplemented with progestogen. Biol Reprod, 54, 531-7.

Butt, B. M., Besser, T. E., Senger, P. L. \& Widders, P. R. 1993. Specific antibody to haemophilus somnus in the bovine uterus following intramuscular immunization. Infect Immun, 61: 2558-2562.

Capuco, A. V., Mein, G. A. \& Nickerson, S. C. 1994. Influence of pulsationless milking on teat canal keratin and mastitis. Journal of Dairy Science, 77, 64-74.

Csapo, A. I., 1956. The relation of threshold to the K gradient in the myometrium. $J$. of Physiology, 133:145-158.

Cebra, C.K., F.B. Garry, R.P. Dinsmore. 1996. Natually occurring acute coliform mastitis in Holstein cattle. J. Vet. Intern. Med. 10:252-257

Ceron, J. J., Eckersall, P. D. \& Martynez-Subiela, S. 2005. Acute phase proteins in dogs and cats: current knowledge and future perspectives. Vet Clin Pathol, 34, 85-99.

Chan, J. P., Chang, C. C., Hsu, W. L., Liu, W. B. \& Chen, T. H. 2010. Association of increased serum acute-phase protein concentrations with reproductive performance in dairy cows with postpartum metritis. Vet Clin Pathol, 39, 72-8.

Chen, G. Y. \& Nuñez, G. 2010. Sterile inflammation: sensing and reacting to damage. Nature Reviews Immunology, 10, 826-837.

Chew, B. P., Erb, R. E., Fessler, J., Callahan, C. J. \& Malven, P. V. 1979. Effects of 
Ovariectomy during Pregnancy and of Prematurely Induced Parturition on Progesterone, Estrogens, and Calving Traits1. Journal of Dairy Science, 62, 557-566.

Clemens, L. E., Siiteri, P. K. \& Stites, D. P. 1979. Mechanism of immunosuppression of progesterone on maternal lymphocyte activation during pregnancy. J Immunol, 122, 1978-85.

Concha, C. 1986. Cell types and their immunological functions in bovine mammary tissues and secretions- a review of the literature. Nord Veterinaermed 38.

Coleman, D. A., Thayne, W. V., Dailey, R. A. 1985. Factors affecting reproductive performance of dairy cows. J. Dairy Sci., 68:1793-1803.

Cooray, R., Waller, K. P. \& Venge, P. 2007. Haptoglobin comprises about $10 \%$ of granule protein extracted from bovine granulocytes isolated from healthy cattle. Veterinary Immunology and Immunopathology, 119, 310-315.

Corbeil, L. B., Schurig, G. D., Duncan, J. R., Corbeil, R. R. \& Winter, A. J.

1974. Immunoglobulin classes and biological functions of Campylobacter (Vibrio) fetus antibodies in serum and cervicovaginal mucus. Infect Immun, 10(3): 422-429.

Crawford, R. G., Leslie, K. E., Bagg, R., Disck, C. P., Duffield, T. F., 2005. The impact of controlled release capsules of monensin on postcalving haptoglobin concentrations in dairy cattle. Can. J. Vet. Res.,69:208-214.

Cullens, F. M. 2005. Effects of the timing of initiation of fat supplementation on productive and reproductive response of periparturient dairy cows during summer. University of Florida.

D'Armiento, J., Dalal, S. S. \& Chada, K. 1997. Tissue, temporal and inducible expression pattern of haptoglobin in mice. Gene, 195, 19-27.

Darbon, J. M., Oury, F., Laredo, J. \& Bayard, F. 1989. Tumor necrosis factor - $\alpha$ inhibits folliclestimulating hormone-induced differentiation in cultured rat granulosa cells. Biochemical and Biophysical Research Communications, 163, 1038-1046.

Dego, O. K., Gijk, J. E. \& Neberbragt, H. 2002. Factors involved in the early pathogenesis of bovine Staphlococcus aureus mastitis with emphasis on bacterial adhesion and invasion. Vet Quart., 24, 181-198.

Del Vecchio, R. P., Matsas, D. J., Inzana, T. J., Sponenberg, D. P. \& Lewis, G. S. 1992. Effect of intrauterine bacterial infusions and subsequent endometritis on prostaglandin F2 alpha metabolite concentrations in postpartum beef cows. Journal of animal science, 70, 31583162.

Demetrio, D. G. B., Santos, R. M., Demetrio, C. G. \& Vasconcelos, J. L. 2007. Factors affecting conception rates following artificial insemination or embryo transfer in lactation Holstein cows. Journal of Dairy Science.

Detilleux, J. C., Kehrli Jr, M. E., Stabel, J. R., Freeman, A. E. \& Kelley, D. H. 1995. Study of immunological dysfunction in periparturient Holstein cattle selected for high and average 
milk production. Veterinary Immunology and Immunopathology, 44, 251-267.

Dosogne, H., Burvenich, C. \& Lohuis, J. A. 1999. Acyloxyacyl hydrolase activity of neutrophil leukocytes in normal early postpartum dairy cows and in cows with retained placenta. Theriogenology, 51, 867-74.

Dulin, A. M., Paape, M. J., Schultze, W. D. \& Weinland, B. T. 1983. Effect of parity, stage of lactation, and intramammary infection on concentration of somatic cells and cytoplasmic particles in goat milk. J Dairy Sci, 66, 2426-33.

Ealy, A. D., Drost, M. \& Hansen, P. J. 1993. Developmental changes in embryonic resistance to adverse effects of maternal heat stress in cows. J Dairy Sci, 76, 2899-905.

Eckersall, P. D. \& Conner, J. G. 1990. Plasma haptoglobin in cattle (Bos taurus) exists as polymers in association with albumin. Comparative Biochemistry and Physiology Part B: Comparative Biochemistry, 96, 309-314.

Eckersall, P. D., Young, F. J., McComb, C., Hogarth, C. J., Safi, S., Weber, A., McDonald, T., Nolan, A. M. \& Fitzpatrick, J. L. 2001. Acute phase proteins in serum and milk from dairy cows with clinical mastitis. Vet Rec, 148, 35-41.

Edgerton, L. A. \& Hafs, H. D. 1973. Serum Luteinizing Hormone, Prolactin, Glucocorticoid, and Progestin in Dairy Cows from Calving to Gestation1. Journal of Dairy Science, 56, 451458.

Edqvist, L.-E., Kindahl, H. \& Stabenfeldt, G. 1978. Release of prostaglandin F2 $\alpha$ during the bovine peripartal period. Prostaglandins, 16, 111-119.

Edwards, J. L. \& Hansen, P. J. 1997. Differential responses of bovine oocytes and preimplantation embryos to heat shock. Molecular Reproduction and Development, 46, 138-145.

El-Din. Zain, A., Nakao, T., Abdel Raouf, M., Moriyoshi, M., Kawata, K. \& Moritsu, Y. 1995. Factors in the resumption of ovarian activity and uterine involution in postpartum dairy cows. Animal Reproduction Science, 38, 203-214.

Eley, D. S., Thatcher, W. W., Head, H. H., Collier, R. J., Wilcox, C. J. \& Call, E. P. 1981. Periparturient and postpartum endocrine changes of conceptus and maternal units in Jersey cows bred for milk yield. J Dairy Sci, 64, 312-20.

Emmanuel, D. G. V., Dunn, S. M. \& Ametaj, B. N. 2008. Feeding High Proportions of Barley Grain Stimulates an Inflammatory Response in Dairy Cows. Journal of Dairy Science, 91, 606-614.

Esposito, G., Irons, P. C., Webb, E. C. \& Chapwanya, A. 2014. Interactions between negative balance, metabolic diseases, uterine health and immune response in transition dairy cows. Animal Reproduction Science, 144, 60-71.

Etzerodt, A., Kjolby, M., Nielsen, M. J., Maniecki, M., Svendsen, P. \& Moestrup, S. K. 2013. Plasma clearance of hemoglobin and haptoglobin in mice and effect of CD163 gene 
targeting disruption. Antioxid Redox Signal, 18, 2254-63.

Etzerodt, A. \& Moestrup, S. K. 2013. CD163 and inflammation: biological, diagnostic, and therapeutic aspects. Antioxid Redox Signal, 18, 2352-63.

Freeman, M., Ashkenas, J., Rees, D. J., Kingsley, D. M., Copeland, N. G., Jenkins, N. A. \& Krieger, M. 1990. An ancient, highly conserved family of cysteine-rich protein domains revealed by cloning type I and type II murine macrophage scavenger receptors. Proc Natl Acad Sci U S A, 87, 8810-4.

Galvao, K. N., Frajblat, M., Butler, W. R., Brittin, S. B., Guard, C. L., Gilbert, R. O. 2010. Feefect of early postpartum on ovulation in dairy cows. Reprod Dom Anim, 45:207-211.

Gier, H. T. \& Marion, G. B. 1968. Uterus of the cow after parturition: involutional changes. Am $J$ Vet Res, 29, 83-96.

Gilbert, R. O., Bosu, W. T. K. \& Peter, A. T. 1990. The effect of Escherichiacoli endotoxin on luteal function in Holstein heifers. Theriogenology, 33, 645-651.

Giri, S. N., Chen, Z., Carroll, E. J., Mueller, R., Schiedt, M. J. \& Panico, L. 1984. Role of prostaglandins in pathogenesis of bovine mastitis induced by Escherichia coli endotoxin. Am J Vet Res, 45, 586-91.

Goff, J. P. \& Horst, R. L. 1997. Physiological changes at parturition and their relationship to metabolic disorders. J Dairy Sci, 80, 1260-8.

Goff, J. P., Horst, R. L. \& Reinhardt, T. A. 1987. The pathophysiology and prevention of milk fever. Veterinary Medicine, 82, 943-950.

Goff, J. P., Kehrli, M. E., Jr. \& Horst, R. L. 1989. Periparturient hypocalcemia in cows: prevention using intramuscular parathyroid hormone. J Dairy Sci, 72, 1182-7.

Golden, B. L., Garrick, D. J. \& Benyshek, L. L. 2009. Milestones in beef cattle genetic evaluation. Journal of Animal Science, 87, E3-E10.

Griffin, T. K., Grindal, R. J., Bramley, A. J. 1988. A multi-valved milking machine cluseter to control intramammary infection in dariy cows. J. of Dairy Res., 55(2): 155-169.

Gronlund, U., Hallen Sandgren, C. \& Persson Waller, K. 2005. Haptoglobin and serum amyloid A in milk from dairy cows with chronic sub-clinical mastitis. Vet Res, 36, 191-8.

Gruys, E., Toussaint, M. J. M., Niewold, T. A. \& Koopmans, S. J. 2005. Acute phase reaction and acute phase proteins. J Zhejiang Univ Sci. B., 6(11): 1045-1056.

Guilbault, L. A., Thatcher, W. W., Collier, R. J., Wilcox, C. J. \& Drost, M. 1985. Carry-over effects of periparturient endocrine changes on postpartum reproductive function of Holstein heifers bred to genetically different service sires. J Anim Sci, 61, 1516-26.

Guilbault, L. A., Thatcher, W. W., Drost, M. \& Hopkins, S. M. 1984a. Source of F series prostaglandins during the early postpartum period in cattle. Biol Reprod, 31, 879-87. 
Guilbault, L. A., Thatcher, W. W., Foster, D. B. \& Caton, D. 1984b. Relationship of 15-keto-13, 14-dihydro-prostaglandin $\mathrm{F}_{2 \alpha}$ concentrations in peripheral plasma with local uterine production of $\mathrm{F}$ series prostaglandins and changes in uterine blood flow during the early postpartum period of cattle. $31,870-878$.

Gymnich, S., Hiss, S., Sauerwein, H. \& Petersen, B. 2003. Haptoglobin in sows at parturition. 4th European Colloquium on Acute Phase Proteins. Segovia, Spain.

Hachenberg, S., Weinkauf, C., Hiss, S. \& Sauerwein, H. 2007. Evaluation of classification modes potentially suitable to identify metabolic stress in healthy dairy cows during the peripartial period. Journal of Animal Science, 85, 1923-1932.

Hammon, D. S., Evjen, I. M., Dhiman, T. R., Goff, J. P. \& Walters, J. L. 2006. Neutrophil function and energy status in Holstein cows with uterine health disorders. Vet Immunol Immunopathol, 113, 21-9.

Hansen, P. J., Soto, P. \& Natzke, R. P. 2004. Mastitis and fertility in cattle- Possible Involvement of inflammation or immune activation in embryonic mortality. American Journal of Reproductive Immunology, 51, 294-301.

Harmon, R. J. 1994. Physiology of mastitis and factors affecting somatic cell counts. Journal of Dairy Science, 77, 2103-2112.

Hayirli, A., Grummer, R. R., Nordheim, E., Crump, P., Beede, D. K., VandeHaar, M. J. \& Kilmer, L. H. 1998. A mathematical model for describing dry matter intake of transition dairy cows. Journal of Dairy Science, 81, 296.

Hayirli, A., Grummer, R. R., Nordheim, E. V. \& Crump, P. M. 2002. Animal and dietary factors affecting feed intake during the prefresh transition period in Holsteins. J Dairy Sci, 85, 3430-43.

Heuwieser, W., Tenhagen, B. A., Tischer, M., Luhr, J. \& Blum, H. 2000. Effect of three programmes for the treatment of endometritis on the reproductive performance of a dairy herd. Veterinary Record, 146, 338-341.

Hirvonen, J., Eklund, K., Teppo, A. M., Huszenicza, G., Kulcsar, M., Saloniemi, H. \& Pyorala, S. 1999. Acute phase response in dairy cows with experimentally induced Escherichia coli mastitis. Acta Vet Scand, 40, 35-46.

Hisatsune, T., Enomoto, A., Nishijima, K., Minai, Y., Asano, Y., Tada, T. \& Kaminogawa, S. 1990. CD8+ suppressor T cell clone capable of inhibiting the antigen-and anti-T cell receptor-induced proliferation of Th clones without cytolytic activity. The Journal of Immunology, 145, 2421-2426.

Hiss, S., Mielenz, M., Bruckmaier, R. M. \& Sauerwein, H. 2004. Haptoglobin Concentrations in Blood and Milk After Endotoxin Challenge and Quantification of Mammary Hp mRNA Expression. Journal of Dairy Science, 87, 3778-3784.

Hiss, S., Weinkauf, C., Hachenberg, S. \& Sauerwein, H. 2009. Short communication: Relationship between metabolic status and the milk concentrations of haptoglobin and 
lactoferrin in dairy cows during early lactation. J Dairy Sci, 92, 4439-43.

Hobbs, A. J., Higgs, A. \& Moncada, S. 1999. Inhibition of nitric oxide synthase as a potential therapeutic target. Annu Rev Pharmacol Toxicol, 39, 191-220.

Hockett, M. E., Almeida, R. A., Rohrbach, N. R., Oliver, S. P., Dowlen, H. H. \& Schrick, F. N. 2005. Effects of Induced Clinical Mastitis During Preovulation on Endocrine and Follicular Function. Journal of Dairy Science, 88, 2422-2431.

Hockett, M. E., Hopkins, F. M., Lewis, M. J., Saxton, A. M., Dowlen, H. H., Oliver, S. P. \& Schrick, F. N. 2000. Endocrine profiles of dairy cows following experimentally induced clinical mastitis during early lactation. Anim Reprod Sci, 58, 241-51.

Hockett, M. E., Rohrbach, N. R., Almeida, R. A., Dowlen, H. H., Lamar, K., Oliver, S. P. \& Schrick, F. N. 2002. Effects of experimentally-induced clinical mastitis on estrous behavior, luteal function, and establishment of pregnancy during early lactation of dairy cows., Journal of Animal Science.

Hoeben, D., Burvenich, C., Trevisi, E., Bertoni, G., Hamann, J., Bruckmaier, R. M. \& Blum, J. W. 2000a. Role of endotoxin and TNF-alpha in the pathogenesis of experimentally induced coliform mastitis in periparturient cows. J Dairy Res, 67, 503-14.

Hoeben, D., Monfardini, E., Opsomer, G., Burvenich, C., Dosogne, H., De Kruif, A. \& Beckers, J. F. 2000b. Chemiluminescence of bovine polymorphonuclear leucocytes during the periparturient period and relation with metabolic markers and bovine pregnancyassociated glycoprotein. J Dairy Res, 67, 249-59.

Hoffmann, B., Schams, D., Gimenez, T., Ender, M. L., Herrmann, C. L., Karg, H. 1973. Changes of progesterone, total oestrogens, corticoids, prolactin and LH in bovine peripheral plasma around parturition with special reference to the effect of exogenous corticoids and a prolactin inhibitor respectively. Acta endocr. Copenh, 73:385-395.

Holtenius, K., Agenäs, S., Delavaud, C. \& Chilliard, Y. 2003. Effects of Feeding Intensity During the Dry Period. 2. Metabolic and Hormonal Responses. Journal of Dairy Science, $86,883-891$.

Horadagoda, N. U., Knox, K. M. G., Gibbs, H. A., Reid, S. W. J., Horadagoda, A., Edwards, S. E. R. \& Eckersall, P. D. 1999. Acute phase proteins in cattle: discrimination between acute and chronic inflammation. Veterinary Record, 144.

Humblet, M. F., Guyot, H., Boudry, B., Mbayahi, F., Hanzen, C., Rollin, F. \& Godeau, J. M. 2006. Relationship between haptoglobin, serum amyloid A, and clinical status in a survey of dairy herds during a 6-month period. Vet. Clin. Pathol., 36, 188-193.

Huzzey, J. M., Duffield, T. F., LeBlanc, S. J., Veira, D. M., Weary, D. M. \& von Keyserlingk, M. A. 2009. Short communication: Haptoglobin as an early indicator of metritis. J Dairy Sci, 92, 621-5.

Huzzey, J. M., Mann, S., Nydam, D. V., Grant, R. J. \& Overton, T. R. 2015. Associations of peripartum markers of stress and inflammation with milk yield and reproductive 
performance in Holstein dairy cows. Prev Vet Med, 120, 291-7.

Izaike, Y. 1990. Effect of suckling and milk yield on postpartum ovarian activity and uterine involution in grazing beef cows. Japan Agricultural Research Quarterly, 24, 209-215.

Jackson, J. A., Shuster, D. E., Silvia, W. J. \& Harmon, R. J. 1990. Physiological responses to intramammary or intravenous treatment with endotoxin in lactating diary cows. J. Dairy Sci., 73(3): 627-632.

Jacobsen, S., Toelboell, T. \& Andersen, P. H. 2004. Does dependency and individual variability in selected clinical, haematological and blood biochemical responses after systemic lipopolysaccharide challenge in cattle. Veterinary Research, 36, 167-178.

Jain, N. C. 1993. Essentials of Veterinary Hemotology, 1 edn. Wiley-Blackwell.

Johnson, J. D., Campisi, J., Sharkey, C. M., Kennedy, S. L., Nickerson, M., Greenwood, B. N. \& Fleshner, M. 2005. Catecholamines mediate stress-induced increases in peripheral and central inflammatory cytokines. Neuroscience, 135, 1295-307.

Jones, M. J., Allison, R. W. 2007. Evaluation of the ruminant complete blood cell count. Veterinary Clinics of North America: Food Animal Practice, 23(3): 377-402.

Kasimanickam, R., T. F. Duffield, R. A. Foster, C. J. Gartley, K. E. Leslie, J. S. Walton, W. H. Johnson. 2005. A comparison of the cytobrush and uterine lavage techniques to evaluate endometrial cytology in clinically normal postpartum dairy cows. Can. Vet. J. 46:255259.

Kehrli, M. E., Jr., Nonnecke, B. J. \& Roth, J. A. 1989. Alterations in bovine neutrophil function during the periparturient period. Am J Vet Res, 50, 207-14.

Kelley, K. W., Johnson, R. W. \& Dantzer, R. 1994. Immunology discovers physiology. Vet Immunol Immunopathol, 43, 157-65.

Khoshvaghti, A., Nazifi, S., Vafafar, A. \& Gheisari, H. R. 2009. Evaluation of serum and milk haptoglobin in some inflammatory diseases of cattle. International Journal Veterinary Research, 3, 31-36.

Kim, H., Hawley, T. S., Hawley, R. G. Baumann, H. 1998. Protein tyrosine phosphate 2 moderates signaling by gp130 but is not required for the induction of acute-phase plasma protein genes in hepatic cells. Mol. Cell Biol., 18(3): 1525-1533.

Kim, E. S. \& Kirkpatrick, B. W. 2009. Linkage disequilibrium in the North American Holstein population. Anim Genet, 40, 279-88.

Kim, M. H., Yang, J. Y., Upadhaya, S. D., Lee, H. J., Yun, C. H. \& Ha, J. K. 2011. The stress of weaning influences serum levels of acute-phase proteins, iron-binding proteins, inflammatory cytokines, cortisol, and leukocyte subsets in Holstein calves. J Vet Sci, 12, $151-7$.

Koets, A. P., N. de Schwartz, P. Tooten, M. Kankofer, J. M. Broekhuijsen-Davies, V. P. M. G. 
Rutten, L. A. M. G. van Leegoed, M. A. M. Taverne, E. Gruys. 1998. Release of proinflammatory cytokines related to prostaglandin-induced parturition in cows. Therogenology. 49:797-812.

Kovac, G., Tothoca, C., Oskar, N. \& Seidel, H. 2011. Milk amyloid A and selected serum proteins in cows suffering from mastitis. 80, 3-9.

Krause, A. R. T., Pfeifer, L. F. M., Montagner, P., Weschenfelder, M. M., Schwegler, E., Lima, M. E., Xavier, E. G., Brauner, C. C., Schmitt, E., Del Pino, F. A. B., Martins, C. F., Correa, M. N. \& Schneider, A. 2014. Associations between resumption of postpartum ovarian activity, uterine health and concentrations of metabolites and acute phase proteins during the transition period in Holstein cows. Animal Reproductive Science, 145, 8-15.

Kristiansen, M., Graversen, J. H., Jacobsen, C., Sonne, O., Hoffman, H. J., Law, S. K. \& Moestrup, S. K. 2001. Identification of the haemoglobin scavenger receptor. Nature, 409, 198-201.

Kujjo, L. L., Bosu, W. T. K. \& Perez, G. I. 1995. Opioid peptides involvement in endotoxininduced suppression of LH secretion in ovariectomized holstein heifers. Reproductive Toxicology, 9, 169-174.

Kunz, P. L., Blum, J. W., Hart, I. C., Bickel, H. \& Landis, J. 1985. Effects of different energy intakes before and after calving on food intake, performance and blood hormones and metabolites in dairy cows. Animal Production, 40, 219-231.

Kurash, J. K., Shen, C. N. \& Tosh, D. 2004. Induction and regulation of acute phase proteins in transdifferentiated hepatocytes. Exp Cell Res, 292, 342-58.

Lai, I. H., Tsao, J. H., Lu, Y. P., Lee, J. W., Zhao, X., Chien, F. L. \& Mao, S. J. 2009. Neutrophils as one of the major haptoglobin sources in mastitis affected milk. Vet Res, 40, 17.

Lai, Y. A., Lai, I. H., Tseng, C. F., Lee, J. \& Mao, S. J. 2007. Evidence of tandem repeat and extra thiol-groups resulted in the polymeric formation of bovine haptoglobin: a unique structure of Hp 2-2 phenotype. J Biochem Mol Biol, 40, 1028-38.

Langlois, M. R. \& Delanghe, J. R. 1996. Biological and clinical significance of haptoglobin polymorphism in humans. Clin Chem, 42, 1589-600.

Lauderdale, J. W., Graves, W. E., Hauser, E. R., Casida, L.E. 1968. Relation of postpartum interval to corpus luteum development, pituitary prolactin activity, and uterine involution in beef cows. (Effect of suckling and interval to breeding). Univ. Wisconsin Res. Bull. 270:42-48.

Lavery, K., Gabler, C., Day, J. \& Killian, G. 2004. Expression of haptoglobin mRNA in the liver and oviduct during the oestrous cycle of cows (Bos taurus). Animal Reproduction Science, 84, 13-26.

LeBlanc, S. J., Duffield, T. F., Leslie, K. E., Bateman, K. G., Keefe, G. P., Walton, J. S. \& Johnson, W. H. 2002. The effect of treatment of clinical endometritis on reproductive 
performance in dairy cows. Journal of Dairy Science, 85, 2237-2249.

Lee, C. S., Wooding, F. B. \& Kemp, P. 1980. Identification, properties, and differential counts of cell populations using electron microscopy of dry cows secretions, colostrum and milk from normal cows. Journal of Dairy Research, 47, 39-50.

Levy, A. P., Asleh, R., Blum, S., Levy, N. S., Miller-Lotan, R. \& Kalet-Litman, S. 2010. Haptoglobin: basic and clinical aspects. Antioxidants \& Redox Signaling, 12, 293-304.

Lewis, G. S. 2003a. Steroidal regulation of uterine resistance to bacterial infection in livestock. Reproductive Biology and Endocrinology, 1, 117.

Lewis, G. S. 2003b. Role of ovarian progesterone and potential role of prostaglandin F2alpha and prostaglandin E2 in modulating the uterine response to infectious bacteria in postpartum ewes. J Anim Sci, 81, 285-93.

Lim, S.-K., Kim, H., Lim, S. K., Ali, A. b., Lim, Y. K., Wang, Y., Chong, S. M., Costantini, F. \& Baumman, H. 1998. Increased Susceptibility in Hp Knockout Mice During Acute Hemolysis. Blood, 92, 1870-1877.

Lin, Y., Xia, L., Turner, J. D. \& Zhao, X. 1995. Morphologic observation of neutrophil diapedesis across bovine mammary gland epithelium in vitro. American Journal of Veterinary Research, 56, 203-207.

Lindell, J. O., Kindahl, H., Jansson, L. \& Edqvist, L. E. 1982. Post-partum release of prostaglandin F2 $\alpha$ and uterine involution in the cow. Theriogenology, 17, 237-245.

Lipperheide, C., Gothe, C., Peterson, B. \& Sommer, H. 1997. Nephelometric assay of haptoglobin in blood plasma from cattle, pigs, horses. Tierarztl, 52, 420-426.

Lush, J. L., Holbert, J. C. \& Willham, O. S. 1936. Genetic history of the holstein-friesian cattle in the United States. Journal of Heredity, 27, 61-72.

Machado, V. S., Bicalho, M. L., Pereira, R. V., Caixeta, L. S., Bittar, J. H., Oikonomou, G., Gilbert, R. O. \& Bicalho, R. C. 2012. The effect of intrauterine administration of mannose or bacteriophage on uterine health and fertility of dairy cows with special focus on Escherichia coli and Arcanobacterium pyogenes. J Dairy Sci, 95, 3100-9.

Machado, V. S., Bicalho, M. L., de Souza Meria, E. B., Rossi, R., Ribeiro, B. L., Lim, S., Santos, T., Kussler, A., Foditsch, C., Ganda, E. K., Okionomou, G., Cheong, S. H., Gilbert, R. O., Bicalho, R. C. 2014. Subcutaneous immunization with inactivated bacterial components and purified protein of Escherichia coli, Fusobacterium necrophorum, and Trueperella pyrogenes prevents puerperal metritis in Holstein dairy cows. PLoS ONE 9(3): e91734.

Mackiewicz, A. 1997. Acute phase proteins and transformed cells. Int Rev Cytol, 170, 225-300.

Madej, A., Kindahl, H., Woyno, W., Edqvist, L. E. \& Stupnicki, R. 1984. Blood levels of 15keto-13, 14-dihydroprostaglandin F2 $\alpha$ during the postpartum period in primiparous cows. Theriogenology, 21, 279-287. 
Madsen, M., Moller, H. J., Nielsen, M. J., Jacobsen, C., Graversen, J. H., van den Berg, T. \& Moestrup, S. K. 2004. Molecular characterization of the haptoglobin.hemoglobin receptor CD163. Ligand binding properties of the scavenger receptor cysteine-rich domain region. J Biol Chem, 279, 51561-7.

Martinez, N., Risco, C. A., Lima, F. S., Bisinotto, R. S., Greco, L. F., Ribeiro, E. S., Maunsell, F., Galvao, K. \& Santos, J. E. 2012. Evaluation of peripartal calcium status, energetic profile, and neutrophil function in dairy cows at low or high risk of developing uterine disease. J Dairy Sci, 95, 7158-72.

McCann, S. M., Kimura, M., Karanth, S., Yu, W. H., Mastronardi, C. A. \& Rettori, V. 2000. The mechanism of action of cytokines to control the release of hypothalamic and pituitary hormones in infection. Ann N Y Acad Sci, 917, 4-18.

Merrill, W. G. \& Smith, V. G. 1954. A comparison of some cellular and chemical constituents of blood at time of parturition and after administration of adrenocorticotrophin. Journal of Dairy Science, 37, 546-551.

Morillo, F. J. \& Legates, J. E. 1970. Genetic Differences Among Holstein-Friesian Herd Improvement Registry Herds1. Journal of Dairy Science, 53, 908-912.

Morimatsu, M., Syuto, B., Shimada, N., Fujinaga, T., Yamamoto, S., Saito, M. \& Naiki, M. 1991. Isolation and characterization of bovine haptoglobin from acute phase sera. J Biol Chem, 266, 11833-7.

Moshage, H. 1997. Cytokines and the hepatic acute phase response. J Pathol, 181, 257-66.

Murata, H. 2007. Stress and acute phase protein response: an inconspicuous but essential linkage. Vet $J$. England.

Murphy, K. 2012. Janeway's Immunobiology, 8th edn. Garland Science, New York, NY.

Murray, R. D., Allison, J. D. \& Gard, R. P. 1990. Bovine endometritis: Comparative efficacy of alfaprostol and intrauterine therapies, and other factors influencing clinical success. Veterinary Record, 127, 86-90.

Nakagawa, H., Yamamoto, O., Oikawa, S., Higuchi, H., Watanabe, A. \& Katoh, N. 1997. Detection of serum haptoglobin by enzyme-linked immunosorbent assay in cows with fatty liver. Research in Veterinary Science, 62, 137-141.

Nakajima, Y., Mikami, O., Yoshioka, M., Motoi, Y., Ito, T., Ishikawa, Y., Fuse, M., Nakano, K. \& Yasukawa, K. 1997. Elevated levels of tumor necrosis factor-alpha (TNF-alpha) and interleukin-6 (IL-6) activities in the sera and milk of cows with naturally occurring coliform mastitis. Res Vet Sci, 62, 297-8.

Nazifi, S., Ahmadi, M. R. \& Gheisari, H. R. 2008. Hematological changes of dairy cows in postpartum period and early pregnancy. Comp Clin Pathol, 17, 157-163.

Nickerson, S. C. 1987. Resistance mechanisms of the bovine udder: New implications for 
mastitis control at the teat end. Journal of the American Veterinary Medical Association, 191, 1484-1488.

Nickerson, S. C., Heald, C. W. 1982. Ceils in local reaction to experimental Staphylococcus aureus infection in the bovine mammary gland. J. Dairy Sci. 65:105.

Nielsen, M. J. \& Moestrup, S. K. 2009. Receptor targeting of hemoglobin mediated by the haptoglobins: roles beyond heme scavenging. Blood, 114, 764-71.

Nielsen, B. H., S. Jacobsen, P.H. Anderson, T.A. Niewold, P.M.H Heegaard. 2004. Acute phase protein concentrations in serum and milk from healthy cows, cows with clinical mastitis and cows with extramammary inflammatory conditions. Vet. Rec. 154:361-365.

Niewold, T. A., Tousaint, M. J. \& Gruys, E. 2003. Monitoring health by acute phase proteins. 4th European colloquim on acute phase proteins. Colloquium, Segovia Spain.

Nightingale, C. R., Sellers, M. D. \& Ballou, M. A. 2015. Elevated plasma haptoglobin concentrations following parturition are associated with elevated leukocyte responses and decreased subsequent reproductive efficiency in multiparous Holstein dairy cows. Veterinary Immunology and Immunopathology, 164, 16-23.

O'Connor, T. M., O'Halloran, D. J. \& Shanahan, F. 2000. The stress response and the hypothalamic-pituitary-adreanal axis: from molecule to melancholia. Quarterly Journal of Medicine, 93, 323-333.

Overton, T. R. \& Waldron, M. R. 2004. Nutritional Management of Transition Dairy Cows: Strategies to Optimize Metabolic Health. Journal of Dairy Science, 87, Supplement, E105-E119.

Paape, M. J., Bannerman, D. D., Zhao, X. \& Lee, J. W. 2003. The bovine neutrophil: Structure and function in blood and milk. Vet Research, 34, 597-627.

Paape, M. J., Shafer-Weaver, K., Capuco, A. V., Van Oostveldt, K. \& Burvenich, C. 2002. Immune surveillance of mammary tissue by phagocytic cells. Biology of the Mammary Gland. Springer.

Park, Y. H., Fox, L. K., Hamilton, M. J., Davis, W. C. 1992. Bovine mononuclear leukocyte subpopulations in peripheral blood and mammary gland secretions during lactation. $J$. Dairy Sci. 75(4): 998-1006.

Park,Y.H., Fox, L.K., Hamilton, M.J., Davis, W.C. 1993. Suppression of proliferative response of BoCD4+ T -lymphocytes by activated BoCD8+ T -lymphocytes in the mammary gland of cows with Staphylococcus aureus mastitis. Veterinary Immunology and Immunopathology 36:137-151.

Paulrud, C. O. 2005. Basic concepts of the bovine teat canal. Veterinary Research Communications, 29, 215-245.

Perez Martinez, S., Franchi, A. M., Viggiano, J. M., Herrero, M. B. \& Gimeno, M. 1998. Effect of prostaglandin F2 alpha (PGF2 alpha) on oviductal nitric oxide synthase (NOS) 
activity: possible role of endogenous NO on PGF2 alpha-induced contractions in rat oviduct. Prostaglandins Other Lipid Mediat, 56, 155-66.

Peter, A. T., Bosu, W. T. \& DeDecker, R. J. 1989. Suppression of preovulatory luteinizing hormone surges in heifers after intrauterine infusions of Escherichia coli endotoxin. Am $J$ Vet Res, 50, 368-73.

Peter, A. T. \& Bosu, W. T. K. 1988. Relationship of uterine infections and folliculogenesis in dairy cows during early puerperium. Theriogenology, 30, 1045-1051.

Petersen, H. H., Nielsen, J. P. \& Heegaard, P. M. 2004. Application of acute phase protein measurements in veterinary clinical chemistry. Vet Res, 35, 163-87.

Philippidis, P., Mason, J. C., Evans, B. J., Nadra, I., Taylor, K. M., Haskard, D. O. \& Landis, R. C. 2004. Hemoglobin scavenger receptor CD163 mediates interleukin-10 release and heme oxygenase-1 synthesis: antiinflammatory monocyte-macrophage responses in vitro, in resolving skin blisters in vivo, and after cardiopulmonary bypass surgery. Circ Res, 94, 119-26.

Phillips, C. J. \& Rind, M. I. 2001. The effects on production and behavior of mixing uniparous and multiparous cows. J Dairy Sci, 84, 2424-9.

Pilla, R., Malvisi, M., Snel, G. G. M., Schwarz, D., König, S., Czerny, C. P. \& Piccinini, R. 2013. Differential cell count as an alternative method to diagnose dairy cow mastitis. Journal of Dairy Science, 96, 1653-1660.

Pittman, D. Q. J., 2011. A neuro-endocrine-immune symphony. J. Endocrinology, 23:1926-1927.

Prescott, M. S., Price, F. T., Wing, H. H. \& Prescott, W. A. 1930. Holstein-Friesian History. The Course Press, Lacona, New York.

Pursley, J. R., Mee M O, Wiltbank M C. Synchronization of ovulation in dairy cows using PGF2 $\alpha$ and GnRH. Theriogenology, 1995; 44:915-923

Putney, D. J., Drost, M. \& Thatcher, W. W. 1988. Embryonic development in superovulated dairy cattle exposed to elevated ambient temperatures between Days 1 to 7 post insemination. Theriogenology, 30, 195-209.

Rainard, P. \& Riollet, C. 2006. Innate immunity of the bovine mammary gland. Veterinary Research, 37, 369-400.

Riollet, C., Rainard, P. \& Poutrel, B. 2000. Cells and cytokines in inflammatory secretions of bovine mammary gland. Advances in Experimental Medicine and Biology, 480, 247-258.

Riollet, C., Rainard, P. \& Poutrel, B. 2001. Cell subpopulations and cytokine expression in cow milk in response to chronic Staphylococcus aureus infection. J Dairy Sci, 84, 1077-84.

Robinson, P. H. 1997. Effect of yeast culture (Saccharomyces cerevisiae) on adaptation of cows to diets postpartum. J Dairy Sci, 80, 1119-25.

Rother, R. P., Bell, L., Hillmen, P. \& Gladwin, M. T. 2005. The clinical sequelae of intravascular 
hemolysis and extracellular plasma hemoglobin: a novel mechanism of human disease. Jama, 293, 1653-62.

Rowson, L. E., Lamming, G. E. \& Fry, R. M. 1953. Influence of ovarian hormones on uterine infection. Nature, 171, 749-750.

Royal, M. D., Darwash, A. O., Flint, A. P. F., Webb, R., Woolliams, J. A., Lammin, G. E. 2000. Declining fertility in dairy cattle: changes in traditional and endocrine parameters of fertility. Anim. Sci., 70:487-501.

Saad, A. M., Concha, C., Astrom, G. 1989. Alterations in neutrophil phagocytosis and lymphocyte blastogenesis in dairy cows around parturition. J. Vet. Med. B., 36:337-345.

Sandholm, M., Honkanen-Buzalski, T., Kaartinen, L. \& Pyörälä, S. 1995. The bovine udder and mastitis. Pharmacology and Toxicology Faculty of Veterinary Medicine, University of Helsinki.

Santos, J. E. P., Cerri, R. L. A., Ballou, M. A., Higginbotham, G. E. \& Kirk, J. H. 2004. Effect of timing of first clinical mastitis occurrence on lactational and reproductive performance of Holstein dairy cows. Animal Reproduction Science, 80, 31-45.

Saremi, B., Al-Dawood, A., Winand, S., Müller, U., Pappritz, J., von Soosten, D., Rehage, J., Dänicke, S., Häussler, S., Mielenz, M. \& Sauerwein, H. 2012. Bovine haptoglobin as an adipokine: Serum concentrations and tissue expression in dairy cows receiving a conjugated linoleic acids supplement throughout lactation. Veterinary Immunology and Immunopathology, 146, 201-211.

Savio, J. D., Boland, M. P. \& Roche, J. F. 1990. Development of dominant follicles and length of ovarian cycles in post-partum dairy cows. Journal of Reproduction and Fertility, 88, 581591.

Schaer, D. J., Schaer, C. A., Buehler, P. W., Boykins, R. A., Schoedon, G., Alayash, A. I. \& Schaffner, A. 2006. CD163 is the macrophage scavenger receptor for native and chemically modified hemoglobins in the absence of haptoglobin. Blood, 107, 373-80.

Schrick, F. N., Hockett, M. E., Saxton, A. M., Lewis, M. J., Dowlen, H. H. \& Oliver, S. P. 2001. Influence of subclinical mastitis during early lactation on reproductive parameters. $J$ Dairy Sci, 84, 1407-12.

Seals, R. C., Lemaster, J. W., Hopkins, F. M. \& Schrick, F. N. 1998. Effects of elevated concentrations of prostaglandin $\mathrm{F} 2$ alpha on pregnancy rates in progestogen supplemented cattle. Prostaglandins Other Lipid Mediat, 56, 377-89.

Seals, R. C., Wulster-Radcliffe, M. C. \& Lewis, G. S. 2002. Modulation of the uterine response to infectious bacteria in postpartum ewes. Am J Reprod Immunol, 47, 57-63.

Smeets, M. B., Fontijn, J., Kavelaars, A., Pasterkamp, G., De Kleijn, D. PV., 2003. The acute phase protein haptoglobin is locally expressed in arthritic and onocological tissues. Int. J. Exp. Pathol., 84(2): 69-74. 
Senger, P. L. 2012. Pathways to pregnancy and parturition. Cenceptions, Inc., Redmond, OR.

Shafer-Weaver, K. A., Pighetti, G. M. \& Sordillo, L. M. 1996. Diminished mammary gland lymphocyte functions parallel shifts in trafficking patterns during the postpartum period. Proc Soc Exp Biol Med, 212, 271-80.

Shafer-Weaver, K. A. \& Sordillo, L. M. 1997. Bovine CD8+ suppressor lymphocytes alter immune responsiveness during the postpartum period. Veterinary Immunology and Immunopathology, 56, 53-64.

Sheldon, I. M., Cronin, J. G., Healey, G. D., Gabler, C., Heuwieser, W., Streyl, D., Bromfield, J. J., Miyamoto, A., Fergani, C. \& Dobson, H. 2014. Innate immunity and inflammation of the bovine female reproductive tract in health and disease. Reproduction, 148, R41-51.

Sheldon, I. M., Lewis, G. S., LeBlanc, S. \& Gilbert, R. O. 2006. Defining postpartum uterine disease in cattle. Theriogenology, 65, 1516-1530.

Sheldon, I. M. \& Noakes, D. E. 1998. Comparison of three treatments for bovine endometritis. Veterinary Record, 142, 575-579.

Sheldon, I. M., Noakes, D. E., Rycroft, A. \& Dobson, H. 2001. Acute phase protein responses to uterine bacterial contamination in caftle after calving. Veterinary Record, 148, 172-175.

Sheldon, I. M., Noakes, D. E., Rycroft, A. N., Pfeiffer, D. U. \& Dobson, H. 2002. Influence of uterine bacterial contamination after parturition on ovarian dominant follicle selection and follicle growth and function in cattle. Reproduction, 123, 837-845.

Shuster, D. E., Kehrli, M. E., Jr., Rainard, P. \& Paape, M. 1997. Complement fragment C5a and inflammatory cytokines in neutrophil recruitment during intramammary infection with Escherichia coli. Infect Immun, 65, 3286-92.

Simenew, K. \& Wondu, M. 2013. Transition period and immunosuppression: Critical period of dairy cattle reproduction. International Journal of Animal and Veterinary Advances, 5, 44-57.

Singh, J., Sidhu, S. S., Dhaliwal, G. S., Pangaonkar, G. R., Nanda, A. S. \& Grewal, A. S. 2000. Effectiveness of lipopolysaccharide as an intrauterine immunomodulator in curing bacterial endometritis in repeat breeding cross-bred cows. Animal Reproduction Science, $59,159-166$.

Sivakumar, A.V.N., G. Singh, V.P. Varshney. 2010. Antioxidants supplementation on acid base balance during heat stress in goats. Asian-Australas J. Anim. Sci. 23:1462-1468.

Skarzynski, D. J., Miyamoto, Y. \& Okuda, K. 2000. Production of prostaglandin f(2alpha) by cultured bovine endometrial cells in response to tumor necrosis factor alpha: cell type specificity and intracellular mechanisms. Biol Reprod, 62, 1116-20.

Skinner, J. G., Brown, R. A., Roberts, L. 1991. Bovine haptoglobin response in clinically defined field conditions. Vet. Rec, 128(7): 147-149. 
Slocombe, L. L. \& Colditz, I. G. 2005. Evaluating The Stress of Production in Cattle Using Haptoglobin. 5th International Colloquium on Animal Acute Phase Proteins. Dublin.

Smith, B. I., Donovan, G. A., Risco, C. A., Young, C. R. \& Stanker, L. H. 1998. Serum haptoglobin concentrations in Holstein dairy cattle with toxic puerperal metritis. Veterinary Research, 142, 83-85.

Soto, P., Natzke, R. P. \& Hansen, P. J. 2003a. Actions of tumor necrosis factor- $\alpha$ on oocyte maturation and embryonic development in cattle. American Journal Reproductive Immunology, 50, 380-388.

Soto, P., Natzke, R. P. \& Hansen, P. J. 2003b. Identification of possible mediators of embryonic mortality caused by mastitis: actions of lipopolysaccharide, prostaglandin $\mathrm{F}_{2 \alpha}$, and the nitric oxide generator, sodium nitroprusside dihydrate, on oocyte maturation and embryonic development in cattle. American Journal of Reproductive Immunology, (50): $263-272$.

Sordillo, L.M., Streicher, K.L. 2002. Mammary gland immunity and mastitis susceptibility. J Mammary Gland Biol Neoplasia 7: 135-146.

Sordillo, L. M., Oliver, S. P., Guidry, A. J., Dermody, J. T. 1988. Humorai immune response of bovine mammary glands colonized with Corynebacterium bovis. Enumeration of plasma cell populations in tissue and immunoglobulin concentrations in milk. J. Vet. Med. 35:617.

Stevenson, J. S. 2001. Reproductive Management of Dairy Cows in High Milk-Producing Herds. Journal of Dairy Science, 84, Supplement, E128-E143.

Stofkova, A. 2009. Leptin and adiponectin: from energy and metabolic dysbalance to inflammation and autoimmunity. Endocr. Regul., 43:157

Staub, O. C., Schalm, O. W., Hughes, J. P., Theilen, G. H. 1959. Bovine hematology. II Effect of parturition and retention of fetal membranes on blood morphology. J. Am. Vet. Med. Assoc., 135:618-622.

Stelwagen, K., Carpenter, E., Haigh, B., Hodgkinson, A., Wheeler, T. T. 2009. Immune components of bovine colostrum and milk. J Animal Sci 87:3-9.

Strange, R., Friis, R. R., Bemis, L. T. \& Geske, F. J. 1995. Programmed cell death during mammary gland involution.

Suzuki, C., Yoshioka, K., Iwamura, S. \& Hirose, H. 2001. Endotoxin induces delayed ovulation following endocrine aberration during the proestrous phase in Holstein heifers. Domestic Animal Endocrinology, 20, 267-278.

Takahashi, E., Uzuka, Y., Tanabe, S., Satoh, M. \& Furuoka, H. 2006. Serum amyloid A and haptoglobin levels in bovine. Journal of Veterinary Medicine, 69, 321-323.

Takeuchi, O. \& Akira, S. 2010. Pattern Recognition Receptors and Inflammation. Cell, 140, 805- 
820.

Taylor, B. C., Dellinger, J. D., Cullor, J. S. \& Stott, J. L. 1994. Bovine Milk Lymphocytes Display the Phenotype of Memory T Cells and Are Predominantly CD8+. Cellular Immunology, 156, 245-253.

Taylor, V. J., Beever, D. E. \& Wathes, D. C. 2003. Physiological adaptations to milk production that affect fertility in high yielding dairy cows. Nottingham University Press, Nottingham, UK.

Theilgaard-Monch, K., Jacobsen, L. C., Nielsen, M. J., Rasmussen, T., Udby, L., Gharib, M., Arkwright, P. D., Gombart, A. F., Calafat, J., Moestrup, S. K., Porse, B. T. \& Borregaard, N. 2006. Haptoglobin is synthesized during granulocyte differentiation, stored in specific granules, and released by neutrophils in response to activation. Blood, 108, 353-61.

Thielen, M. A., Mielenz, M., Hiss, S., Zerbe, H., Petzl, W., Schuberth, H. J., Seyfert, H. M. \& Sauerwein, H. 2007. Short communication: Cellular localization of haptoglobin mRNA in the experimentally infected bovine mammary gland. J Dairy Sci, 90, 1215-9.

Thomsen, J. H., Etzerodt, A., Svendsen, P. \& Moestrup, S. K. 2013. The haptoglobin-CD163Heme Oxygenase-1 pathway for hemoglobin scavenging. Oxidative Medicine and Cellular Longevity, 2013, 11.

Tizard, I. R. 2013. Veterinary immunology: an introduction. Saunders, Philadelphia.

Trawick, D. R. \& Bahr, J. M. 1986. Modulation of the primary and secondary antifluoresceyl antibody response in rats by 17 beta-estradiol. Endocrinology, 118, 2324-30.

Tseng, C. F., Lin, C. C., Huang, H. Y., Liu, H. C. \& Mao, S. J. 2004. Antioxidant role of human haptoglobin. Proteomics, 4, 2221-8.

Uchida, E., Katoh, N., Bell, A. W. \& Overton, T. R. 2006. Appearance of haptoglobin in serum from cows at parturition. Journal of Veterinary Medical Science.

van Engelen, E., de Groot, M. W., Breeveld-Dwarkasing, V. N. A., Everts, M. E., van der Weyden, G. C., Taverne, M. A. M. \& Rutten, V. P. M. G. 2009. Cervical ripending and parturition in cows are driven by a cascade of pro-inflammatory cytokines. Repod. Domest. Anim., 44, 834-841.

Van Gorp, H., Delputte, P. L. \& Nauwynck, H. J. 2010. Scavenger receptor CD163, a Jack-ofall-trades and potential target for cell-directed therapy. Mol Immunol, 47, 1650-60.

van Knegsel, A. T. M., van den Brand, H., Dijkstra, J., van Straalen, W. M., Heetkamp, M. J. W., Tamminga, S. \& Kemp, B. 2007. Dietary Energy Source in Dairy Cows in Early Lactation: Energy Partitioning and Milk Composition. Journal of Dairy Science, 90, $1467-1476$.

Vincent, D. L. \& Inskeep, E. K. 1986. Role of progesterone in regulating uteroovarian venous concentrations of PGF2 $\alpha$ and PGE2 during the estrous cycle and early pregnancy in ewes. Prostaglandins, 31, 715-733. 
Waller, K. P. 2002. Mammary gland immunology around parturition. Biology of the Mammary Gland. Springer.

Weinberg, E. D. 1987. Pregnancy-associated immune suppression: risks and mechanisms. Microb Pathog, 3, 393-7.

Weinkauf, C., S. Hachenberg, S. Hiss, U. Muller, H. Sauerwein. 2005. Haptoglobin in serum and milk of cows and its relation to udder health and metabolic disorders. $5^{\text {th }}$ International Colloquium on Animal Acute Phase Proteins, Dublin. 32.

Wicher, K. B. \& Fries, E. 2010. Evolutionary aspects of hemoglobin scavengers. Antioxid Redox Signal, 12, 249-59.

Worku, M., Paape, M. \& Marquardt, W. 1994. Modulation of Fc receptors for IgG on bovine polymorphonuclear neutrophils by interferon-gamma through de novo RNA transcription and protein synthesis. American journal of veterinary research, 55, 234-238.

Wyle, F. A. \& Kent, J. R. 1977. Immunosuppression by sex steroid hormones. The effect upon PHA- and PPD-stimulated lymphocytes. Clin Exp Immunol, 27, 407-15.

Yang, F., Haile, D. J., Berger, F. G., Herbert, D. C., Beveren, E. V., Ghio, A. J. 2003. Haptoglobin reduces lung injury associated with exposure to blood. Am. J. Physiol. Lung. Cell. Mol. Physiol., 284:402-409.

Yavas, Y., Walton, J. S. 2000. Postpartum acyclicity in suckled beef cows: A review. Theriogenology, 54(1): 25-55.

Yoshino, K., Katoh, N., Takahashi, K. \& Yuasa, A. 1992. Purification of a protein from serum of cattle with hepatic lipidosis, and identification of the protein as haptoglobin. American Journal of Veterinary Research.

Yue, X. P., Dechow, C. \& Liu, W. S. 2015. A limited number of Y chromosome lineages is present in North American Holsteins. J Dairy Sci, 98, 2738-45.

Zadoks, R. N., Allore, H. G., Barkema, H. W., Sampimon, O. C., Wellenberg, G. J. \& Grohn, Y. T. 2001. Cow and quarter level risk factors for Streptococcus uberus and Staphlococcus aureus mastitis. Journal of Dairy Science, 84, 2649-2663.

Zecconi, A., Hamanno, J., Bronzo, V., Moroni, P., Giovannini, G. \& R., P. 2002. Relationship between teat tissue immune defences and intramammary infections. Biology of the Mammary Gland. Springer, New York, NY, USA. 